\title{
A Review on the Control Parameters of Natural Convection in Different Shaped Cavities with and without Nanofluid
}

\author{
Sara Rostami ${ }^{1,2}{ }^{-}$, Saeed Aghakhani ${ }^{3}$, Ahmad Hajatzadeh Pordanjani ${ }^{4}$, Masoud Afrand ${ }^{5,6, *}$, \\ Goshtasp Cheraghian ${ }^{7}$, Hakan F. Oztop ${ }^{8}$ and Mostafa Safdari Shadloo ${ }^{9}$ \\ 1 Laboratory of Magnetism and Magnetic Materials, Advanced Institute of Materials Science, \\ Ton Duc Thang University, Ho Chi Minh City, Vietnam; sara.rostami@tdtu.edu.vn \\ 2 Faculty of Applied Sciences, Ton Duc Thang University, Ho Chi Minh City, Vietnam \\ 3 Department of Mechanical Engineering, Najafabad Branch, Islamic Azad University, Najafabad, Iran; \\ aghakhani2012@yahoo.com \\ 4 Department of Mechanical Engineering, Shahrekord University, Shahrekord, Iran; ahmad.haj.p@gmail.com \\ 5 Institute of Research and Development, Duy Tan University, Da Nang 550000, Vietnam \\ 6 Faculty of Electrical-Electronic Engineering, Duy Tan University, Da Nang 550000, Vietnam \\ 7 Department of Civil Engineering, Technische Universität Braunschweig, 38106 Braunschweig, Germany; \\ g.cheraghian@tu-braunschweig.de \\ 8 Department of Mechanical Engineering, Technology Faculty, Firat University, 23119 Elazig, Turkey; \\ hfoztop1@gmail.com \\ 9 CORIA-CNRS(UMR6614), Normandie University, INSA of Rouen, 76000 Rouen, France; \\ mostafa.safdari-shadloo@insa-rouen.fr \\ * Correspondence: masoudafrand@duytan.edu.vn
}

Received: 12 July 2020; Accepted: 13 August 2020; Published: 19 August 2020

\begin{abstract}
Natural convection in cavities is an interesting subject for many researchers. Especially, in recent years, the number of articles written in this regard has grown enormously. This work provides a review of recent natural convection studies. At first, experimental studies were reviewed and, then, numerical studies were examined. Then, the articles were classified based on effective parameters. In each section, numerical studies were examined the parameters added to the cavity such as magnetic forces, fin, porous media and cavity angles. Moreover, studies on non-rectangular cavities were investigated. Free convection in enclosures depends more on the fluid velocity relative to the forced convection, leading to the opposite effect of some parameters that should essentially enhance rate of heat transfer. Nanoparticle addition, magnetic fields, fins, and porous media may increase forced convection. However, they can reduce free convection due to the reduction in fluid velocity. Thus, these parameters need more precision and sometimes need the optimization of effective parameters.
\end{abstract}

Keywords: natural convection; cavity; numerical study; nanofluid; non-Newtonian

\section{Introduction}

Free convection happens in various industries such as solar cells, air, and space, food industry, solar and nuclear collectors, etc. Therefore, it has been studied in different geometries. Cavities are the most important host for these mechanisms of heat transfer. In these cavities, heat transfer occurs in a small space. The heat transfer mechanism in closed cavities is natural due to the absence of an external device to accelerate fluid flow. Heat transfer generally involves three mechanisms, including conduction, convection, and radiation heat transfer. Each of these mechanisms can become sub-branches. One of 
the branches of convection is the free or natural one. Figure 1 presents various types of heat transfer mechanisms with their sub-branches.

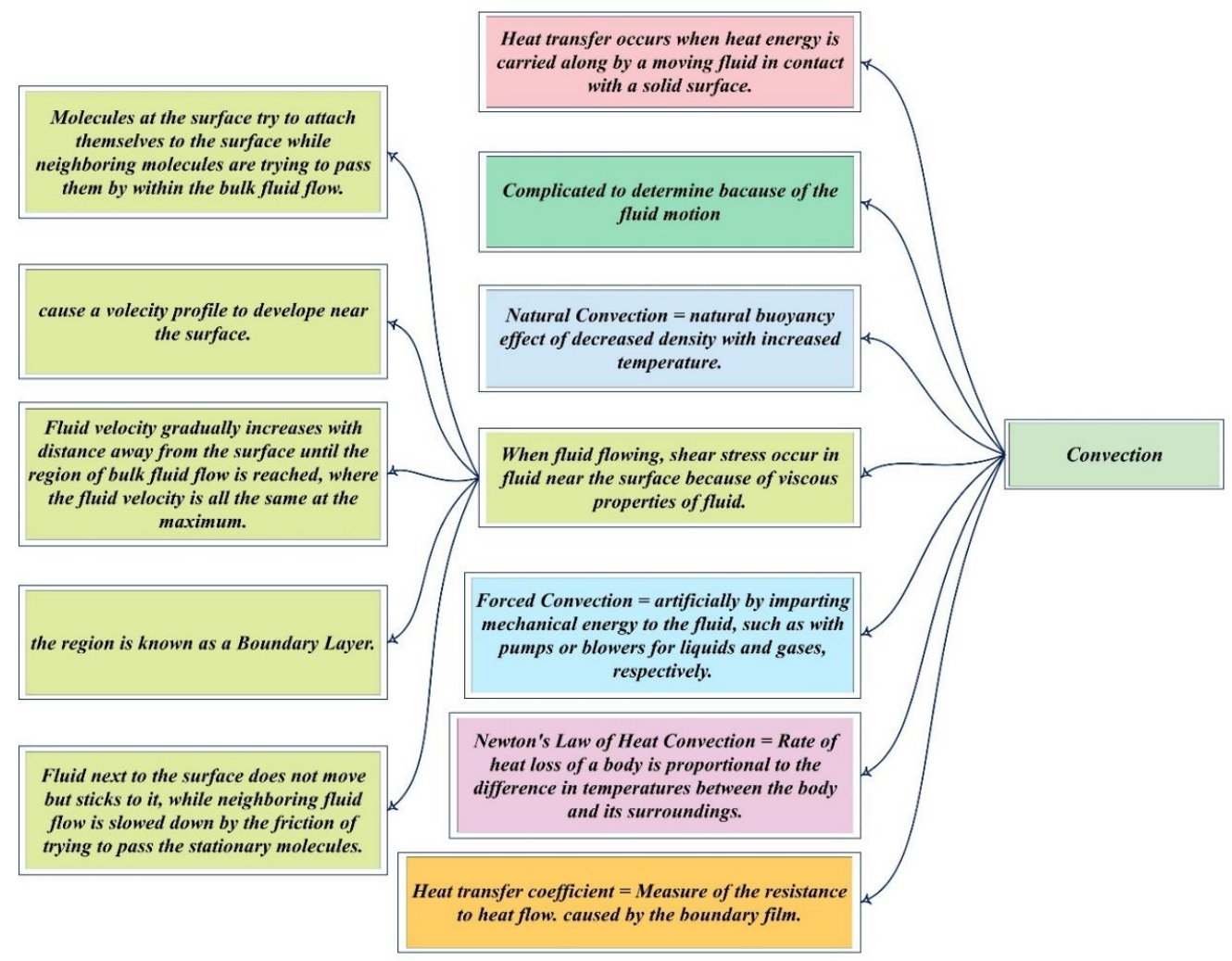

Figure 1. Types of heat transfer mechanisms and their subdivisions [1].

Various applications of cavities in the industry include electronic equipment cooling, solar-related equipment, packaging industries, heat exchangers, power plants, petrochemicals, petroleum industries, and melting metals, etc. The importance of evaluating free convection in cavities, as well as an increased number of studies in this field, means that there is a need for review studies. Free convection can be divided into two subdivisions of internal and external convection. As shown in Figure 2, in the case of internal convection, the fluid is in a closed environment and the temperature difference of the walls causes convection. The right figure indicates free convection and the left one shows forced one.

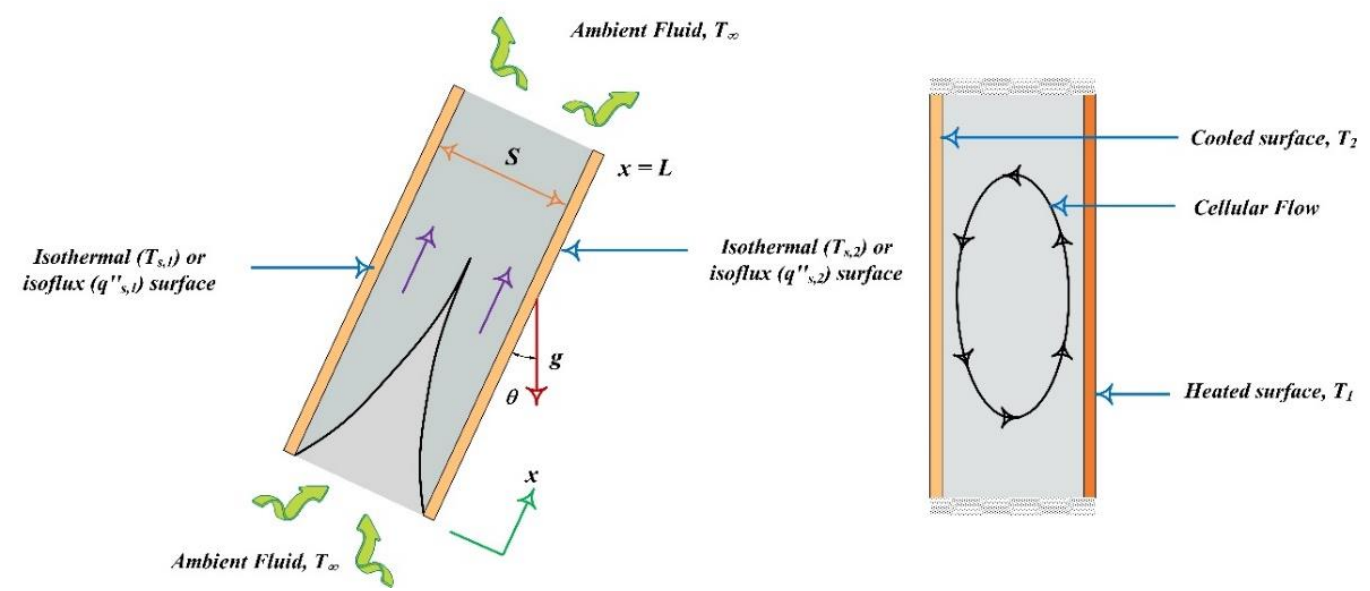

Figure 2. Internal convection flow [2]. 
Another kind of free convection is external flow. In this case, the fluid encounters a plate at a different temperature in an open environment. Consequently, the changing of temperature near the wall, and the creation of difference in the density gradient make free convection. An example of external free convection is shown in Figure 3, which demonstrates different shapes of boundary layers at different wall angles. If some factors such as fan or pump cause fluid motion and its collision to the plane, forced convection happens and if the fluid motion is due to the difference of density because of temperature difference, free convection occurs.

\section{Cold Fluid Jets}
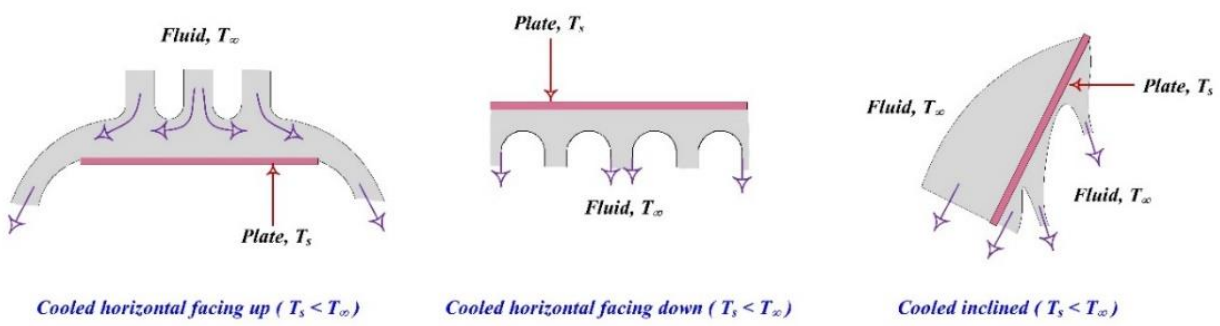

Cooled horizontal facing down $\left(T_{s}<T_{\infty}\right)$

Cooled inclined $\left(T_{s}<T_{\infty}\right)$

\section{Warm Fluid Jets}

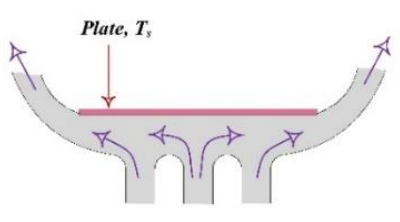

Fluid, $T_{x}$

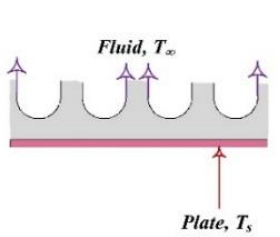

Heated horizontal facing up $\left(T_{s}>T_{m}\right)$

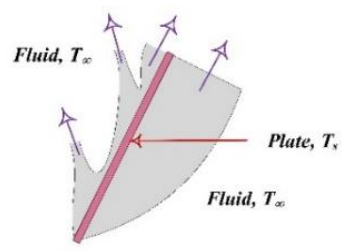

Heated inclined $\left(T_{s}>T_{\infty}\right)$

Figure 3. External convection flow on flat plate with different angles [2].

Free convection has many applications in industry or even in human daily life. Two examples of application of free convection are illustrated in Figure 4. The home environment and heating of water due to a heat source are examples of free convection because of the temperature difference in a closed environment. As the temperature gradient increases, the free convection also strengthens and its value increases.

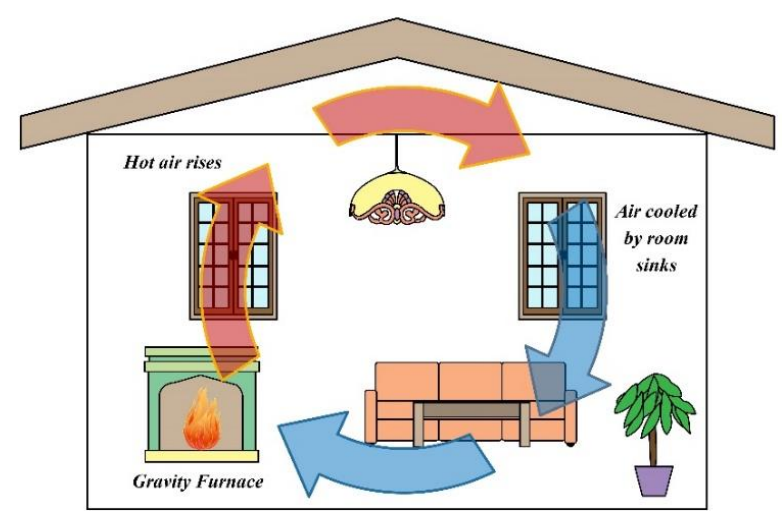

(a)

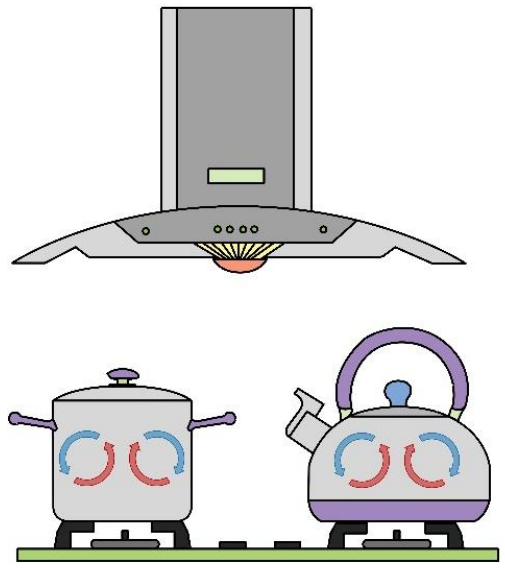

(b)

Figure 4. An example of some applications of free convection. (a) home environment, (b) heating of water [2]. 
In order to create free convection flow, it is essential to notice the effect of temperature on the fluid density. In other words, a density gradient occurs due to the temperature difference in the environment to create convection. The buoyancy force is created due to the density gradient that can displace the fluid. An approximation is needed to calculate the density difference created in the fluid. Many researchers used the Boussinesq approximation, which relies on the negligible effect of density changes in the momentum equation can be ignored and the effect of density changes is considered only in terms of the fluid motion equation include the gravity acceleration. This approximation can make the momentum equation simpler and make it possible to consider the effect of the density difference. Of course, it is more appropriate to use this approximation for low temperatures. According to the above explanation, it has been shown that free convection is of excessive importance. Free convection within enclosures is an important matter so that it becomes the main focus of this paper.

In these articles, researchers collect and review a series of articles in a particular field, especially articles that have been published in recent years. Given developments regarding cavities, a researcher can understand the development by reading review articles. The current study attempts to present articles on the free convection in cavities in a summarized form.

\section{Experimental Studies}

A large number of experimentally and numerical studies exist in the literature. Some researchers study heat transfer field and some of them study economy field of heat device [3-11]. Karatas and Delbentli [12] included radiation effects in their heat transfer study on a 3-dimensional rectangular cavity. They used air fluid with Rayleigh number $(R a)$ between $1.6 \times 10^{5}$ and $4.67 \times 10^{7}$, and examined aspect ratio (AR) effect of the cavity on thermal performance. They changed the aspect ratio between 1 and 6, and eventually expressed an equation in terms of $R a$ number and AR for $N u_{\text {ave }}$. Mahmoudinezhad et al. [13] attached a fin and with an angle toward the horizon. They investigated Rayleigh number effect in $1.5 \times 10^{5}$ to $4.5 \times 10^{5}$ range and fin angle of 0 to 90 degrees. They found that the minimum Nusselt number was in the 90-degree fin and the maximum was in 45 degrees. $\mathrm{Li}$ and Peterson [14] investigated the nanofluid alumina natural convection. They found that with increasing volumetric percentages of nanoparticles, the heat transfer characteristics raised. Ho et al. [15] examined a suspension containing alumina nanopowder in a cavity and realized that dispersing more nanoparticles was in the range of 1 to $4 \%$. Karatas et al. [16] examined air fluid free convection. $R a$ number was considered between $4.5 \times 10^{5}$ and $1.13 \times 10^{8}$ and the aspect ratio in the range 1 to 6 on the Nusselt number. They found that when the wall temperature is applied sinusoidally compared to a constant temperature, the Nusselt number decreases. Vasiliev et al. [17] studied turbulent flow considering the Ra number between $2 \times 10^{9}$ and $1.6 \times 10^{10}$. Bharti et al. Researchers [18] investigated water heat transfer of for $R a$ between $7.05 \times 10^{5}$ and $1.84 \times 10^{7}$. Sides had been considered at different temperatures, and horizontal walls had been considered insulated.

Zhang et al. $[19,20]$ examined the turbulent regime of free convection. They examined a three-dimensional rectangular cavity and the influence of $R a$ on heat transfer. Chen et al. [21] investigated fin geometry effect and its position on heat transfer of airflow by adding a fin to the hot surface. Cordoba et al. [22] also examined air natural convection in the rectangular cavity. Mahdavi et al. [23] examined heat transfer of natural and laminar convections of the air and waters in a 3-D cavity for $R a$ between of $1.3 \times 10^{8}$ and $1.19 \times 10^{9}$ range. Saxena et al. [24] studied the water-filled open cavity and examined its effect on $\mathrm{N} u$ by resizing the cavity. Table 1 shows a summary of some experimental investigations performed on the enclosures. 
Table 1. Summary of experimental investigations performed on the enclosures.

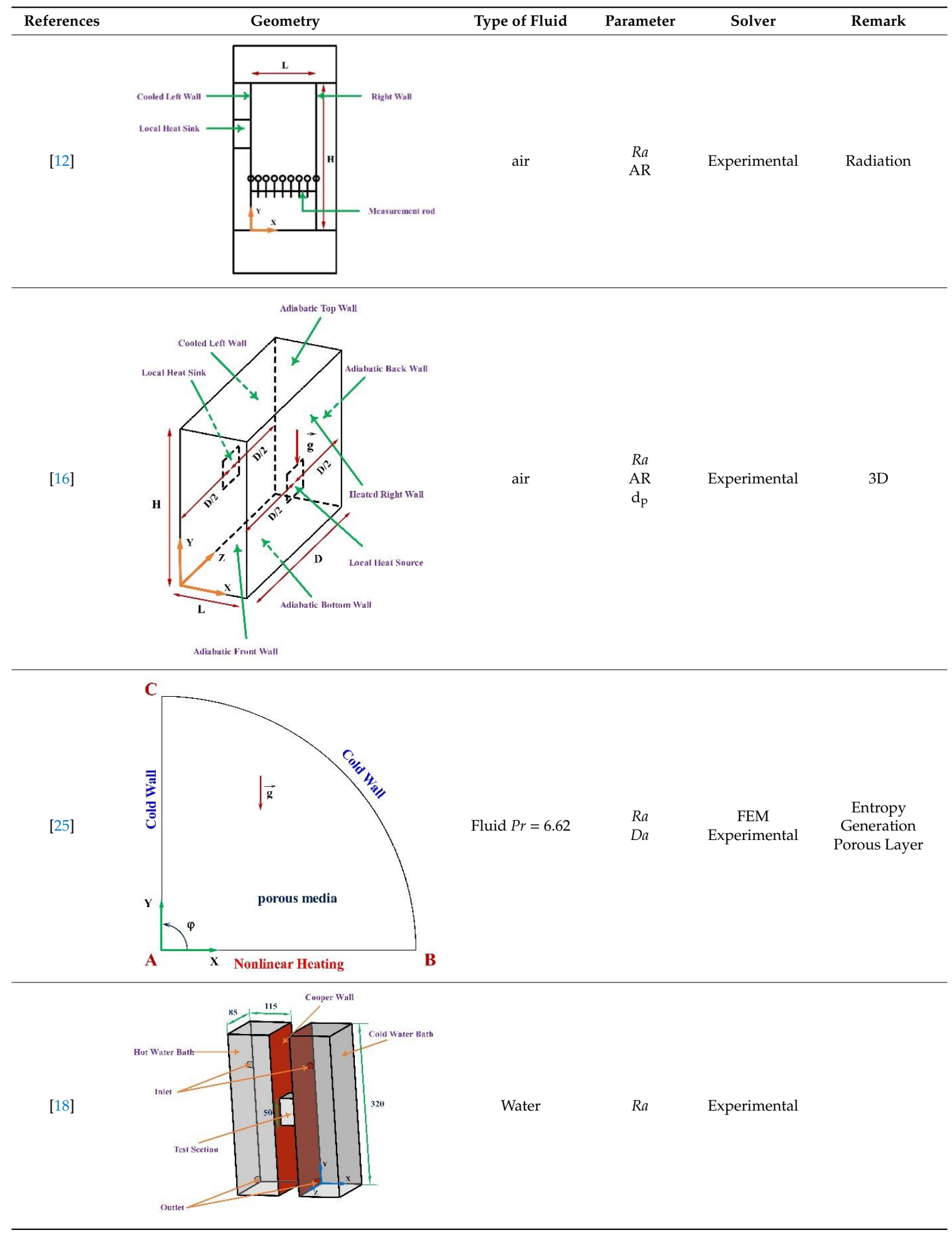


Table 1. Cont.

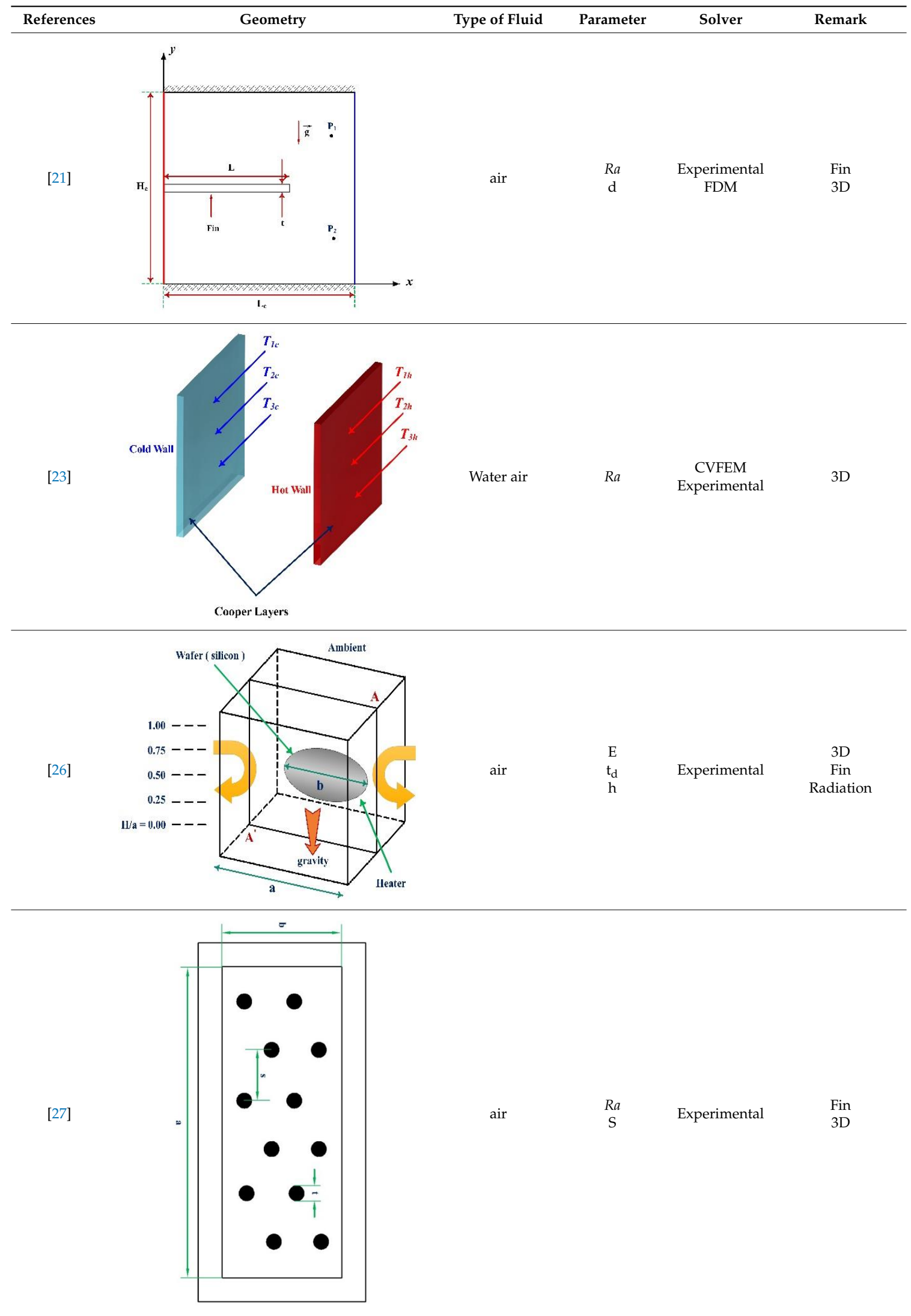




\section{Numerical Studies}

Due to time spending and the high cost of conducting experiments, the researchers used numerical methods to study the natural convection in the cavities. Knowing thermophysical fluid properties in the cavity is necessary to use numerical methods and solve the governing equations. These properties are expressed by tables or relationships depending on the constituents and the parameters that the fluid depends on.

\subsection{Governing Equations}

The governing equations assert as follows by assuming laminar, stable flow, incompressible, and with the fluid assumption in a continuous environment. In these equations, the effects of radiation and viscosity loss are neglected. Equation (1) is the mass conservation equation, Equations (2) and (3) are the momentum conservation equation and (4) is the energy conservation Equation (4) (with Boussinesq approximation).

$$
\begin{gathered}
\frac{\partial u}{\partial x}+\frac{\partial v}{\partial y}=0 \\
u \frac{\partial u}{\partial x}+v \frac{\partial u}{\partial y}=-\frac{1}{\rho} \frac{\partial p}{\partial x}+\frac{1}{\rho}\left(\frac{\partial}{\partial x}\left(\mu \frac{\partial u}{\partial x}\right)+\frac{\partial}{\partial y}\left(\mu \frac{\partial u}{\partial y}\right)\right) \\
u \frac{\partial v}{\partial x}+v \frac{\partial v}{\partial y}=-\frac{1}{\rho} \frac{\partial p}{\partial y}+\frac{1}{\rho}\left(\frac{\partial}{\partial x}\left(\mu \frac{\partial v}{\partial x}\right)+\frac{\partial}{\partial y}\left(\mu \frac{\partial v}{\partial y}\right)\right)+g \beta\left(T-T_{c}\right) \\
\left(u \frac{\partial T}{\partial x}+v \frac{\partial T}{\partial y}\right)=\frac{k}{\rho C_{P}}\left(\frac{\partial^{2} T}{\partial x^{2}}+\frac{\partial^{2} T}{\partial y^{2}}\right)
\end{gathered}
$$

\subsection{Thermophysical Properties of Fluids in Cavities}

As we need to know the properties of fluid for solving the governing equations, it is essential to study the properties of different fluids in a section. Some researchers, in light of abundance of fluids, such as air and water, examined these two fluids in the cavity. Since Choi [28] used nanofluids for the first time, many researchers have studied the heat transfer by adding these types of fluids to the cavities. Since nanofluids show better thermal performance than simple fluids, in recent years, researchers have been studying this type of fluids. Moreover, some researchers examined non-Newtonian fluids in the cavities. The properties of all three types of fluids are discussed below.

\subsubsection{Air and Water}

One of the most important fluids used in numerical studies of the cavity is the air or water. Due to their abundance and availability, these fluids are widely used in industries. Hence, many researchers used water or air as the operating fluid in their cavity [29-34]. In most numerical studies, the properties of these two fluids were fixed and these properties for temperature and pressure of the room (See Table 2).

Table 2. Properties of air and water in room temperature and pressure.

\begin{tabular}{ccccc}
\hline & $\rho\left(\mathbf{k g} / \mathbf{m}^{3}\right)$ & $\mathrm{C}_{\mathbf{p}}(\mathbf{k J} / \mathbf{k g} . \mathbf{K})$ & $\mathbf{k}(\mathbf{W} / \mathbf{m . K})$ & $\mu(\mathbf{k g} / \mathbf{m . s})$ \\
\hline Water [35] & $9.971 \times 10^{2}$ & 4.179 & $6.13 \times 10^{-1}$ & $1 \times 10^{-3}$ \\
\hline Air [36] & 1.169 & 1.0064 & $2.607 \times 10^{-2}$ & $1.853 \times 10^{-5}$ \\
\hline
\end{tabular}

However, due to the fact that the properties of these two fluids depend on temperature, the researchers also tried to obtain a relationship between the properties of air and water with the temperature. In Table 3, the properties of the water, dry air, and saturated fluids are provided. 
Table 3. Properties of water, dry air and saturated fluids.

\begin{tabular}{|c|c|c|c|c|}
\hline$\rho\left(\mathrm{kg} / \mathrm{m}^{3}\right)$ & $C_{p}(\mathrm{~kJ} / \mathrm{kg} . \mathrm{K})$ & k (W/m.K) & $\mu(\mathrm{kg} / \mathrm{m} . \mathrm{s})$ & \\
\hline $\begin{array}{l}765.33+1.8142 \times \mathrm{T} \\
-0.0035 \times \mathrm{T}^{2}\end{array}$ & $\begin{array}{c}28.07-0.2817 \times \mathrm{T} \\
+0.00125 \times \mathrm{T}^{2}-2.48 \times \\
10^{-6} \times \mathrm{T}^{3}+1.857 \times \\
10-9 \times \mathrm{T}^{4}\end{array}$ & $\begin{array}{c}-0.5752+0.006397 \times \mathrm{T} \\
-8.151 \times 10-6 \times \mathrm{T}^{2}\end{array}$ & $\begin{array}{c}0.0967-8.207 \times 10^{-4} \times \mathrm{T} \\
+2.344 \times 10^{-6} \mathrm{~T}^{2}-2.244 \\
\times 10^{-9} \times \mathrm{T}^{3}\end{array}$ & [23] Water \\
\hline $\begin{array}{l}((3.484-1.317) \\
\left.\times x_{V}\right) \times \frac{P_{0}}{273.15+T}\end{array}$ & $\begin{array}{c}1.034-2.8488 \times 10^{-4} \times \mathrm{T} \\
+7.8168 \times 10^{-7} \times \mathrm{T}^{2} \\
-4.9707 \times 10^{-10} \times \mathrm{T} 3 \\
+1.077 \times 10^{-13} \times \mathrm{T}^{4}\end{array}$ & $\begin{array}{c}-2.2765 \times 10^{-3}+1.259 \times \\
10^{-4} \times \mathrm{T}-1.481 \times 10^{-7} \times \\
\mathrm{T}^{2}+1.7355 \times 10^{-10} \times \mathrm{T} 3 \\
-1.0666 \times 10^{-13} \times \mathrm{T}^{4} \\
+2.476 \times 10^{-17} \times \mathrm{T}^{5}\end{array}$ & $\begin{array}{c}-9.8601 \times 10^{-1}+9.0801 \\
\times 10^{-2} \times \mathrm{T}-1.1763 \times \\
10^{-4} \times \mathrm{T}^{2}+1.2349 \times 10^{-7} \\
\times \mathrm{T}^{3}-5.797 \times 10^{-11} \times \mathrm{T}^{4}\end{array}$ & [36] Dry air \\
\hline $\begin{array}{c}1.2933-5.588 \times \\
10^{-3} \times \mathrm{T}+3.860 \times \\
10^{-5} \times \mathrm{T}^{2}-5.253 \\
\times 10^{-7} \times \mathrm{T}^{3}\end{array}$ & $\begin{array}{c}1.0045+2.0506 \times 10^{-3} \times \\
\mathrm{T}-1.6315 \times 10^{-4} \times \mathrm{T}^{2} \\
+6.2123 \times 10^{-6} \times \mathrm{T}^{3} \\
-8.8304 \times 10^{-8} \times \mathrm{T}^{4} \\
+5.071 \times 10^{-11} \times \mathrm{T}^{5}\end{array}$ & $\begin{array}{c}2.4007 \times 10^{-2}+7.2784 \\
\times 10^{-5} \times \mathrm{T}-1.788 \times 10^{-2} \\
\times \mathrm{T}^{2}-1.3517 \times 10^{-9} \times \mathrm{T}^{3} \\
-3.3224 \times 10^{-11} \times \mathrm{T}^{4}\end{array}$ & $\begin{aligned} & 1.7157 \times 10^{-5}+4.7224 \\
& \times 10^{-8} \times \mathrm{T}-3.663 \times 10^{-10} \\
& \times \mathrm{T}^{2}+1.873 \times 10^{-12} \times \mathrm{T}^{3} \\
& \quad-8.050 \times 10^{-14} \times \mathrm{T}^{4}\end{aligned}$ & [37] Saturated air \\
\hline
\end{tabular}

The number of papers reviewed by these two fluids in recent years is less than before (see Table 4), and most researchers are interested in using nanofluids in the cavities. However, Gupta et al. [38] studied natural convection along with the radiation of air fluid in an open cavity. They found that heat transfer near open walls is more than elsewhere. Bhowmick et al. [39] used a triangular cavity and found that the heat transfer rate improved with growing $R a$. Grosan et al. [40] examined vibrating wall using the finite differential method. Kogawa et al. [41] included radiation effects in turbulent flow using the finite volume method (FVM). They used water vapor and carbon dioxide fluids as air fluids. Foruzan nia et al. [42] examined natural convection along with transient radiation of gas flux using a finite difference method (FDM). Their cavity consists of several solid walls and two fluid parts.

Table 4. Some articles used working fluid of air and water in the enclosures.

\begin{tabular}{lllll}
\hline References & Type of Fluid & Parameter & Solver & Remark \\
\hline$[38]$ & & & & Open Cavity \\
Radiation
\end{tabular}


Table 4. Cont

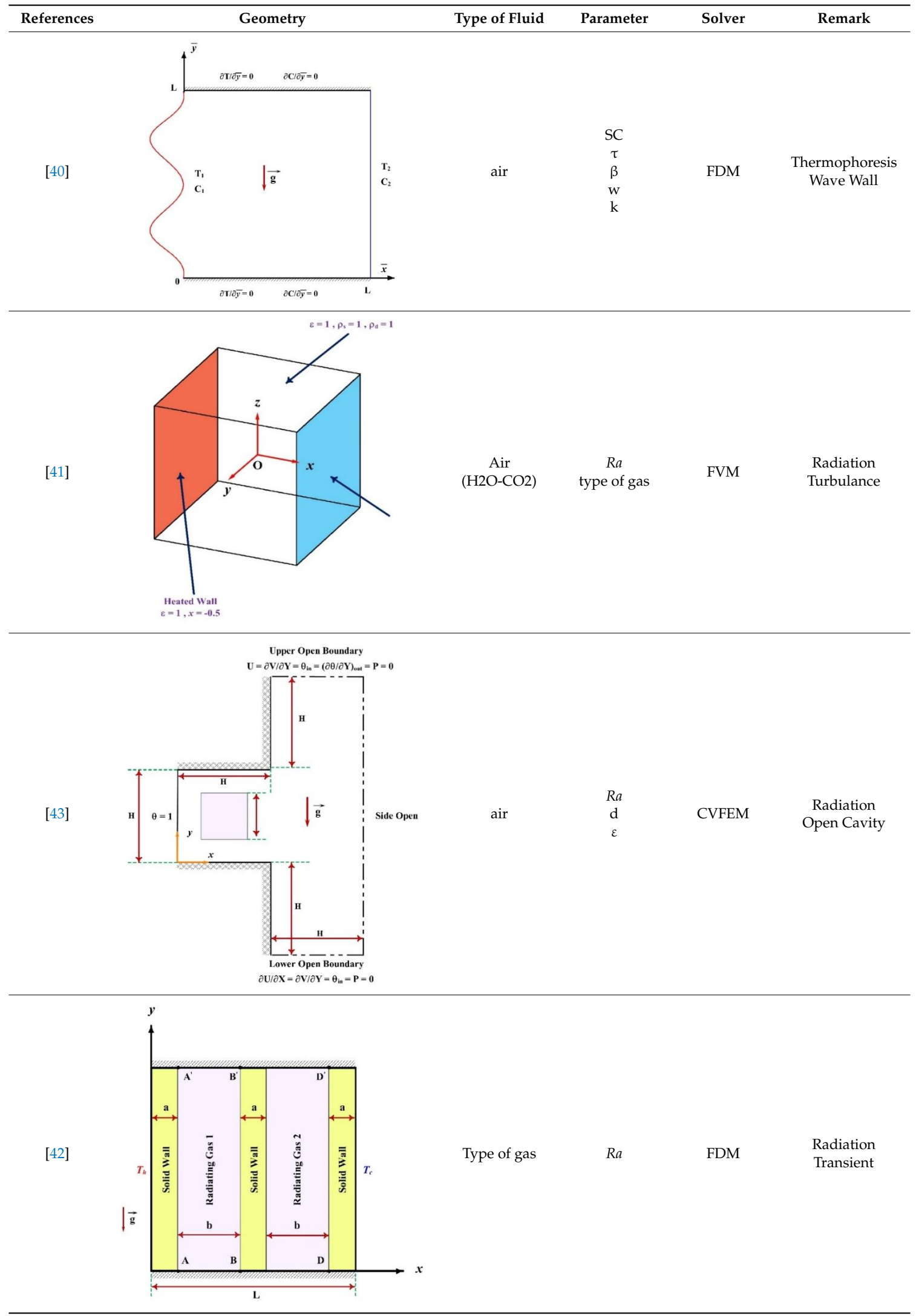


Table 4. Cont.

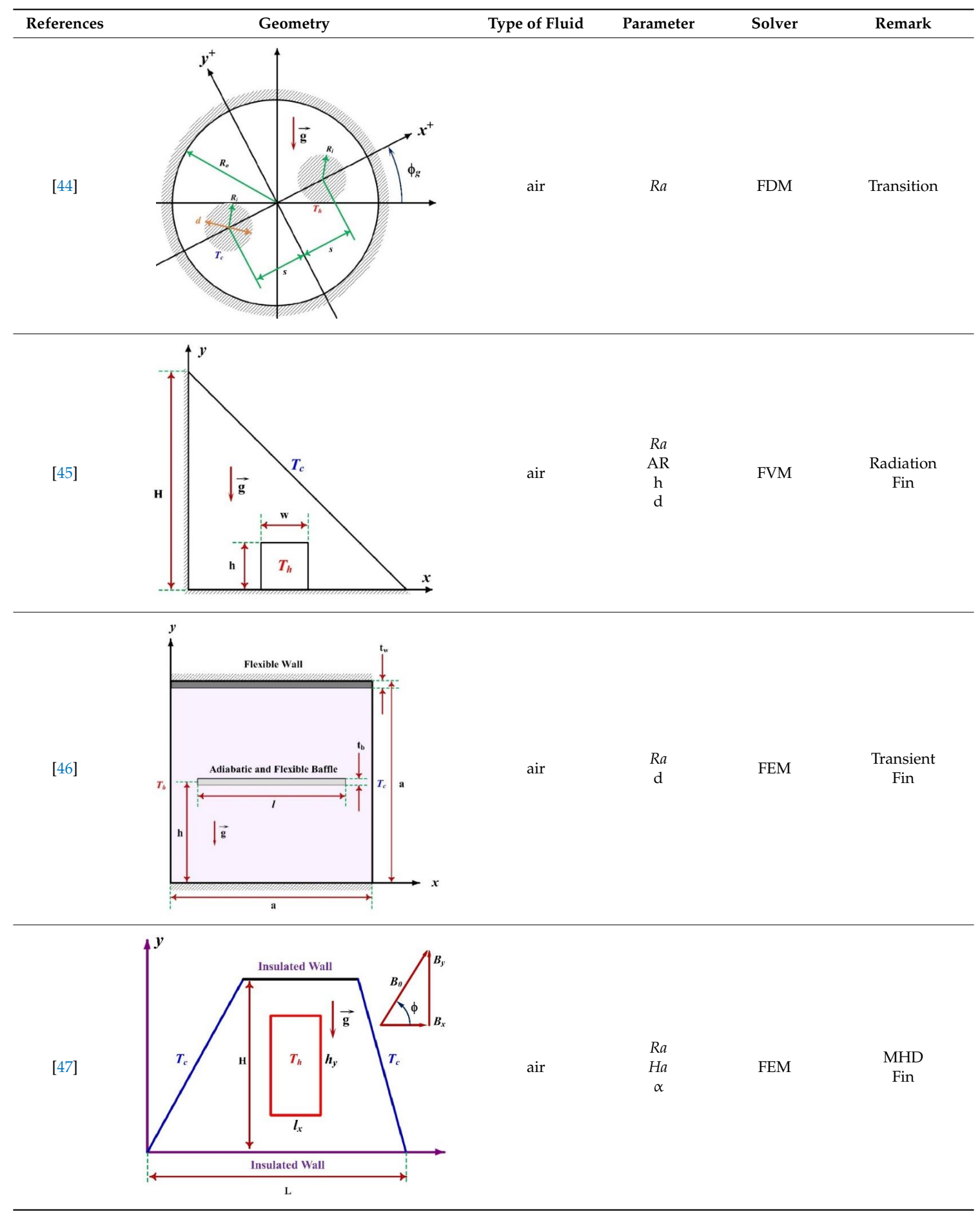

\subsubsection{Nanofluids}

With the advent of science and the ever-increasing need of humans for energy, the researchers attempted to use fluids with higher thermal conductivity in the cavities. Therefore, by adding nanofluids instead of air and water, they studied the heat transfer in the heat device [48-68]. The study of nanofluids has grown dramatically in recent years, and articles that have used these fluids are increasing. Their thermal expansion, specific heat capacity, and density are calculated by the following equations:

$$
\rho_{\mathrm{nf}}=(1-\varphi) \rho_{\mathrm{f}}+\varphi \rho_{\mathrm{s}}
$$




$$
\begin{gathered}
\left(c_{\mathrm{p}}\right)_{\mathrm{nf}}=(1-\varphi)\left(\mathrm{c}_{\mathrm{p}}\right)_{\mathrm{f}}+\varphi\left(c_{\mathrm{p}}\right)_{\mathrm{s}} \\
\left(\rho c_{\mathrm{p}}\right)_{\mathrm{nf}}=(1-\varphi)\left(\rho c_{\mathrm{p}}\right)_{\mathrm{f}}+\varphi\left(\rho c_{\mathrm{p}}\right)_{s} \\
\beta_{\mathrm{nf}}=(1-\varphi) \beta_{\mathrm{f}}+\varphi \beta_{s}
\end{gathered}
$$

The viscosity of nanofluids is an important property is measured by performing tests on various nanofluids, volumes, and temperatures [69-79]. A collection of well-known relationships regarding viscosity of nanofluids is briefly listed in Table 5 .

Table 5. Relationships obtained for nanofluid viscosity.

\begin{tabular}{cc}
\hline Correlation & Ref \\
\hline$\mu_{\text {eff }}=(1+2.5 \varphi)$ & Einstein [80] \\
\hline$\mu_{\text {eff }}=\frac{1}{(1-\varphi)^{2.5}}$ & Brinkman [81] \\
\hline$\mu_{\text {eff }}=\left(1+2.5 \varphi+6.5 \varphi^{2}\right)$ & Batchelor [82] \\
\hline$\mu_{\text {eff }}=\left(1+2.5 \varphi+25.4 \varphi^{2}+\mathrm{O}\left(\varphi^{3}\right)\right)$ & Lundgren [83] \\
\hline$\mu_{\text {eff }}=$ & Graham [84] \\
\hline$\mu_{\text {eff }}=\left(1+2.5 \varphi+\left(\frac{125}{64 \varphi_{\mathrm{p} \text { max }}}\right) \varphi^{2}+\ldots\right)$ & Simha [85] \\
\hline$\mu_{\text {eff }}=\exp \left(\frac{2.5 \varphi}{1-\mathrm{k} \varphi}\right)$ & Mooney [86] \\
\hline$\mu_{\text {eff }}=\mu_{\mathrm{f}}\left(1+\frac{1.25 \varphi}{1-\frac{\varphi}{0.78}}\right)$ & Eilers [87] \\
\hline$\mu_{\text {eff }}=\mu_{\mathrm{f}}\left(1+\frac{1.25 \varphi}{1-\varphi} \varphi\right)$ & Saito [88] \\
\hline$\mu_{\text {eff }}=\frac{9}{8}\left[\frac{\left(\varphi / \varphi_{\mathrm{m}}\right)^{1 / 3}}{1-\left(\varphi / \varphi_{\mathrm{m}}\right)^{1 / 3}}\right]$ & Frankel and Acrivos [89] \\
\hline
\end{tabular}

The most important reason for using nanofluids is their ability to the thermal conductivity so that thermal conductivity became the most important property. There are several calculation methods have been presented by researchers in order to measure the thermal conductivity of nanofluids. Many researchers are using experimental relationships for the thermal conductivity to express an equation for these fluids [90-103]. Some other researchers are also using theoretical relations, like ones listed in Table 6, considering Brownian motion, thermophoresis, clustering, to name a few, which are used to estimate nanofluid thermal conductivity.

Table 6. The relationships presented on the thermal conductivity for different nanofluids.

\begin{tabular}{cc}
\hline Ref & Correlation \\
\hline Maxwell [104] & $\mathrm{k}_{\text {eff }}=\mathrm{k}_{\mathrm{f}} \frac{\mathrm{k}_{\mathrm{p}}+2 \mathrm{k}_{\mathrm{f}}+2 \varphi\left(\mathrm{k}_{\mathrm{p}}-\mathrm{k}_{\mathrm{f}}\right)}{\mathrm{k}_{\mathrm{p}}+2 \mathrm{k}_{\mathrm{f}}-\varphi\left(\mathrm{k}_{\mathrm{p}}-\mathrm{k}_{\mathrm{f}}\right)}$ \\
\hline Wasp [105] & $\mathrm{k}_{\text {eff }}=\mathrm{k}_{\mathrm{f}} \frac{\mathrm{k}_{\mathrm{p}}+2 \mathrm{k}_{\mathrm{f}}-2 \varphi\left(\mathrm{k}_{\mathrm{p}}-\mathrm{k}_{\mathrm{f}}\right)}{\mathrm{k}_{\mathrm{p}}+2 \mathrm{k}_{\mathrm{f}}+\varphi\left(\mathrm{k}_{\mathrm{f}}-\mathrm{k}_{\mathrm{p}}\right)}$ \\
\hline Bruggeman [106] & $\varphi\left[\frac{\mathrm{k}_{\mathrm{p}}-\mathrm{k}_{\text {eff }}}{\mathrm{k}_{\mathrm{p}}+2 \mathrm{k}_{\text {eff }}}\right]+(1-\varphi)\left[\frac{\left.\mathrm{k}_{\mathrm{f}}-\mathrm{k}_{\text {eff }}\right]}{\mathrm{k}_{\mathrm{f}}+2 \mathrm{k}_{\text {eff }}}\right]=0$ \\
\hline Hamiltonn and Crosse [107] & $\mathrm{k}_{\text {eff }}=\mathrm{k}_{\mathrm{f}} \frac{\mathrm{k}_{\mathrm{p}}+(\mathrm{n}-1) \mathrm{k}_{\mathrm{f}}+(\mathrm{n}-1) \varphi\left(\mathrm{k}_{\mathrm{p}}-\mathrm{k}_{\mathrm{f}}\right)}{\mathrm{k}_{\mathrm{p}}+(\mathrm{n}-1) \mathrm{k}_{\mathrm{f}}-\varphi\left(\mathrm{k}_{\mathrm{p}}-\mathrm{k}_{\mathrm{f}}\right)}$ \\
\hline
\end{tabular}


Table 6. Cont.

\begin{tabular}{cc}
\hline Ref & Correlation \\
\hline Koo and Kleinstreuer [108,109] & $\mathrm{k}_{\text {eff }}=\mathrm{k}_{\mathrm{f}} \frac{\mathrm{k}_{\mathrm{p}}+2 \mathrm{k}_{\mathrm{f}}+2 \varphi\left(\mathrm{k}_{\mathrm{p}}-\mathrm{k}_{\mathrm{f}}\right)}{\mathrm{k}_{\mathrm{p}}+2 \mathrm{k}_{\mathrm{f}}-\varphi\left(\mathrm{k}_{\mathrm{f}}-\mathrm{k}_{\mathrm{p}}\right)}+5 \times 10^{4} \theta \rho_{\mathrm{f}} \mathrm{C}_{\mathrm{pf}} \varphi \mathrm{f}(\mathrm{T}, \varphi) \sqrt{\frac{\mathrm{K}_{\mathrm{B}} \mathrm{T}}{\rho_{\mathrm{f}} \mathrm{d}_{\mathrm{p}}}}$ \\
$\mathrm{f}(\mathrm{T}, \varphi)=(-6.04 \varphi+0.4705) \mathrm{T}+1722.3 \varphi-134.63$
\end{tabular}

\subsubsection{Non-Newtonian Fluids}

Many fluids such as the ones used in the food industry, pharmaceuticals, dye industry, adhesives, etc., whose shear-stress and strain are not linear-dependent. Non-Newtonian fluids can be divided into different categories based on their behavior. Figure 5 illustrates the types of non-Newtonian fluids and their relationship between strain and stress. Non-Newtonian fluids can exhibit different behaviors due to applied strains. Non-Newtonian yield material fluids have a certain amount of stress. In shear-thinning fluids, the stress decreases with the strain rate, while non-Newtonian shear thickening fluids behave inversely. Their stress increases with the strain rate. Figure 5 shows the behavior of these fluids in terms of stress and strain.

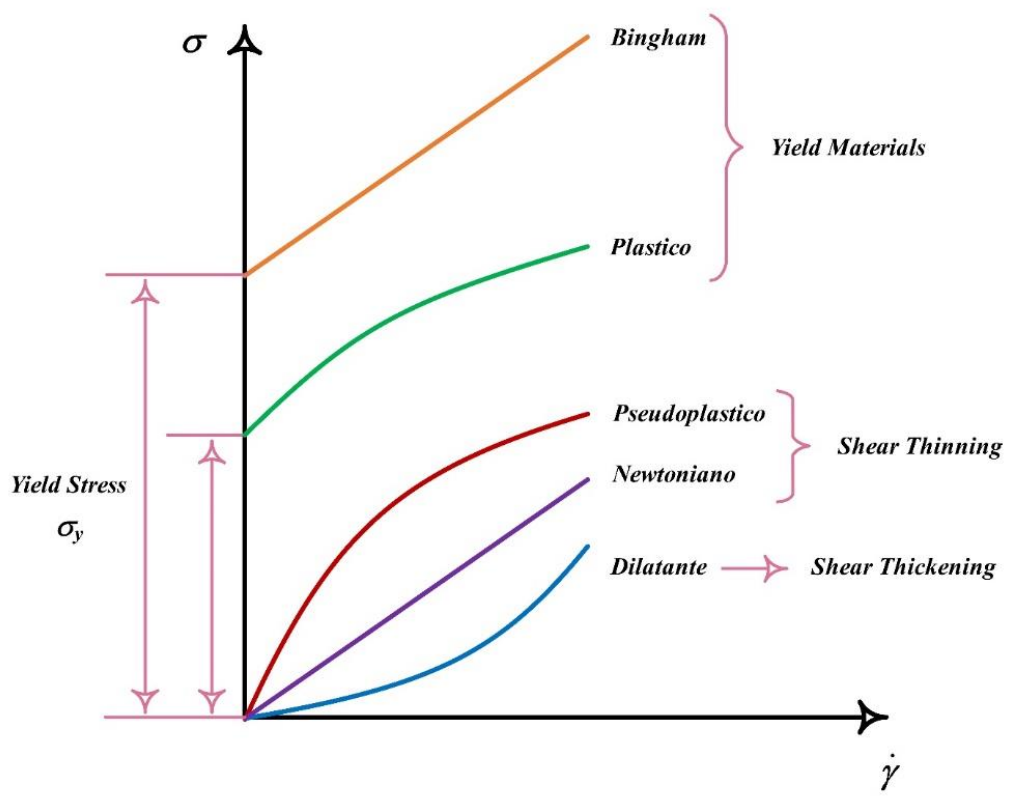

Figure 5. Comparison of non-Newtonian and Newtonian fluids based on their stress and strain variations [69].

The third type of fluid, which some researchers added to the cavities to study heat transfer are non-Newtonian fluids and some models for the stress and strain relationship are presented [114-125]. The shear stress tensor of the power-law model, which is widely used for non-Newtonian fluids in numerical studies of cavities, is described as follows:

$$
\tau_{i j}=2 \mu_{a} D_{i j}=\mu_{a}\left(\frac{\partial u_{i}}{\partial x_{j}}+\frac{\partial v_{j}}{\partial y_{i}}\right)
$$


In (9), $\mathrm{D}_{\mathrm{ij}}$ and $\mu_{\mathrm{a}}$ are the tensor of shear rate and the apparent viscosity, respectively.

$$
\mu_{\mathrm{a}}=\mathrm{K}\left\{2\left[\left(\frac{\partial \mathrm{u}}{\partial \mathrm{x}}\right)^{2}+\left(\frac{\partial \mathrm{v}}{\partial \mathrm{y}}\right)^{2}\right]+\left(\frac{\partial \mathrm{v}}{\partial \mathrm{x}_{\mathrm{j}}}+\frac{\partial \mathrm{u}}{\partial \mathrm{y}_{\mathrm{i}}}\right)^{2}\right\}^{\frac{(\mathrm{n}-1)}{2}}
$$

In (10), $\mathrm{n}$ and $\mathrm{K}$ are the coefficient and power-law index, respectively. Quasi-plastic fluids are those with $\mathrm{n}$ greater than unity, dilatant fluids are those with $\mathrm{n}$ lower than unity, and Newtonians are those with $n$ equal to unity. For example, Zhou and Bayazitoglu [126] examined a power-law fluid flow by means of the FVM. They found that with the growing $\mathrm{n}, \mathrm{Nu}$ decreases. Moreover, in a different power-law index, increasing the Rayleigh has a different effect on $\mathrm{Nu}$. Wang et al. [127] used Lattice Boltzmann (LBM) method and examined the sinusoidal thermal boundary condition and power-law model was used for fluid modeling. They found that raising $\mathrm{n}$ caused a reduction of $\mathrm{Nu}$. Table 7 summarizes some of the studies related to convection in the enclosures using non-Newtonian fluids.

Table 7. Brief of articles about non-Newtonian fluids within enclosures.

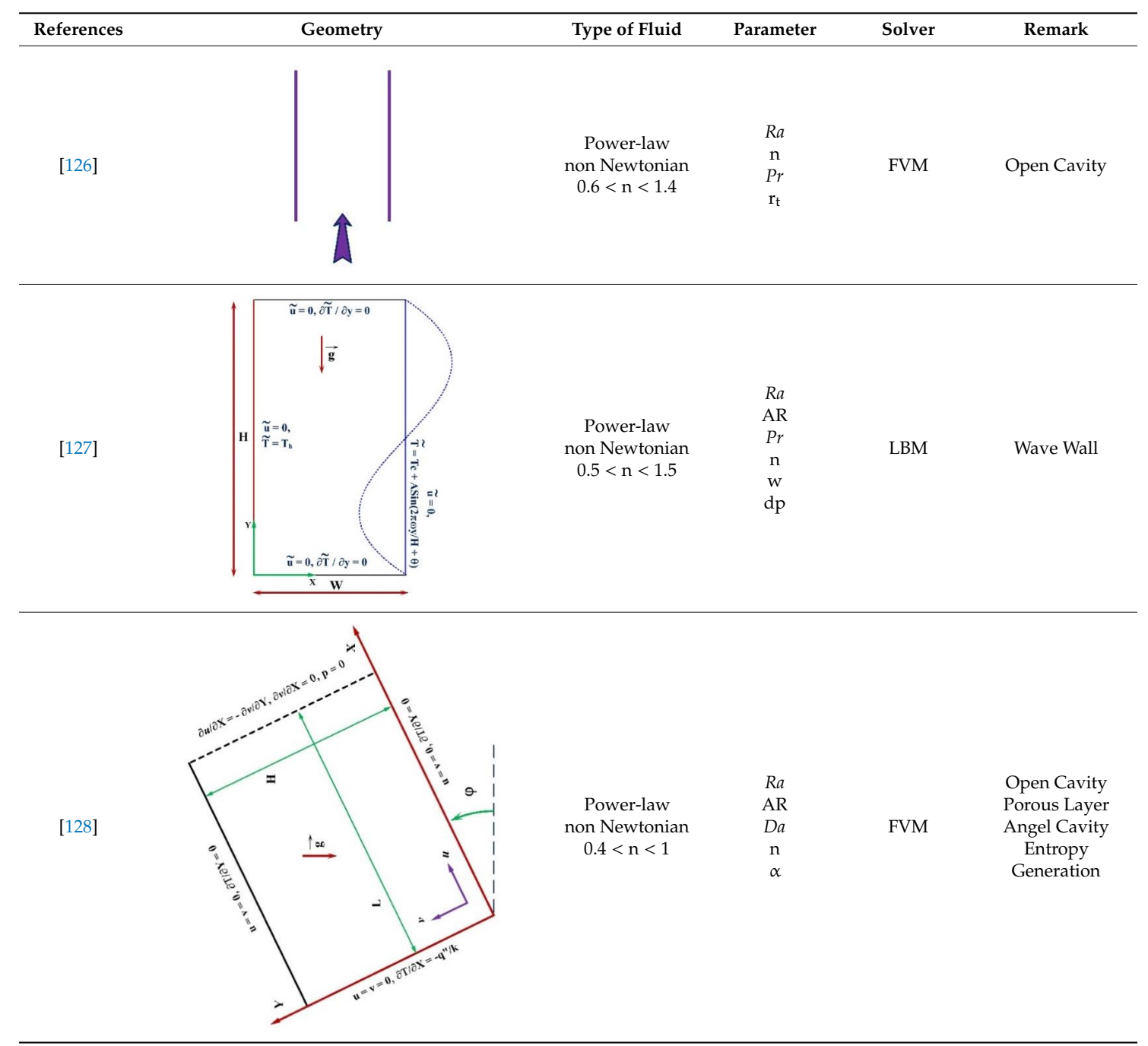


Table 7. Cont

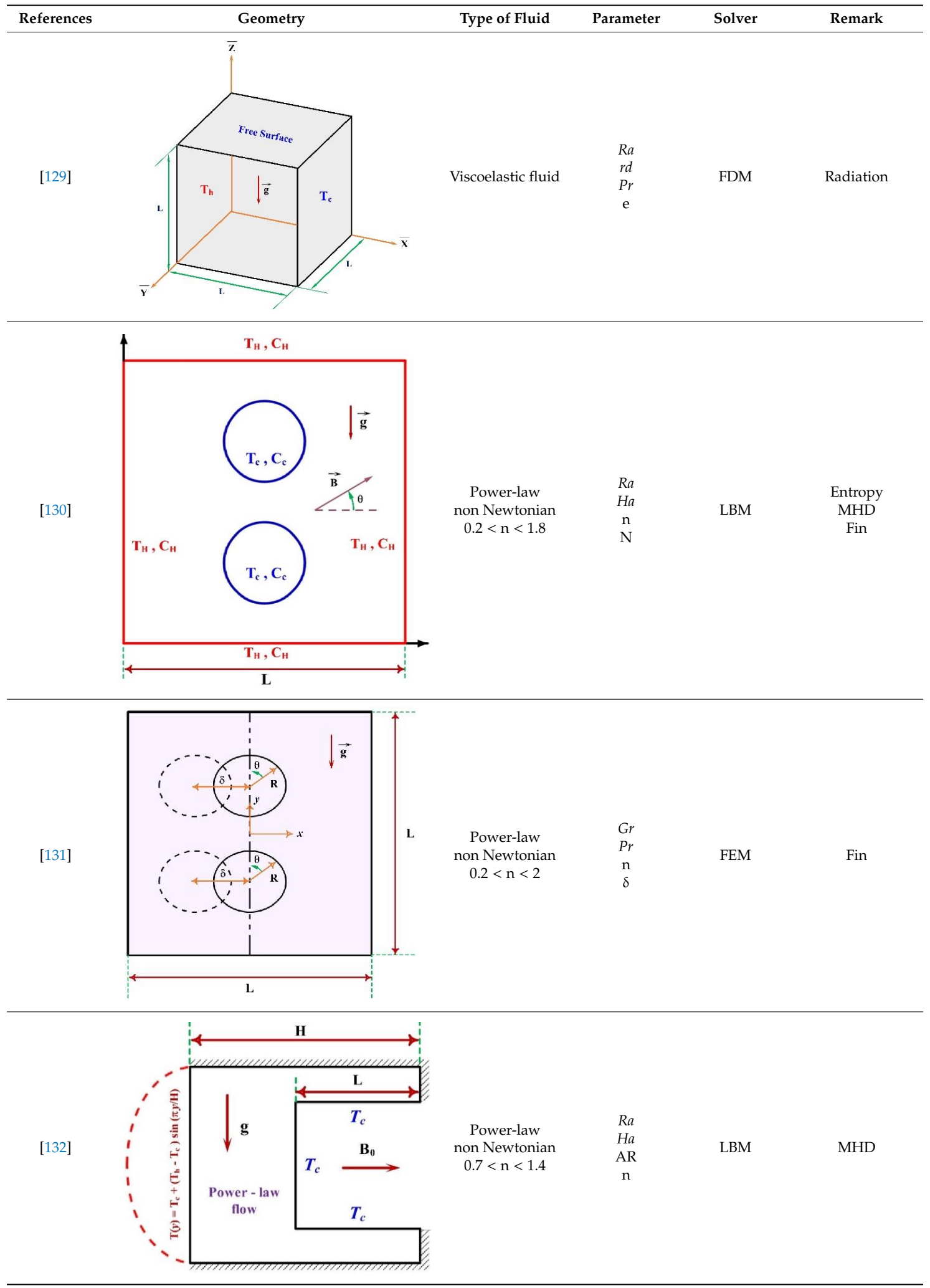




\section{Effective Parameters on Heat Transfer in Cavities}

At the beginning of cavities examination, the researchers examined simple cavities. The geometry of these cavities is either square or rectangular, and the side walls temperature is constant. In these studies, the effective parameters on $\mathrm{Nu}$ were low and the influence of $\mathrm{R} a$ on $\mathrm{Nu}$ was often investigated. Over time, researchers have tried to improve their studies by adding other effective parameters and changing geometry of the cavities. The following can be considered as simple examples for examining the natural convection in the cavities.

Most of the studies investigated quadratic cavities and the parameters affecting heat transfer include Rayleigh number and thermophysical properties of the operating fluid [49,58-63,133-143]. With the advancement of science, researchers also investigated the natural convection in enclosures by adding other imperative parameters such as the magnetic field, fins, porous medium, etc. In the following, the work done with each of the important parameters is important.

\subsection{Inclined Cavity}

Some researchers examined the effect of this parameter on $\mathrm{Nu}$, temperature, velocity fields by angling the cavity. By giving angle to the cavity, the gravitational force on the cavity also receives an angle. Hence, momentum equations will be as follows:

$$
\begin{aligned}
& \mathrm{u} \frac{\partial \mathrm{u}}{\partial \mathrm{x}}+\mathrm{v} \frac{\partial \mathrm{u}}{\partial \mathrm{y}}=-\frac{1}{\rho} \frac{\partial \mathrm{p}}{\partial \mathrm{x}}+\frac{1}{\rho}\left(\frac{\partial}{\partial \mathrm{x}}\left(\mu \frac{\partial \mathrm{u}}{\partial \mathrm{x}}\right)+\frac{\partial}{\partial \mathrm{y}}\left(\mu \frac{\partial \mathrm{u}}{\partial \mathrm{y}}\right)\right)+\mathrm{g} \beta\left(\mathrm{T}-\mathrm{T}_{\mathrm{c}}\right) \sin \gamma \\
& \mathrm{u} \frac{\partial \mathrm{v}}{\partial \mathrm{x}}+\mathrm{v} \frac{\partial \mathrm{v}}{\partial \mathrm{y}}=-\frac{1}{\rho} \frac{\partial \mathrm{p}}{\partial y}+\frac{1}{\rho}\left(\frac{\partial}{\partial \mathrm{x}}\left(\mu \frac{\partial \mathrm{v}}{\partial \mathrm{x}}\right)+\frac{\partial}{\partial \mathrm{y}}\left(\mu \frac{\partial \mathrm{v}}{\partial \mathrm{y}}\right)\right)+\mathrm{g} \beta\left(\mathrm{T}-\mathrm{T}_{\mathrm{c}}\right) \cos \gamma
\end{aligned}
$$

In the above equations, $\gamma$ is the angle of cavity relative to the horizon line. Naturally, due to absence of gravity in the mass and energy conservation equations, no change is made in these two equations. In the study of Goodarzi et al. [144] a constant flux source in the chamber has been studied. They examined the effect of Grashof number on $N u$ in the range of 400 to 40,000,000. Emami et al. [145] focused on water/copper nanofluid as a two-phase fluid in a cavity. They examined the cavity by adding a porous medium and found that the porous media was beneficial in strong convection, but in poor convection, it may reduce $N u$. Raizah et al. [128] studied a porous cavity and found that $N u$ increased by raising $R a$ and reducing power-law index.

Kefayati et al. [146,147] reviewed Bingham fluid natural convection through the Finite Difference Lattice Boltzmann (FDLBM) method. They examined the angle effect of the cavity. Sajjadi et al. [148] used the copper/water nanofluid using LBM, they investigated the effect of cavity angles from 0 to 60 degrees. Hosseini et al. [149] used several nanofluids in diagonal cavities. They used nanoparticles, for example, $\mathrm{Cu}, \mathrm{Ag}, \mathrm{Al}_{2} \mathrm{O}_{3}$, and $\mathrm{TiO}_{2}$, in water-base fluid. Sheremet et al. [150] studied alumina/water nanofluid using the FDM in order to the free convection investigation. Ogut [151] examined various angles from 0 to 90 degrees. He used copper oxide, silver oxide, and alumina nanofluids in water base fluid. Abu-nada and Oztop [152] studied influence of cavity angle on $N u$ by means of the FVM. They used the copper/water nanofluid as an operating fluid and changed the angle of cavity from 0 to 120 degrees. Oztop et al. [59] modified the angle of cavity by studying the heat transfer rate in a cavity with sinusoidal thermal boundary condition by means of the FVM. They changed the angle of cavity from 0 to 90 degrees, and by adding nanofluid of copper and titanium water examined the percentage effects of nanofluids. Table 8 presents a number of articles studied inclined enclosures. 
Table 8. Summary of some articles studied enclosures with different inclination angles.

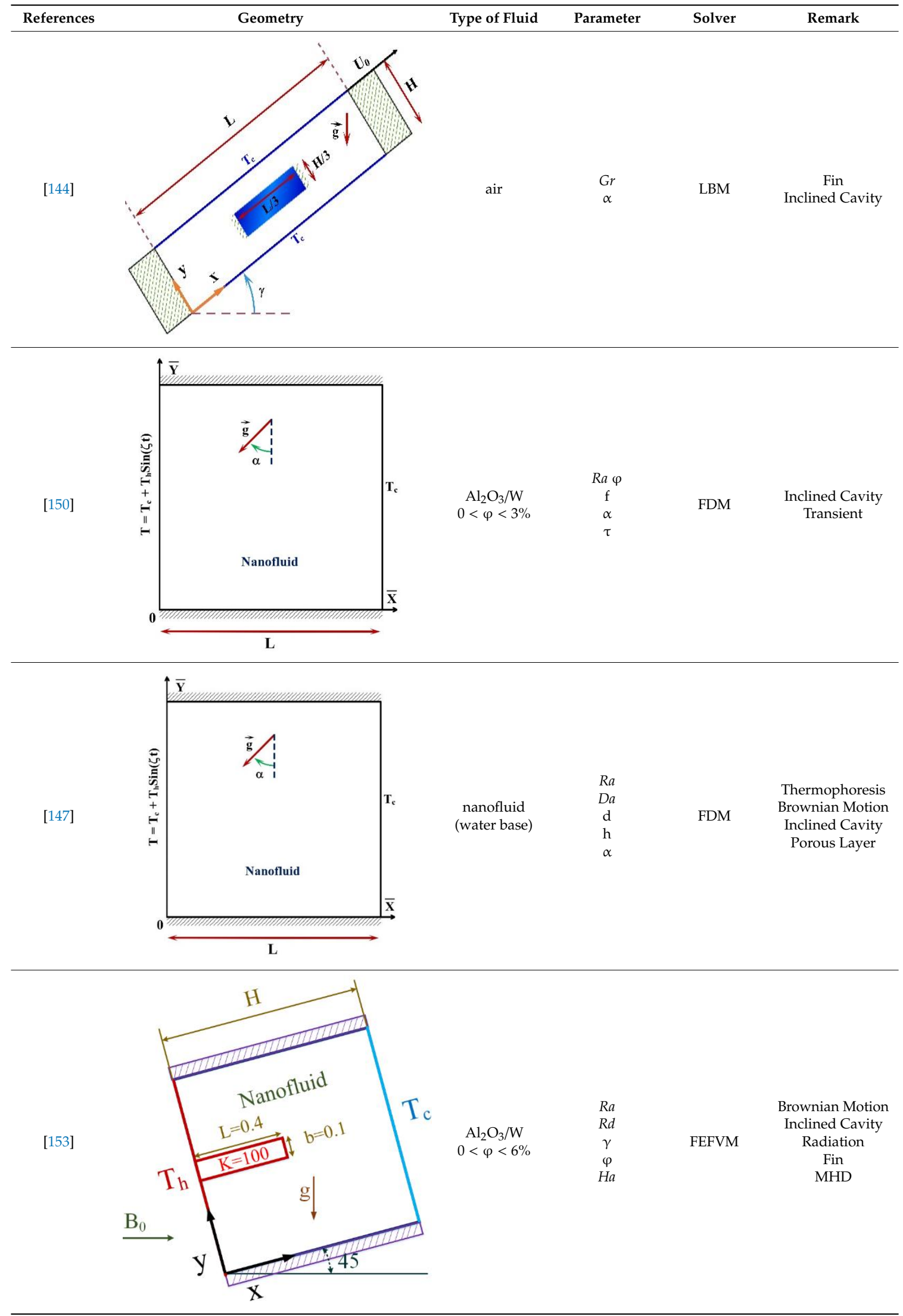


Table 8. Cont.

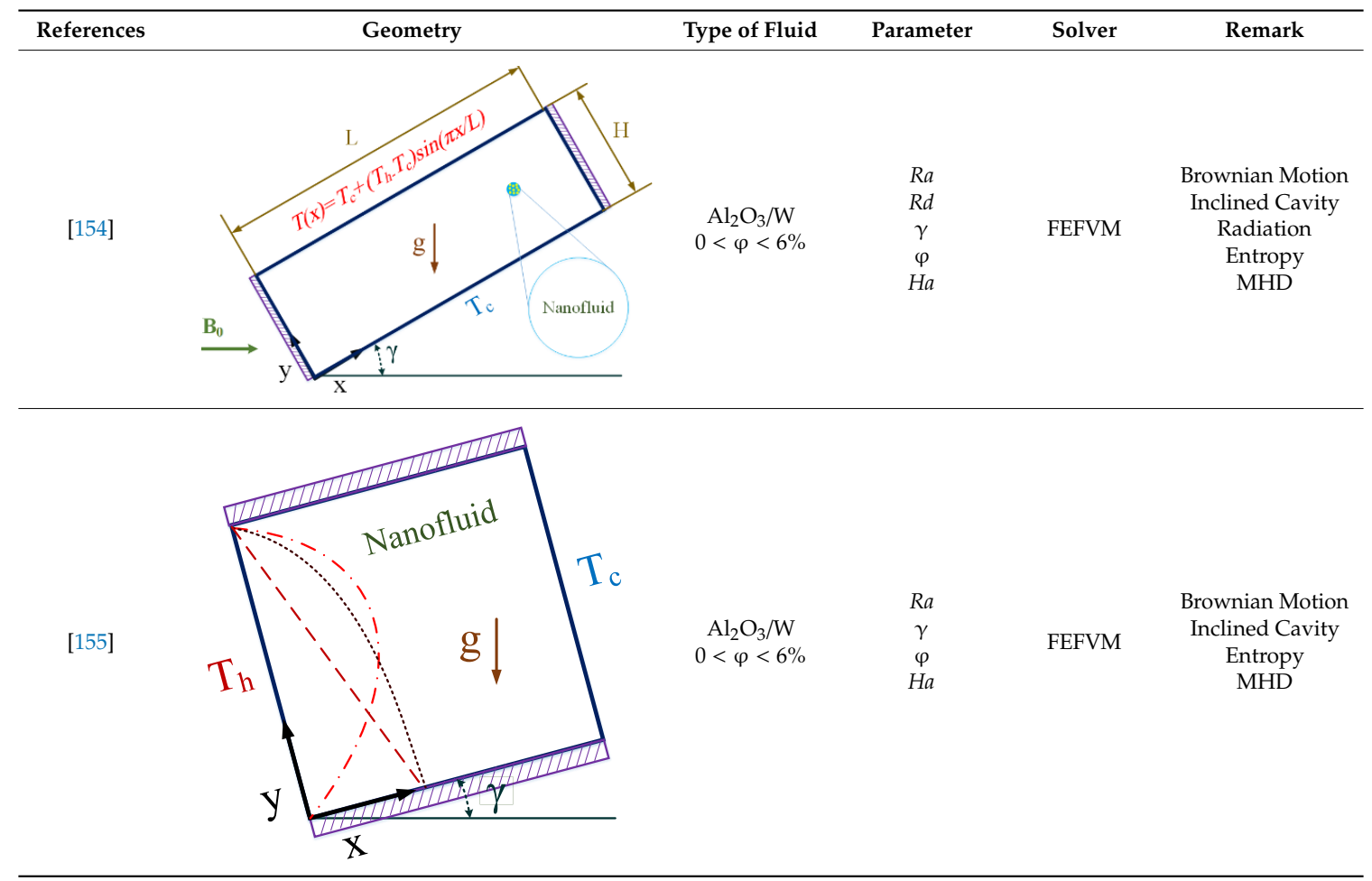

\subsection{Adding a Fin to Cavity}

Adding a fin to cavity is one of the most commonly used ways is to increase the heat exchange surfaces. As the heat exchange surface increases, the fluid and the wall are in greater contact with each other, which intensifies the overall heat transfer according to Newton's law of cooling. Hence, the blades or fins attracted much attention. Adding a blade or a fin to the surface can increase the heat transfer. Of course, another important issue is the ability to pump. By addition of fin, the energy loss in the fluid and the pressure difference increase due to the shear stress. Therefore, it is necessary to be careful in the use of fins in the desired dimensions and proportions. Therefore, many researchers have attempted to optimize the dimensions of blades or fins. Fins can have different shapes and sizes some of which can be seen in Figure 6. Since the fine size is very important in Nu due to the lack of free space, the addition of fin to them has been one of the challenges in discussing the free convection. Excessive fin size can narrow the space in the chamber and reduce the fluid flow rate.

Researchers also examined the effect of fin in the cavities [156-160]. By adding a constant temperature fin, a temperature boundary condition is added to the boundary condition equations. If the fin has a thermal conductivity, in addition to the fin boundary condition, the following relation should also be added to the equations. This relation is the energy equation for the fin.

$$
\frac{\partial}{\partial \mathrm{x}}\left(k_{f i n} \frac{\partial \mathrm{T}}{\partial \mathrm{x}}\right)+\frac{\partial}{\partial \mathrm{y}}\left(k_{f i n} \frac{\partial \mathrm{T}}{\partial \mathrm{y}}\right)=0
$$

In some cases, the fin is placed on constant temperature walls or the thermal conductivity, and in some cases, it is placed as a heat source within the cavity. Selimefendigil and Öztop [161] added a barrier to the center of enclosure to evaluate the impact of these barriers on $\mathrm{Nu}$. Sheikholeslami and Sadoughi [162] investigated the effect of four fixed temperature fins in a square enclosure under a magnetic field. Sheikholeslami and Ganji [163] used LBM to examine the fin effect. Miroshnichenko et al. [164] investigated water/alumina nanofluid by the FDM in order to study the free convection. They placed a thermal source in the lower part of the cavity and evaluated the effect of cavity angle on $N u$. They concluded that the most $N u$ appears at 60 angles. Rahimi et al. [165] 
investigated an L-shaped cavity using LBM method. There was a fixed temperature fin in the cavity. Alsabery et al. [166] also examined the effect of a fin in cavities by means of the FDM.

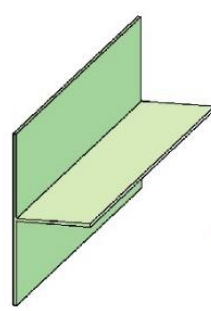

(1)

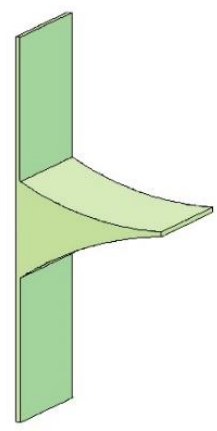

(4)

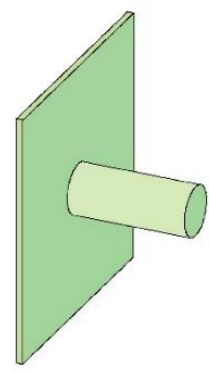

(7)

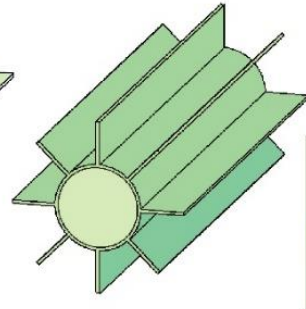

(2)

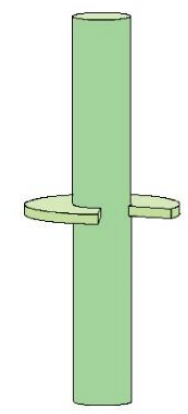

(5)

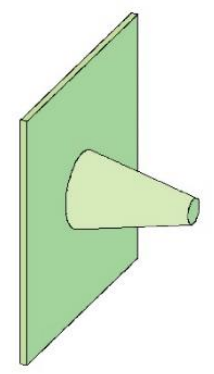

(8)

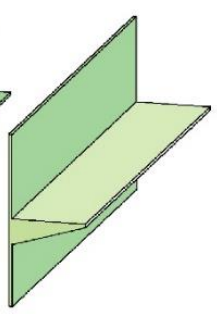

(3)

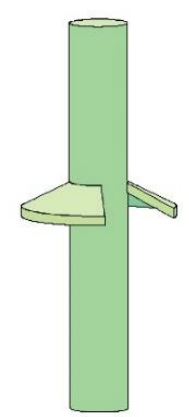

(6)

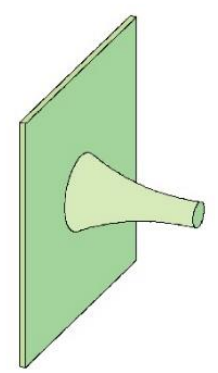

(9)
(1) Longitudinal fin - Rectangular profile

(2) Longitudinal fin - Rectangular profile

(3) Longitudinal fin - Trapezoidal profile

(4) Longitudinal fin - Concave parabolic

(5) Radial fin-Rectangular profile

(6) Radial fin - Triangular profile

\section{( 7) Pin fin - Cylindrical}

(8) Pin fin - Tapered profile

(9) Pin fin - Concave Parabolic

Figure 6. Some types of fins used in different enclosures [2].

Siavashi et al. [167] examined the copper-nickel nanofluid while considering two porous fins. They found that by adding a high-Darcy fin, the heat transfer was increased and by adding a low-Darcy fin, the heat transfer was reduced. Alsabery et al. [168] examined the free convection using the FDM. There is a barrier with thermal conductivity within the cavity and, thus, they found that the ratio of thermal conductivity and block size were good controllers for heat transfer. Lugarimi et al. [43] studied the natural and turbulent convection heat by means of the FVM. Inside the cavity, there was a square barrier. Larger fins provide lower $N u$ values. Alsabery et al. [169] focused on effect of thermophoresis and Brownian motion using the FDM. There was a barrier with a conductivity coefficient in the cavity and with increasing its thermal conductivity in the $R a, N u$ increases. Raisi and Arvin [46] examined the heat transfer of transient air using FDM. They put an insulating and flexible rectangular fin inside the cavity and found that by growing the $R a, N u$, and the deformation of the elastic part of the fin increases.

Sheikholeslami et al. [170] examined alumina/water nanofluids Using LBM in a 3-D model under an angled magnetic field. There was a spherical barrier with a warm temperature inside the rectangular three-dimensional cavity. Sobhani et al. [171] included the radiation in a fined cavity. 
Tighchi et al. [172] did similar research using LBM. Akter and Parvin [47] examined the MHD flow of air using the finite element method (FEM). Increasing $R a$ and decreasing $H a$ would enhance $N u$. Saeid [158] examined natural and laminar air convection heat transfer in by FVM. The fin position of the constant heat flux in the floor has been studied. Izadi et al. [173] examined the multiwalled carbon nanotube (MWCNT)- $\mathrm{Fe}_{3} \mathrm{O}_{4} /$ water hybrid nanofluid by means of the LBM. The cavity was in the shape of T-inverted and there was a fin with fixed thermal flux on its floor. Shun et al. [174] examined a square cavity with a number of fins inside it. Pordanjani et al. [175] examined two rectangular fins effect on $\mathrm{Nu}$.

Kwak et al. [26] examined the presence of a spherical fin in the cavity. Hoghoughi et al. [176] examined a circular fin cavity. Mun et al. [177] examined presence of four circular fins. Kefayati and Tang $[178,179]$ evaluated the effect of a circular fin in two separate studies. Riahi et al. [180] also examined a rectangular cavity with two circular fins within them. Kefayati and tang [130] studied two circular fins inside it. Hussein et al. [181] examined the effect of a thin fin. Park et al. [182] examined the presence of two circular fins. Cho et al. [183] examined the natural convection with two circular and elliptical fins in a vertical rectangular cavity. Mishra et al. [131] investigated the influence of two circular fins. Verma et al. [27] evaluated adding a number of fins. Table 9 presents some articles that used fins in their work.

Table 9. Summary of some enclosures equipped with fins.

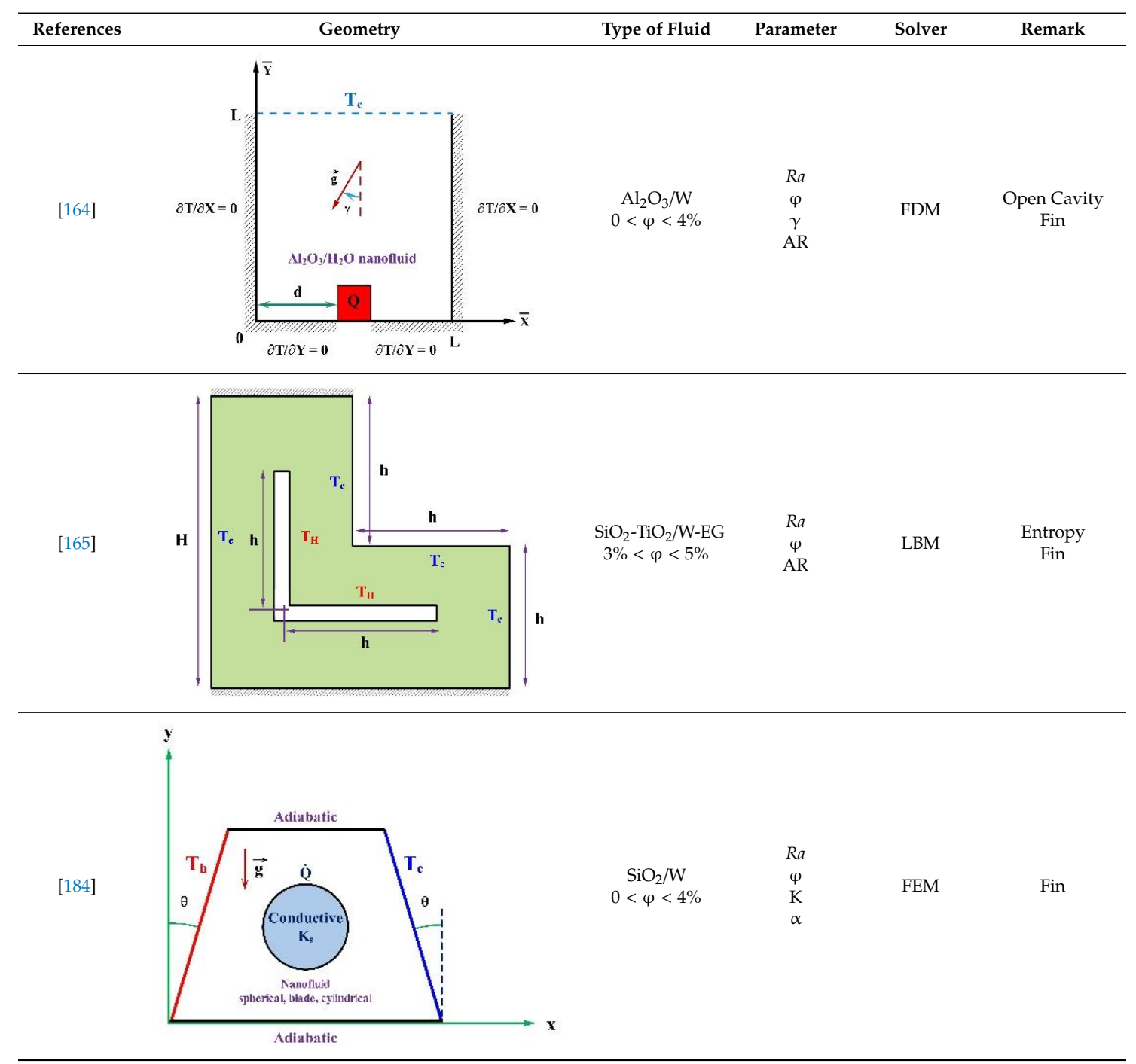


Table 9. Cont

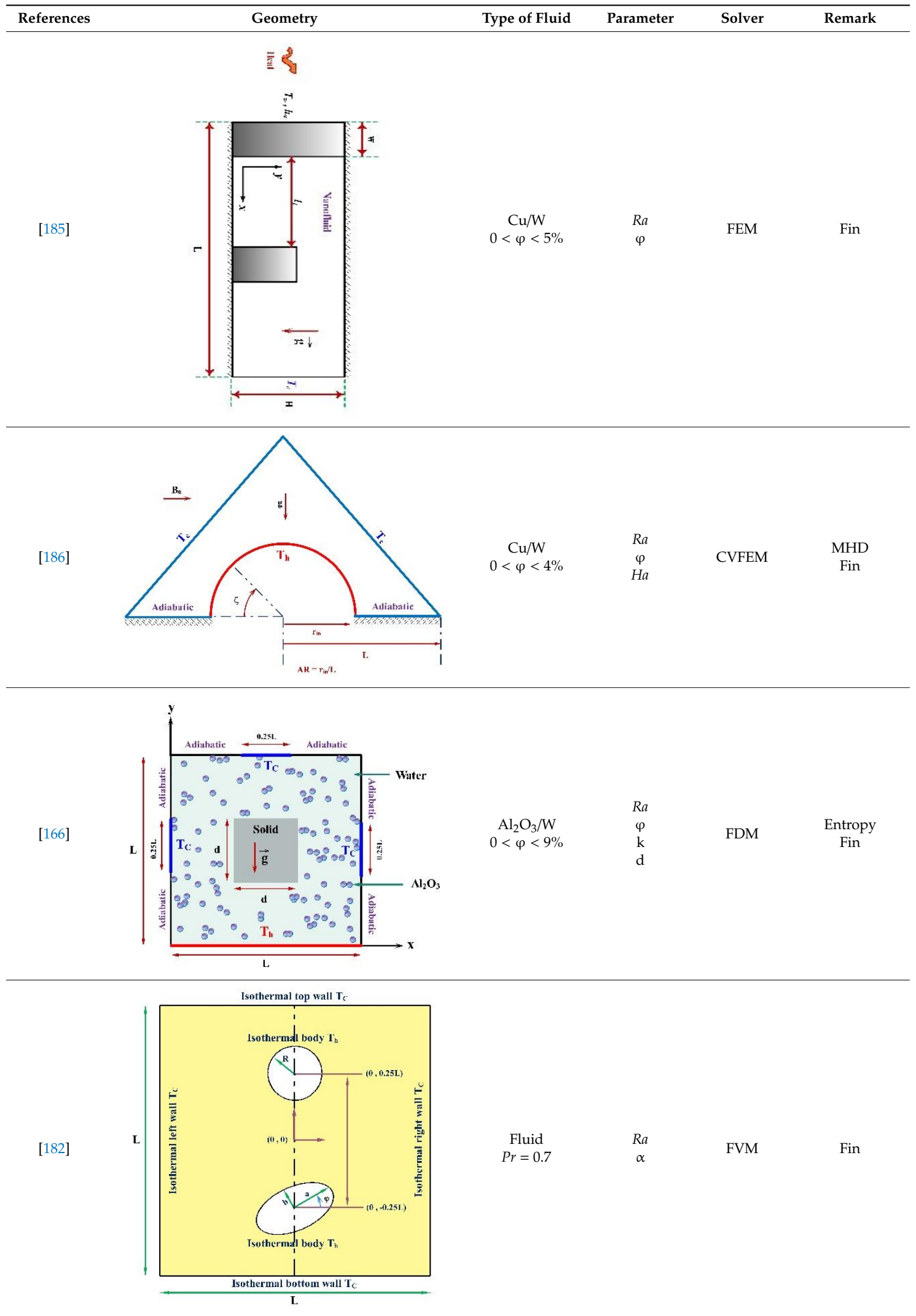


Table 9. Cont

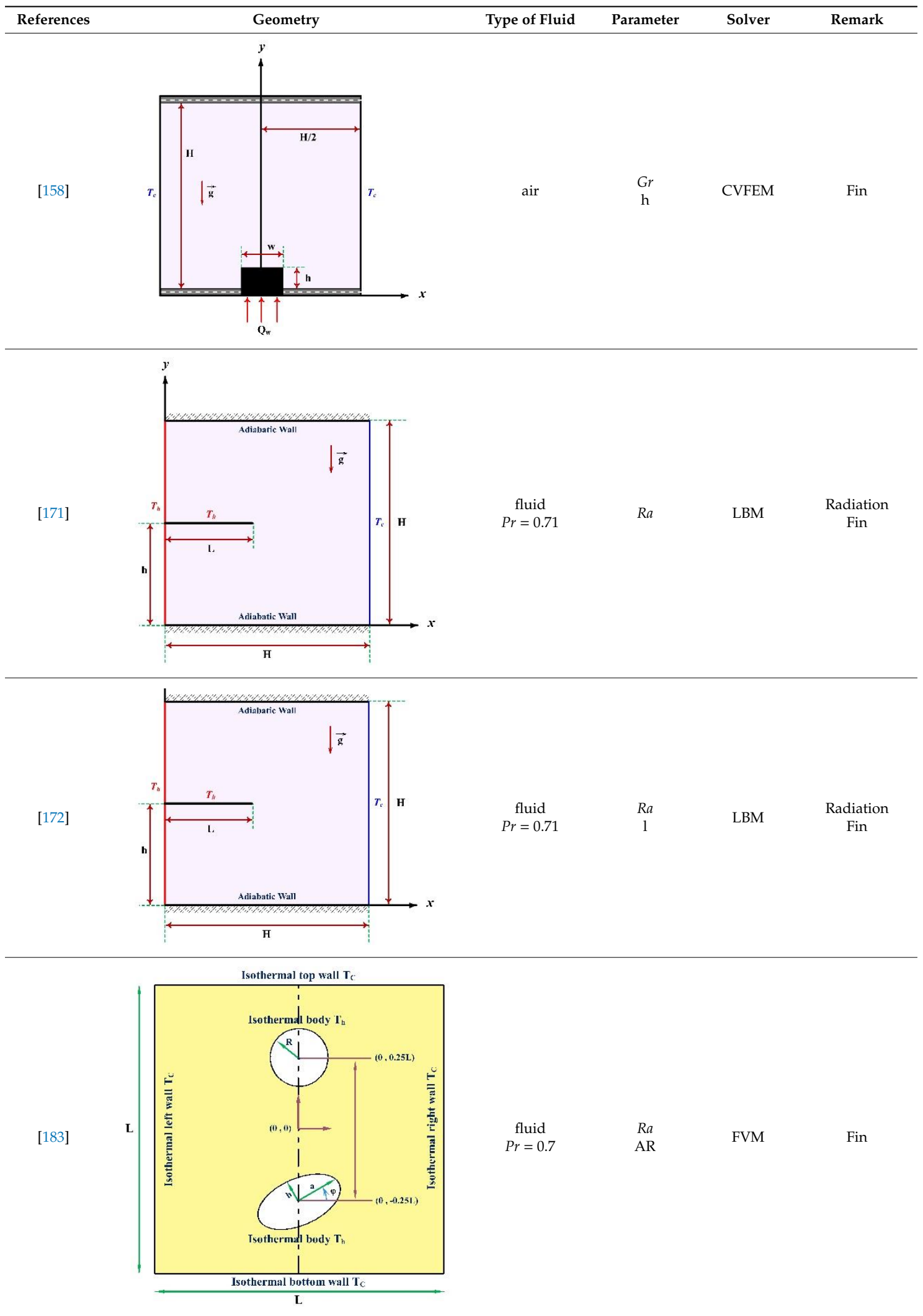


Table 9. Cont

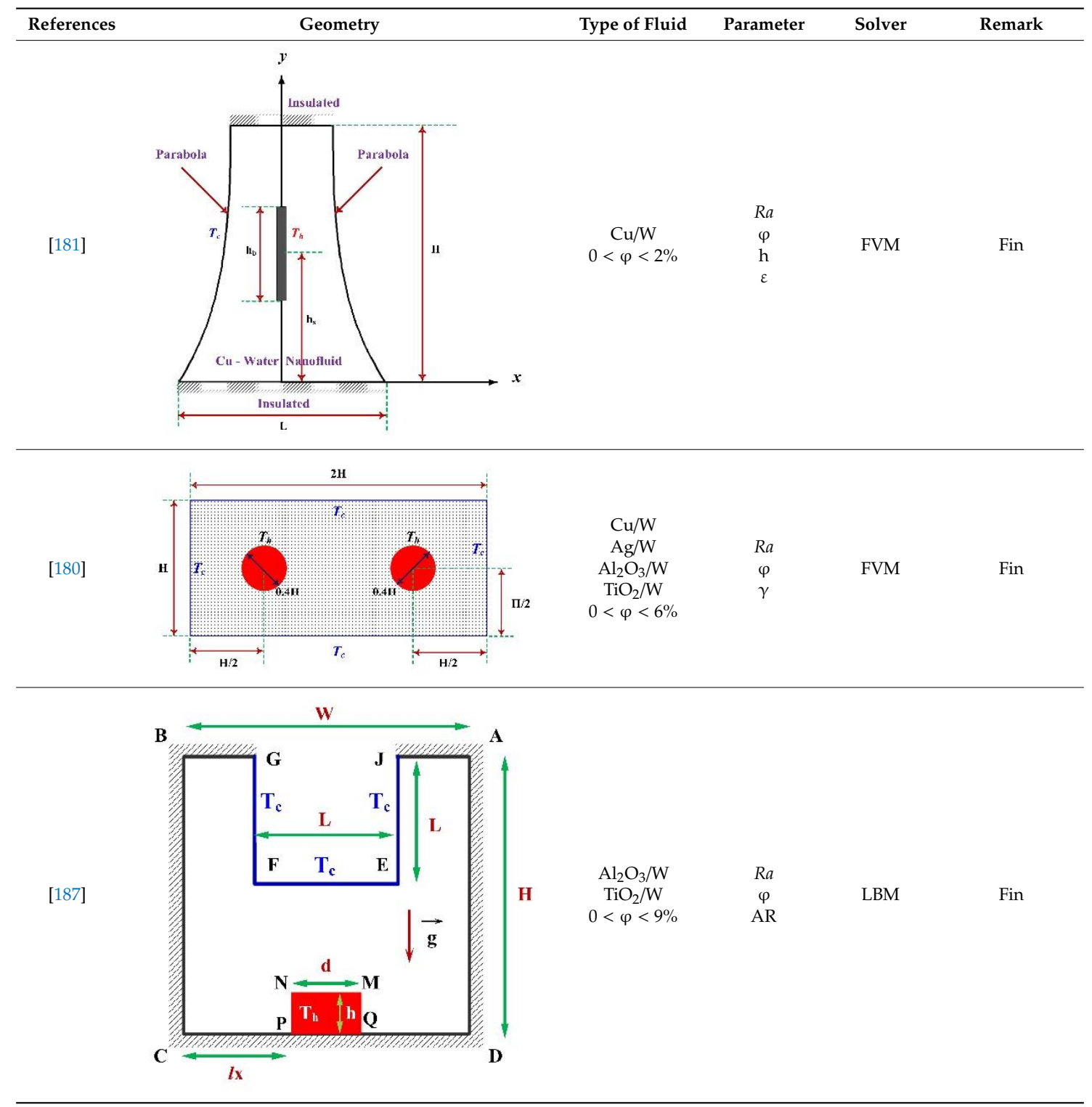

\subsection{Applying a Magnetic Field}

The magnetic field is inevitable in many industries because of the electricity near the heat transfer devices works as a flow controller. The presence of a magnetic field in different thermal devices can have different effects. The lid of some appliances, such as ducts or heatsinks, can improve heat transfer or reduce it like enclosures. Hence, the researchers have been studied heat transfer in a magnetic field. Figure 7 shows the types of magnetic field in a tube. It can be seen that a special magnetic field is created by placing different types of magnet in different situation.

Addition of magnetic field leads to the accumulation of nanoparticles. Figure 8 illustrated the effect of the magnetic field on nanoparticles and their accumulation. 


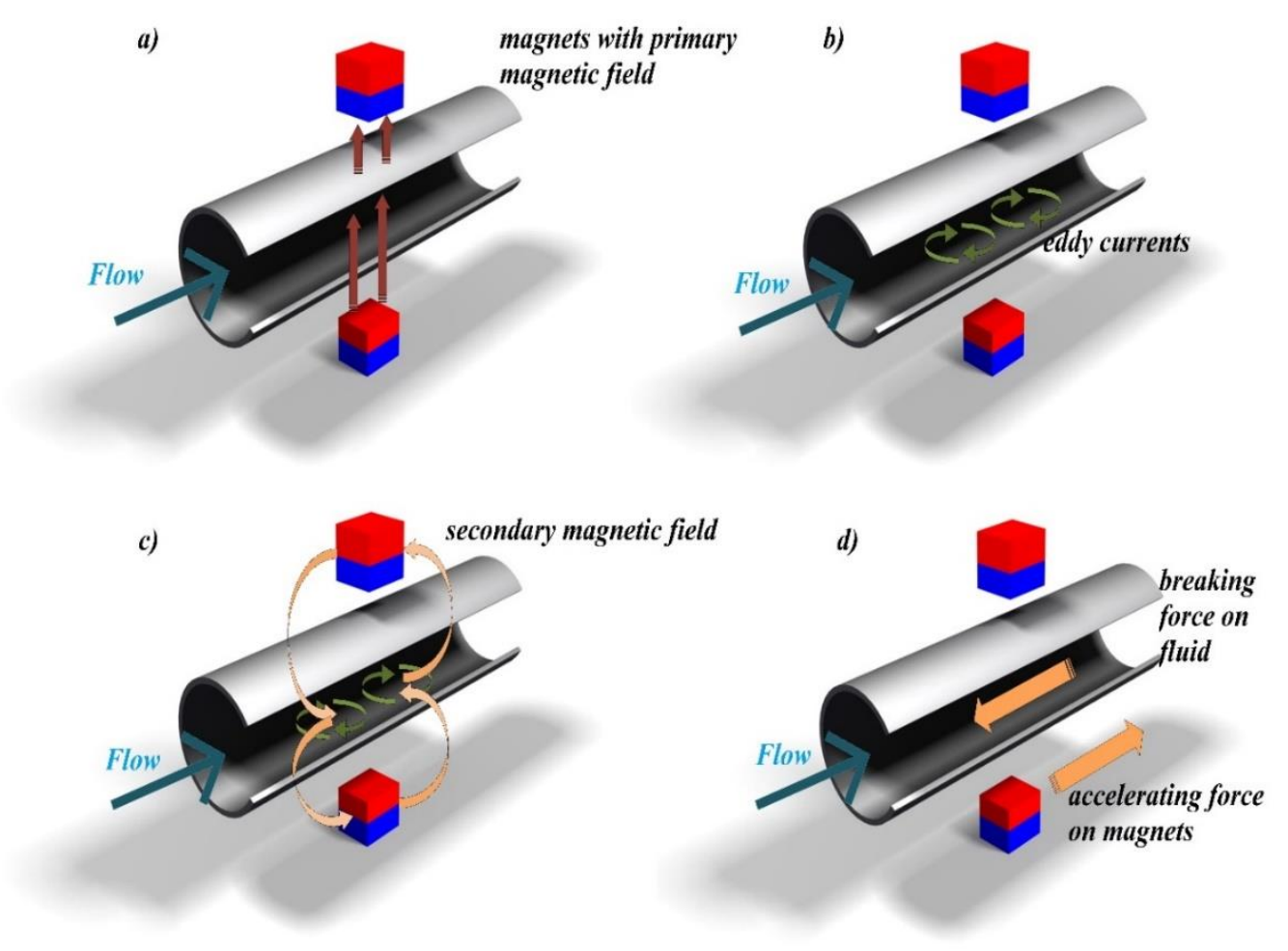

Figure 7. The Lorentz force in different arrangements of different magnetic fields [188]. (a) Magnets with primary magnetic field (b) Eddy currents (c) Secondary magnetic field (d) Breaking force on fluid.

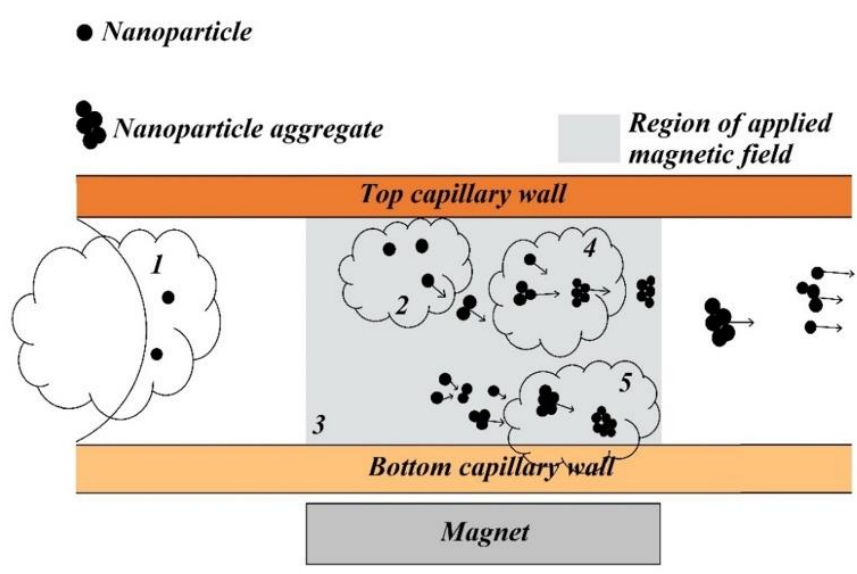

\section{The nature of the fluid and fluid flow}

2. The magnetic response and subsequent motion of nanoparticles under an applied magnetic field

3. The nature of the externally applied magnetic feild

4.The aggregation of nanoparticles under an applied magnetic field

5. The capture of nanopartivles, and nanoparticle aggregates

Figure 8. Effect of the magnetic field on nanoparticle accumulation in nanofluid [188].

The magnetic field leads to the generation of a new force in the nanofluid in addition to Lorentz force. This force can displace the fluid. In some cases, such as free convection in enclosures, it prevents the fluid displacement due to the buoyancy force, as the cavity is sometimes affected by the magnetic field in industry; researchers also examined the influence of a magnetic field on $N u$ [189-198]. The researchers have tried to study this issue using various angular fields. Some researchers have entered the field along the horizon and some examined the effect of magnetic field angle by giving 
angle to the cavity. By applying the angular magnetic field, the momentum equations are as below. Equations of energy and mass conservations, in addition, did not change.

$$
\begin{gathered}
\mathrm{u} \frac{\partial \mathrm{u}}{\partial \mathrm{x}}+\mathrm{v} \frac{\partial \mathrm{u}}{\partial \mathrm{y}}=-\frac{1}{\rho} \frac{\partial \mathrm{p}}{\partial \mathrm{x}}+\frac{1}{\rho}\left(\frac{\partial}{\partial \mathrm{x}}\left(\mu \frac{\partial \mathrm{u}}{\partial \mathrm{x}}\right)+\frac{\partial}{\partial \mathrm{y}}\left(\mu \frac{\partial \mathrm{u}}{\partial \mathrm{y}}\right)\right)-\frac{\sigma \mathrm{B}^{2}}{\rho}\left(v \sin \Omega \cdot \cos \Omega-\mathrm{usin}^{2} \Omega\right) \\
\frac{\partial \mathrm{v}}{\partial \mathrm{x}}+\mathrm{v} \frac{\partial \mathrm{v}}{\partial \mathrm{y}}=-\frac{1}{\rho} \frac{\partial \mathrm{p}}{\partial \mathrm{y}}+\frac{1}{\rho}\left(\frac{\partial}{\partial \mathrm{x}}\left(\mu \frac{\partial \mathrm{v}}{\partial \mathrm{x}}\right)+\frac{\partial}{\partial \mathrm{y}}\left(\mu \frac{\partial \mathrm{v}}{\partial \mathrm{y}}\right)\right)-\frac{\sigma \mathrm{B}^{2}}{\rho}\left(u \sin \Omega \cdot \cos \Omega-\mathrm{v} \cos ^{2} \Omega\right)+\mathrm{g} \beta\left(\mathrm{T}-\mathrm{T}_{\mathrm{c}}\right)
\end{gathered}
$$

In the above equations, $\Omega, \sigma$, and $B$ are magnetic field angle, electrical coefficient, and strength of magnetic field, respectively. Sajjad et al. [199] studied the effect of the magnetic field on natural convection of copper/water nanofluid and realized that its greatest influence of magnetic field occurred in Rayleigh $10^{4}$ and the least effect occurred on $10^{3}$. Selimefendigil and Oztop [200] did similar work on copper oxide/water and alumina/water nanofluids using the finite element method. There is a conductive wall in the cavity and there are two different nanofluids on both sides. They found that with increasing wall thermal conductivity, the $\mathrm{R} a$ and decreasing $\mathrm{Ha}$ increased the heat transfer rate.

Selimefendigil and Oztop [201] worked on carbon nanotube (CNT)/water nanofluids under an angular magnetic field using FEM. There was a conductive obstacle in the middle that separates fluid and nanofluid. They eventually found that by raising the height and the vibrational number of the conduction wall, the Nusselt number decreased by 27 to 32 percent. Kefayati [51] investigated various magnetic fields, $\mathrm{Ra}$, and nanoparticles concentration on $\mathrm{Nu}$, and found that by raising the volumetric percentage of ferromagnetism nanofluids in different $\mathrm{Ra}, \mathrm{Nu}$ is reduced. Mahmoudi et al. [50] studied the free convection of aluminum oxide nanofluid in a chamber numerically. With a rise in $\mathrm{Ra}$ and a decrease of $\mathrm{Ha}, \mathrm{Nu}$ increases and the magnetic field directly controls the nanoparticles effect. Mejri et al. [202] and Sivaraj and Sheremet [203] did similar works on alumina/water and iron oxide/water nanofluids, respectively. They found that the magnetic field angle is an excellent controller for heat transfer. Ashorynejad and Shahriari [204] investigated natural convection of the hybrid alumina-copper nanofluid under a magnetic field in an open cavity by the LBM method. One of the walls of cavity had a sinusual temperature along with vibration.

They found that $\mathrm{Nu}$ augmented by growing $\mathrm{R} a$ and volumetric percentage of nanoparticles, and reducing the Hartmann number. Haq et al. [205] investigated a porous cavity with the finite element method and using vibrating surfaces under a magnetic field. Increasing the vibrations length number and $R a, N u$ increases and it decreases by growing the Hartmann number. Javaherdeh and Najjanezami [206] investigated the water flow in a porous medium inside a cavity under a magnetic field using the LBM method. Growing the Darcy number raises Nu. Sheikholeslami and Shehzad [207] examined the natural convection of copper oxide nanofluid as a number in a cavity exposed to constant angular flux. The bottom was kept warm and the top was isolated. They studied the effects of $R a$, Darcy, Hartmann, and percent volumes of nanoparticles on heat transfer. Selimefendigil and Oztop [208] investigated a 3-dimensional cavity under magnetic flux using the finite element. There is copper oxide nanofluid in the cavity. They found that growing the nanoparticles concentration and $R a$ increased $\mathrm{Nu}$. Sheikholeslami and Sadoughi [162] considered the natural convection of the copper oxide nanofluid under a fixed angular magnetic field using LBM. Sides were maintained cool and the bottom and top kept isolated. There were four heaters; two hot, and two cold. They understood that $\mathrm{Nu}$ reduced with growing $\mathrm{Ha}$ and augmented with growing $\mathrm{R} a$. Al-Rashed et al. [209] investigated the natural convection of a 3-D cavity containing CNT/water nanofluids under an angular magnetic field in the FVM. They reported that by increasing $R a$ and declining $H a$, the Nusselt number increases. Dogonchi et al. [210] examined the effect of vibrating walls by FVM. Raising the $R a$ and the nanoparticles concentration intensifies the Nusselt number. Table 10 presents the papers on the effect of magnetic field in the convection system. 
Table 10. Articles studied the enclosures under the influence of the magnetic field.

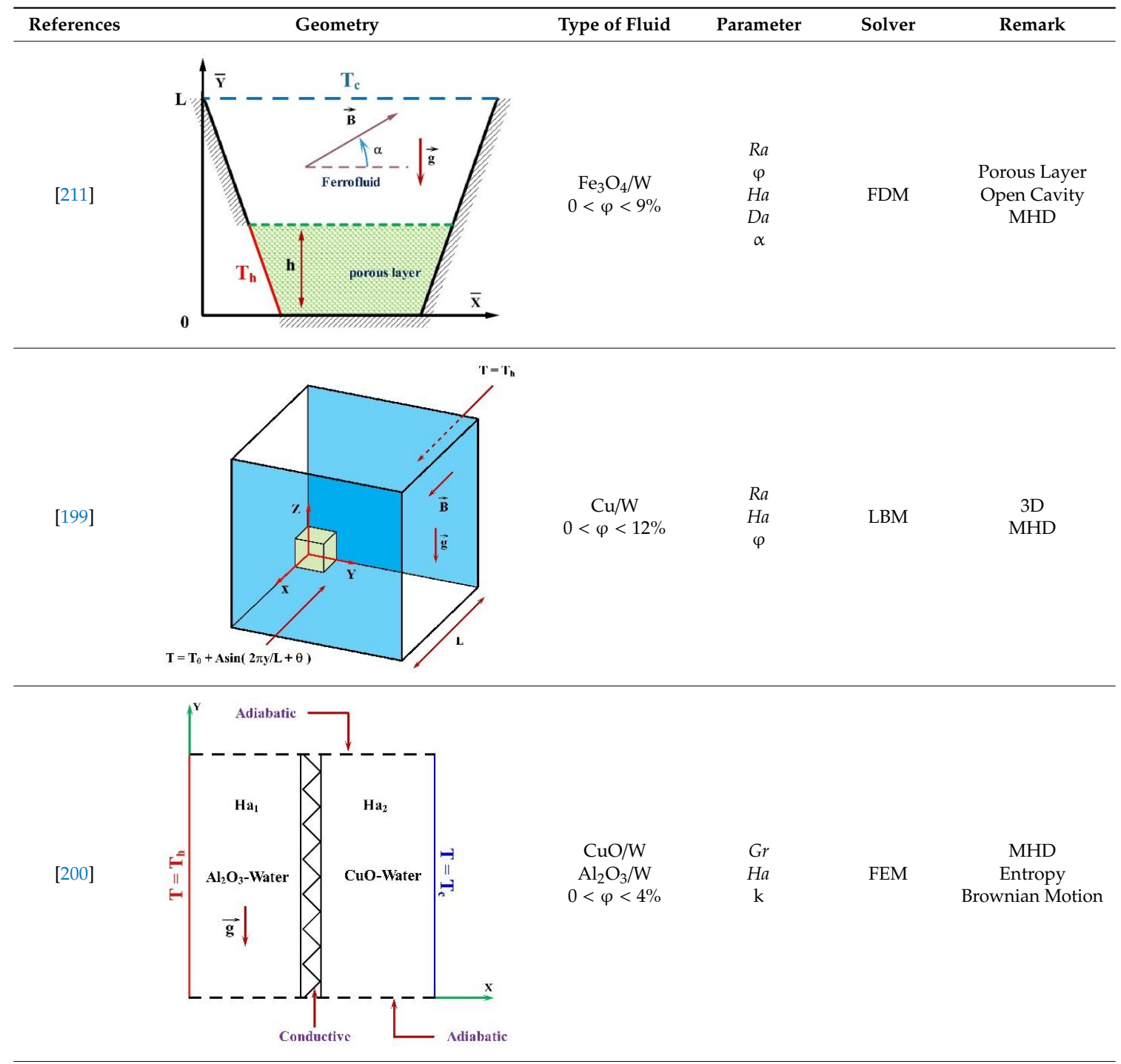

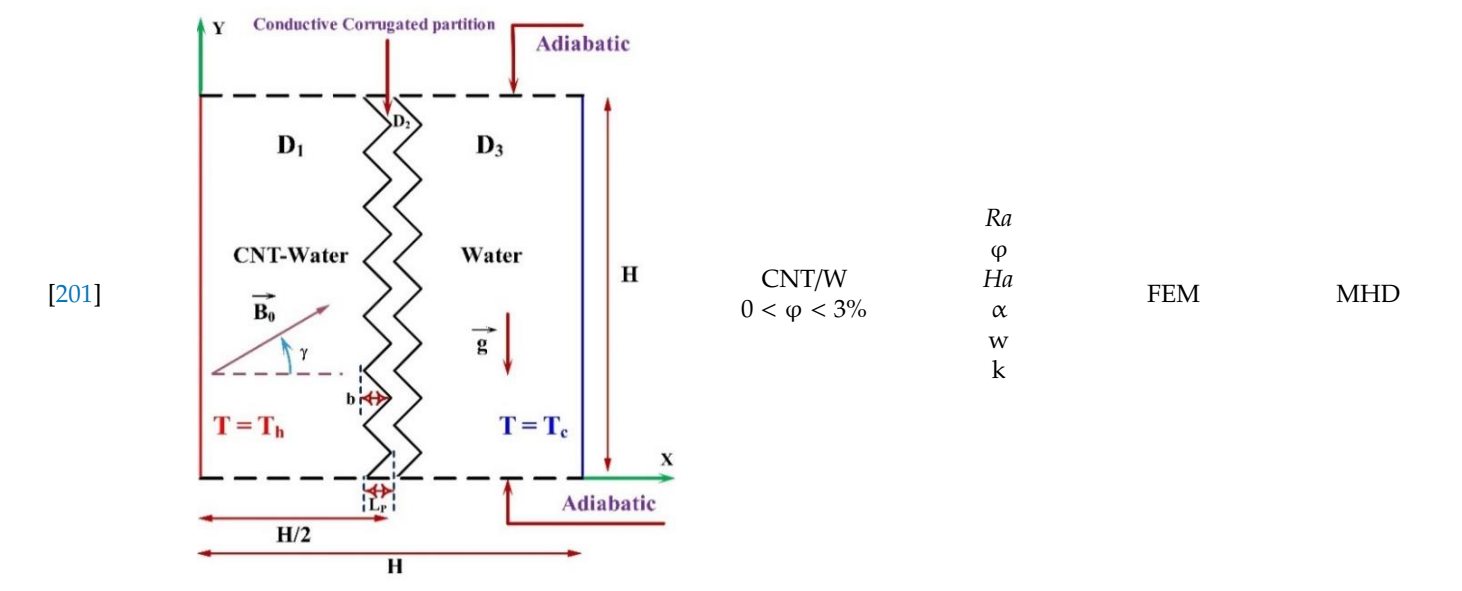


Table 10. Cont.

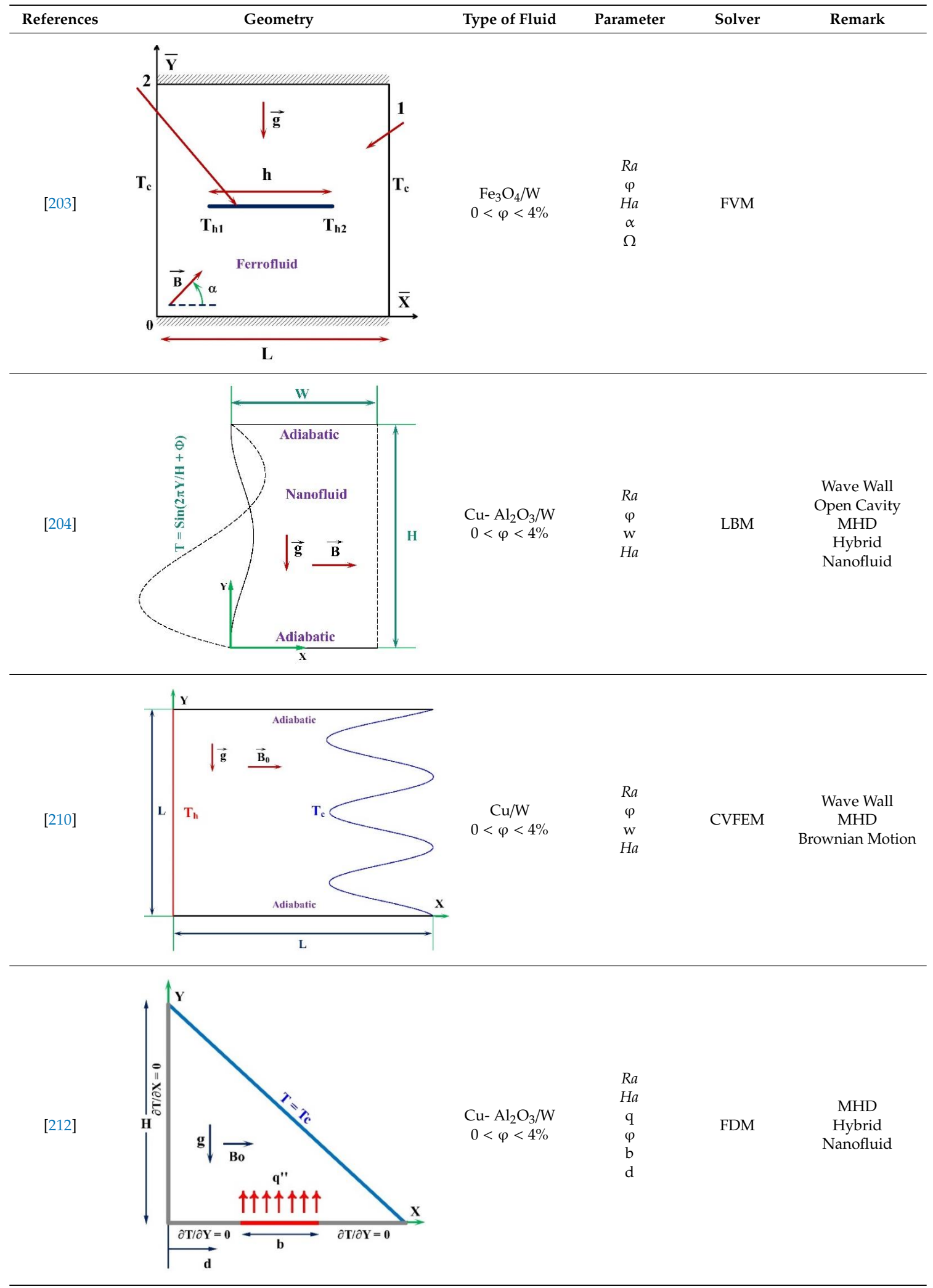


Table 10. Cont.

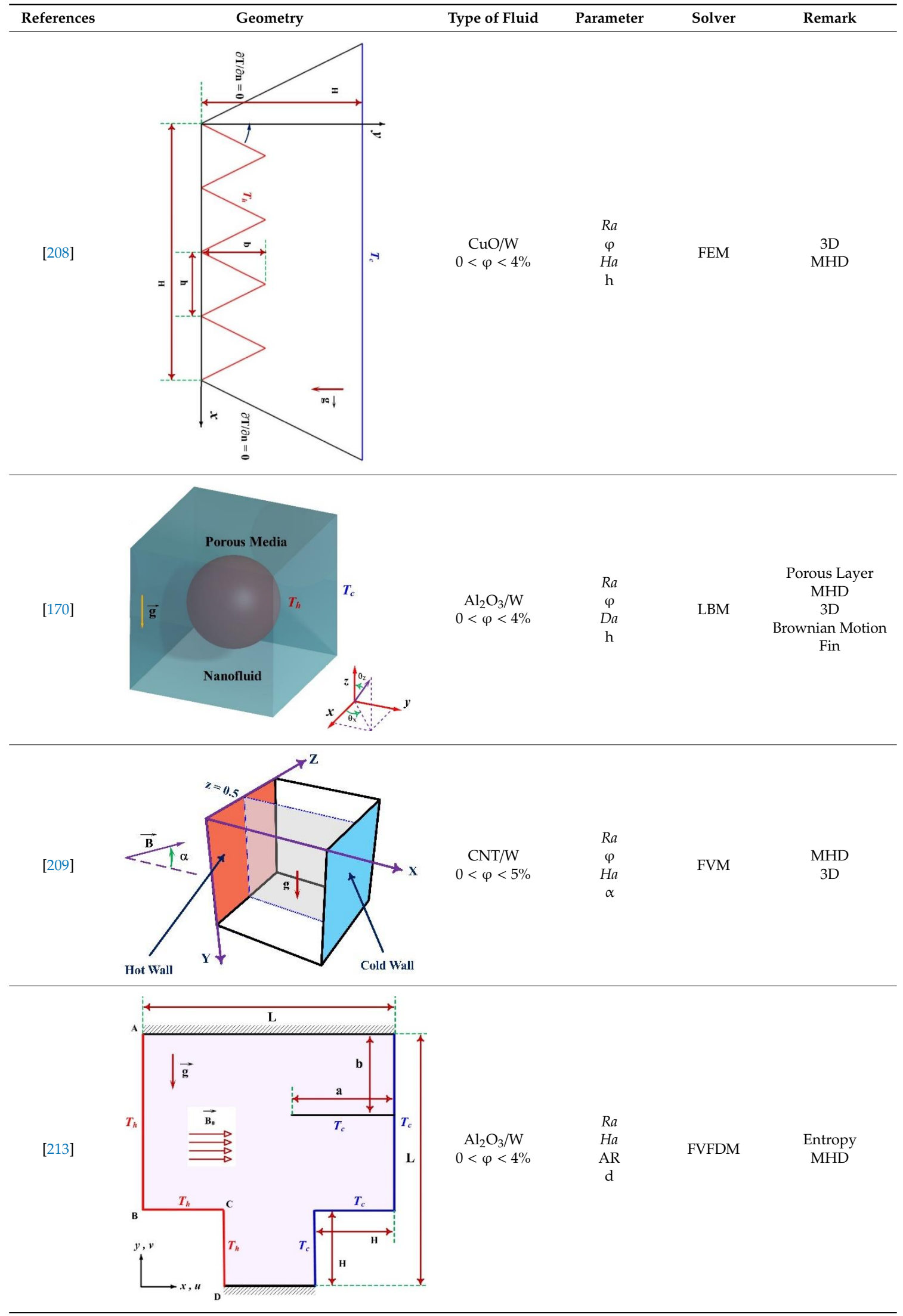


Table 10. Cont.

References

\subsection{Add Porous Media to the Cavity}

Porous material consists of a solid medium that the fluid can pass through its parts. Passage of fluid through the porous medium can have important influences on the pressure difference and the heat transfer in systems. Figure 9 shows a part of a porous environment in which a fluid flow. This environment can in some cases even act as a fin and transfer the heat. In many cases, the porous environment also acts as a filter of fluid flow. In addition, the porous environment leads to intensification in pressure drop and the pumping power because of an enhancement in the shear stress. Therefore, in cases such as closed enclosures where the fluid velocity is slowed down, it can have a high impact on the heat transfer. It should be considered that the porosity value affects the heat transfer rate.

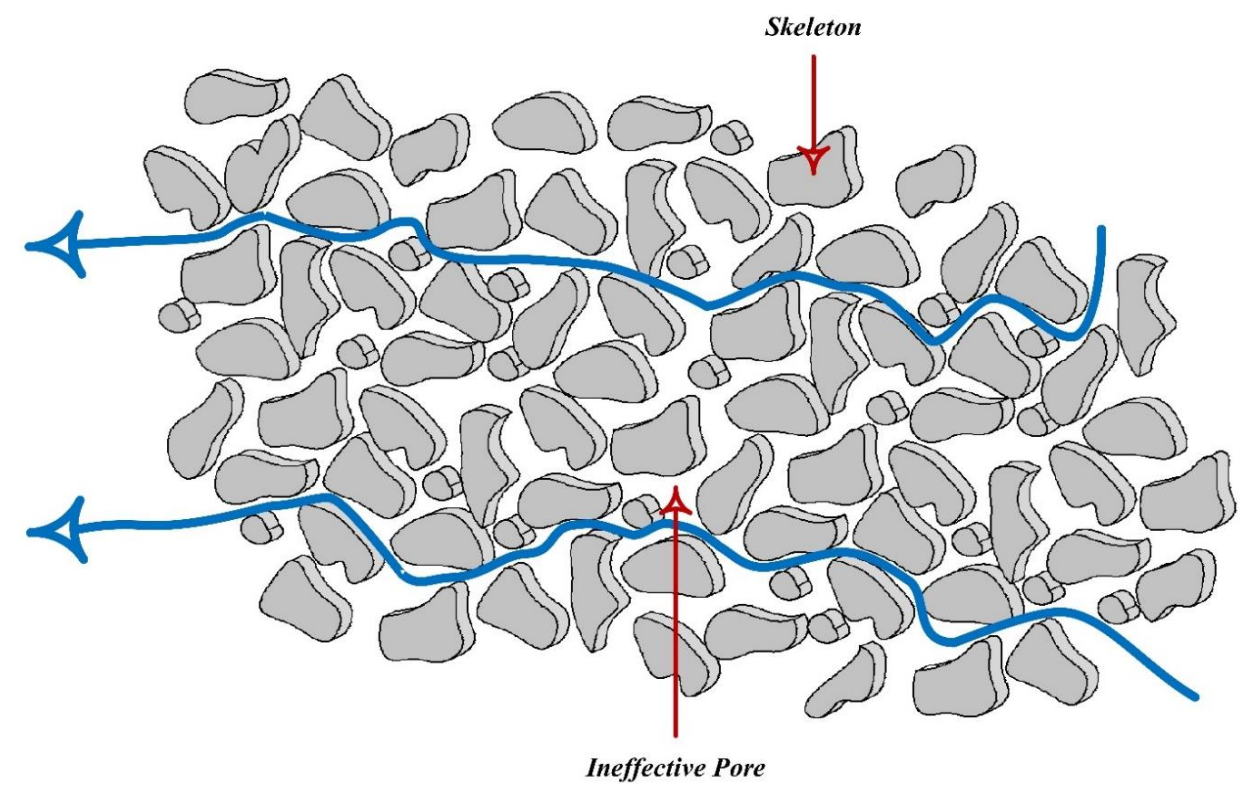

Figure 9. Schematic of a porous medium in which a fluid flows [216]. 
Since engineers have to use porous media in some industrial and engineering environments, some researchers have explored the effect of adding porous media to the cavities [217]. By adding a porous medium, the Darcy relationship of the momentum equations has variations which can be seen below. Of course, the energy and mass conservation equations remain unchanged [205].

$$
\begin{gathered}
\mathrm{u} \frac{\partial \mathrm{u}}{\partial \mathrm{x}}+\mathrm{v} \frac{\partial \mathrm{u}}{\partial \mathrm{y}}=-\frac{1}{\rho} \frac{\partial \mathrm{p}}{\partial \mathrm{x}}+\frac{1}{\rho}\left(\frac{\partial}{\partial \mathrm{x}}\left(\mu \frac{\partial \mathrm{u}}{\partial \mathrm{x}}\right)+\frac{\partial}{\partial \mathrm{y}}\left(\mu \frac{\partial \mathrm{u}}{\partial \mathrm{y}}\right)\right)-\frac{\mu}{\rho K} \mathrm{u} \\
\mathrm{u} \frac{\partial \mathrm{v}}{\partial \mathrm{x}}+\mathrm{v} \frac{\partial \mathrm{v}}{\partial \mathrm{y}}=-\frac{1}{\rho} \frac{\partial \mathrm{p}}{\partial \mathrm{y}}+\frac{1}{\rho}\left(\frac{\partial}{\partial \mathrm{x}}\left(\mu \frac{\partial \mathrm{v}}{\partial \mathrm{x}}\right)+\frac{\partial}{\partial \mathrm{y}}\left(\mu \frac{\partial \mathrm{v}}{\partial \mathrm{y}}\right)\right)-\frac{\mu}{\rho K} \mathrm{v}+\mathrm{g} \beta\left(\mathrm{T}-\mathrm{T}_{\mathrm{c}}\right)
\end{gathered}
$$

Darcy's law has acceptable results for viscous currents. The relationship between the pressure gradient and average volume velocity can be obtained using Forchheimer's modification of Darcy's model. This relation can add the term of nonlinear drag to Darcy's law [218].

$$
\begin{gathered}
\frac{\partial \mathrm{p}}{\partial \mathrm{x}}=-\frac{\mu_{f}}{K} u_{D}-\frac{c_{f} \rho_{0}}{\sqrt{K}}\left\|\sqrt{\left(u_{D}^{2}+v_{D}^{2}\right)}\right\| u_{D} \\
\frac{\partial \mathrm{p}}{\partial \mathrm{y}}=-\frac{\mu_{f}}{K} v_{D}-\frac{c_{f} \rho_{0}}{\sqrt{K}}\left\|\sqrt{\left(u_{D}^{2}+v_{D}^{2}\right)}\right\| v_{D}-g \beta \rho_{0}\left(T-T_{0}\right)
\end{gathered}
$$

The values of $u_{D}$ and $v_{D}$ represent seepage velocity along the $x-, y$-directions. In the above relation $c_{f}$ is the dimensionless inertia parameter which can be expressed by Ergun's [219] model as follows:

$$
c_{\mathrm{f}}=\frac{1.75}{\sqrt{150 \epsilon^{2}}}
$$

where $\epsilon$ is the porosity value. In Equations (18) and (19), the first term represents the linear drag produced by Darcy and the second term is the nonlinear drag produced by Forchheimer.

Brinkman [220] improved the Darcy flow model. This relation is valid for high viscous flow (without porous matrix) with high permeability limitation. In this case, the relationship between the pressure gradient and the average volume velocity is obtained as follows:

$$
\begin{aligned}
& \frac{\partial \mathrm{p}}{\partial \mathrm{x}}=-\frac{\mu_{f}}{K} u_{D}+\mu_{\mathrm{eff}} \nabla^{2} u_{D} \\
& \frac{\partial \mathrm{p}}{\partial \mathrm{x}}=-\frac{\mu_{f}}{K} v_{D}+\mu_{\mathrm{eff}} \nabla^{2} u_{D}
\end{aligned}
$$

Here $\mu_{\text {eff }}$ indicates the fluid effective viscosity. According to Brinkman's model, energy equations and the momentum will be as follows: [221,222].

$$
\begin{gathered}
\mathrm{u}_{1} \frac{\partial \mathrm{u}_{1}}{\partial \mathrm{x}}+v_{1} \frac{\partial \mathrm{u}_{1}}{\partial \mathrm{y}}=-\frac{1}{\rho_{0}} \frac{\partial \mathrm{p}}{\partial \mathrm{x}}+\frac{1}{\rho_{0}}\left(\frac{\partial}{\partial \mathrm{x}}\left(\mu_{\mathrm{eff}} \frac{\partial \mathrm{u}_{1}}{\partial \mathrm{x}}\right)+\frac{\partial}{\partial \mathrm{y}}\left(\mu_{\mathrm{eff}} \frac{\partial \mathrm{u}_{1}}{\partial \mathrm{y}}\right)\right)-\frac{\epsilon \mu_{\mathrm{eff}}}{\rho_{0} K} \mathrm{u}_{1} \\
\mathrm{u}_{1} \frac{\partial v_{1}}{\partial \mathrm{x}}+v_{1} \frac{\partial v_{1}}{\partial \mathrm{y}}=-\frac{1}{\rho_{0}} \frac{\partial \mathrm{p}}{\partial \mathrm{y}}+\frac{1}{\rho_{0}}\left(\frac{\partial}{\partial \mathrm{x}}\left(\mu_{\mathrm{eff}} \frac{\partial v_{1}}{\partial \mathrm{x}}\right)+\frac{\partial}{\partial \mathrm{y}}\left(\mu_{\mathrm{eff}} \frac{\partial v_{1}}{\partial \mathrm{y}}\right)\right)-\frac{\epsilon \mu_{\mathrm{eff}}}{\rho_{0} K} v_{1}+\mathrm{g} \beta\left(\mathrm{T}-\mathrm{T}_{0}\right) \\
\in \rho c_{p}\left(\frac{\partial\left(\mathrm{u}_{1} T\right)}{\partial \mathrm{x}}+\frac{\partial\left(v_{1} T\right)}{\partial \mathrm{y}}\right)=\frac{\partial}{\partial \mathrm{x}}\left(\mathrm{k}_{\text {eff }} \frac{\partial \mathrm{T}}{\partial \mathrm{x}}\right)+\frac{\partial}{\partial \mathrm{y}}\left(\mathrm{k}_{\mathrm{eff}} \frac{\partial \mathrm{T}}{\partial \mathrm{y}}\right)
\end{gathered}
$$

Here $k_{\text {eff }}$ denotes the effective thermal conductivity of the porous media saturated fluid. The relation between Darcy and intrinsic velocities is $u_{\mathrm{D}}=\epsilon u_{1}, v_{\mathrm{D}}=\epsilon v_{1}$.

Astanina et al. [211] carried out research on a partially-porous trapezoidal enclosure filled by iron oxide nanofluids using the FDM. Miroshnichenko et al. [223] examined the natural convection of aluminum oxide nanofluid in an open cavity. There are two porous walls inside the cavity, 
which separates the nanofluid in it into two parts. They found that $\mathrm{Nu}$ increases by raising the volumetric percentage of nanofluids between the warm wall and the porous medium at low intervals. Sheikholeslami and Seyednezhad [224] examined the natural convection with $\mathrm{Fe}_{3} \mathrm{O}_{4} / \mathrm{EG}$ nanofluid radiation in a two-dimensional asymmetric cavity using the finite element method. There is a porous environment in the cavity. They realized that raising $R a$ and the radiation parameter leads to a raise in $N u$. Sheikholeslami et al. [225] studied the natural convection along with radiation in a porous enclosure with FVFEM. Gibanov et al. [226] evaluated the natural convection of iron oxide nanofluids using the FDM in a horizontal magnetic field. They used two different porous media in a rectangular cavity and used the Brinkman extended Darcy model to model porous environments.

Raizah et al. [128] examined an open angular porous cavity with power-law fluids and used the Darcy method for the porous medium. Finally, using the FVM, they solved the governing equations of the cavity. They found that with increasing $R a$ and decreasing angle of the cavity, the aspect ratio and power-law index would cause the heat transfer rate to increase. Dutta and Biswas [25] studied the natural convection in the finite element method in a circular, quarter circle cavity. There was a porous environment within the cavity. It was realized that with growing the Darcy number, $N u$ increased. Ahmed et al. [227] studied the porous medium in a conical enclosure by FEM. Dutta et al. [228] examined a quarter of porous enclosure. Table 11 presents some of the articles in which the porous media is used in the enclosure.

Table 11. Summary of some articles related to heat transfer in enclosures saturated with porous media.

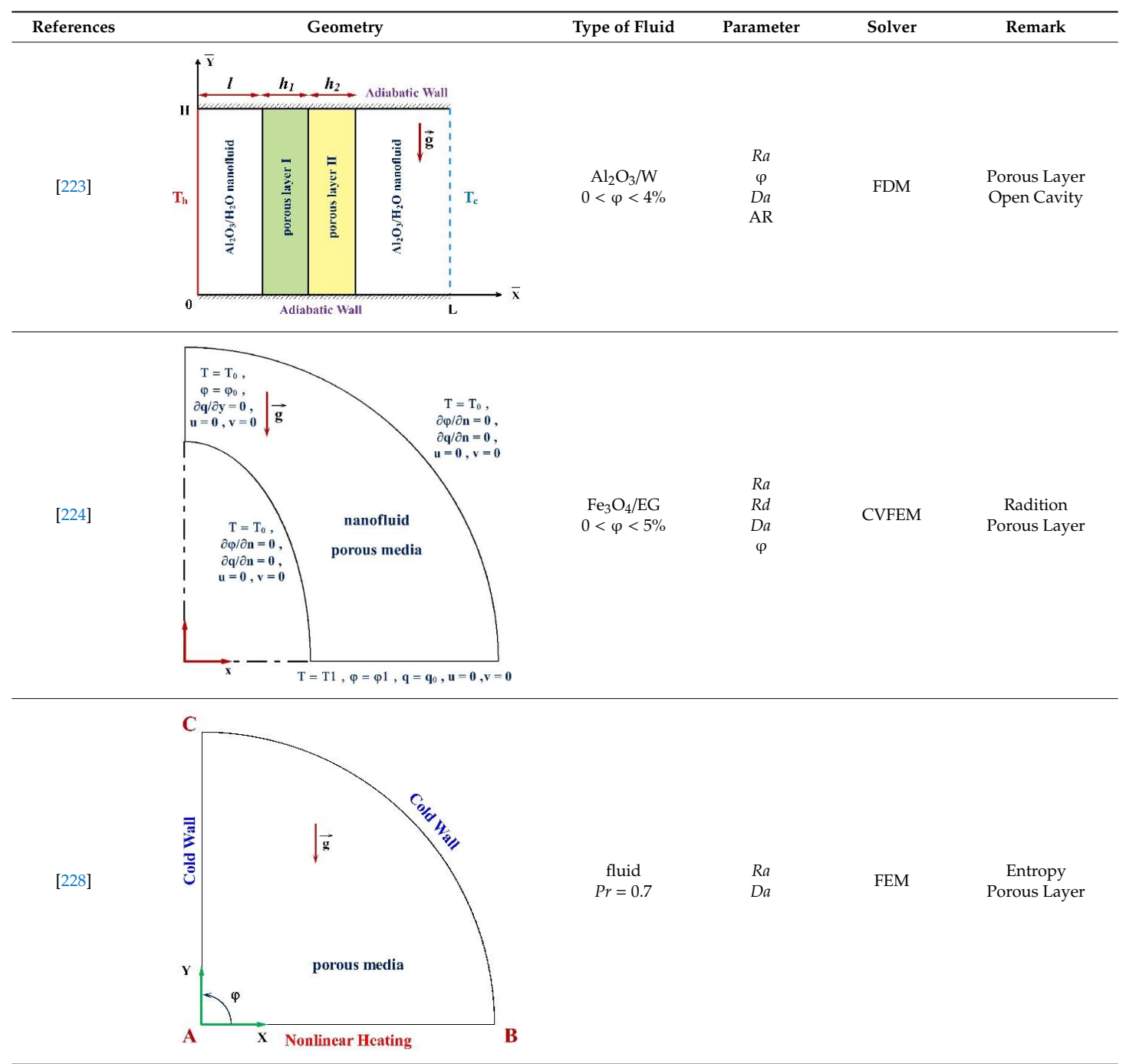


Table 11. Cont.

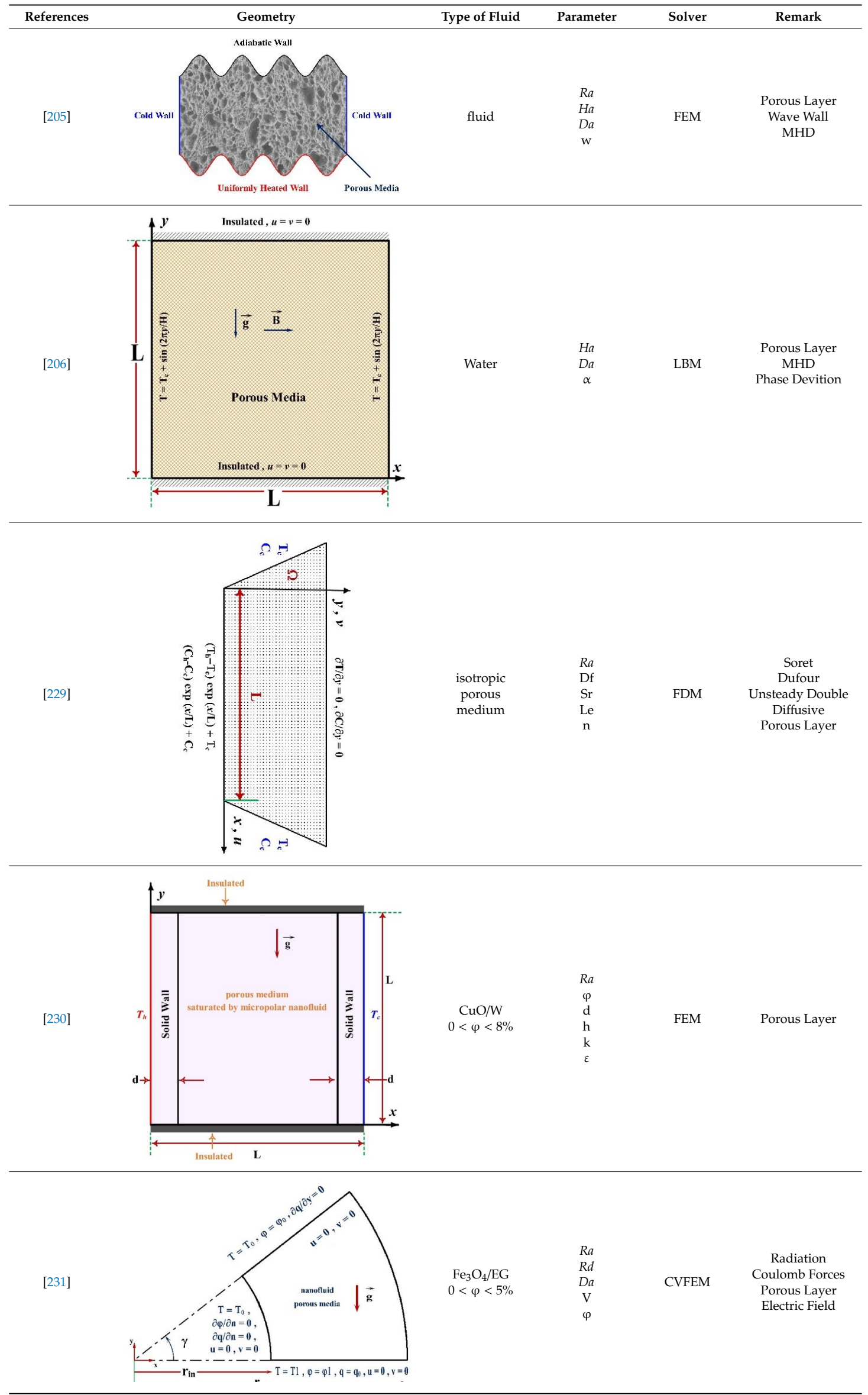




\section{Cavity with Two-Phase Approach}

In general, both two-phase and single-phase methods can be utilized to simulate nanofluid flow. Many of the simulations employed single-phase fluid inside the enclosure, however, in some papers, especially for nanofluids, the researchers used two-phase analysis for their simulations. In the following, some of two-phase methods and some related articles are introduced. There are several methods for modeling multiphase flow (Figure 10) that will be explained below.

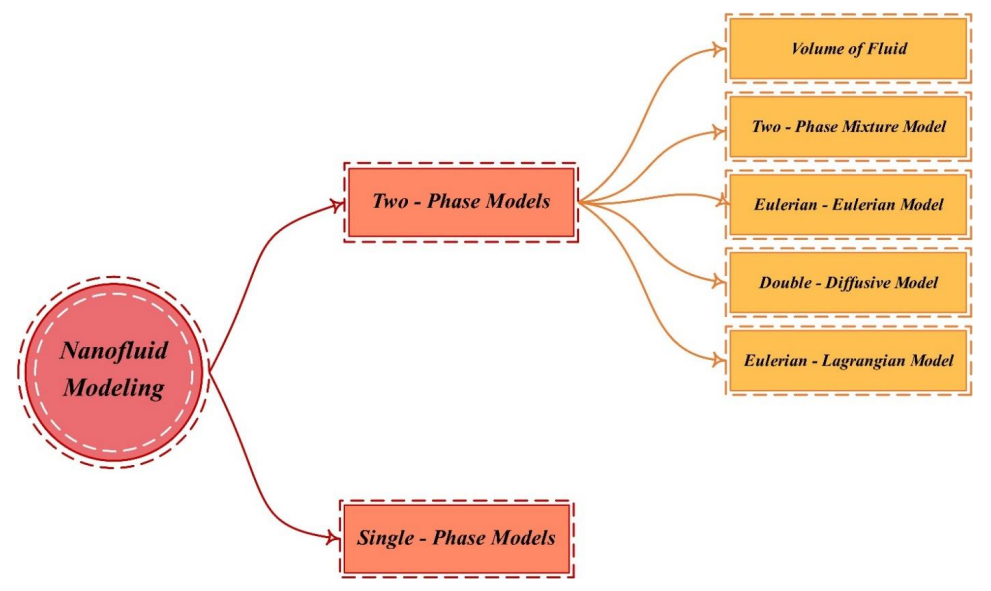

Figure 10. Simulation methods for nanofluids [60].

\subsection{Eulerian-Eulerian Approach}

Different phases are considered as continuous ones in the Eulerian-Eulerian method. The concept of phase volume fraction is presented duo to the fact that phases were not mixed. Concentration is considered as a continuous function, spatially and temporally, and sum of them is equal to unity. Each phase has its conservation equation and obtained separately that have the same structure for all phases [232].

\subsubsection{Volume of Fluid Model}

The volume of fluid model is a model used to immiscible suspensions simulation when the interfaces among phases are important. In this model, momentum equations are assumed to the fluid and a volume fraction is solved in computational cells to every volume fraction. This approach is used to model the stratified flow, free-surface flow, filling of a reservoir, movement of the liquid surface due to the turbulence, movement of bubbles and transient or steady tracking of the gas-liquid interface. The method is less commonly used for nanofluids within enclosures. It seems that this model alone is not capable to simulate the two-phase of nanofluids [233].

\subsubsection{Mixing Model}

This model is used for multi-phase fluids. The mixing model uses a hybrid momentum equation so that the mean properties of the different phases are considered in the equation. For dispersed phases, this model uses relative velocity. Of course, if the model does not consider the movement of the dispersed phase, it models the multi-phase flow as a homogeneous medium. Applications of this model are particle-laden and bubbly flows, as well as cyclonic separators. Many researchers used this method to simulate two-phase nanofluid flows in enclosures [234-242].

\subsubsection{Eulerian Model}

This model is the most complex multi-phase model in terms of the number of equations and relationships. This model solves the continuity and momentum equations phase by phase, separately. The coupling of these equations is done by the pressure and inter-phase exchange coefficients. 
The coupling is based on the type of phases so that it is different for fluid-solid flows from fluid-fluid ones. Although this model has the potential of simulating multiphase nanofluid flows, and even predicts nanoparticle deposition, it has received less attention due to the complexity and high number of equations [243-247].

\subsection{Eulerian-Lagrangian Approach}

In this model, the fluid phase is considered continuously by solving the time-averaged Navier-Stokes equations. However, the discrete phase is solved by tracking the motion of particles, bubbles, or droplets within the fluid. Energy is exchanged between phases. In fact, the trajectory of each particle is determined in this method. Since the particle trajectory is known, this model is suitable for modeling spray dryers, fuel combustion, and flows containing particles, However, it is not suitable for modeling liquid-liquid mixtures, fluidized bed substrates or any other applications where the secondary phase volume fraction cannot be neglected. Due to its many equations and difficulties, this method has been used less frequently in enclosures and is more applicable for combustion or phase conversion problems [248].

Danjie et al. [249] investigated the heat transfer of copper/water nanofluid using the Lattice-Boltzmann method in a square cavity. By considering the $R a$ ranging between $10^{3}$ and $10^{6}$ and range of the nanoparticles volume fraction between $1 \%$ and $5 \%$, they realized that the two-phase model should be used instead of single-phase homogeneous one due to the creation of slip in the nanofluid when $R a$ or nanofluid concentration are relatively high. Goodarzi et al. [237] examined a shallow rectangular enclosure filled with $\mathrm{CuO}$ using a mixture two-phase method. They carried out their study in the range of Grashof number of $10^{5}$ to $10^{10}$. They considered the effect of the Brownian motion. A summary of some articles presented in the field of two-phase nanofluids indicated in Table 12.

Table 12. Summary of some articles related to two-phase nanofluid flow in enclosures.

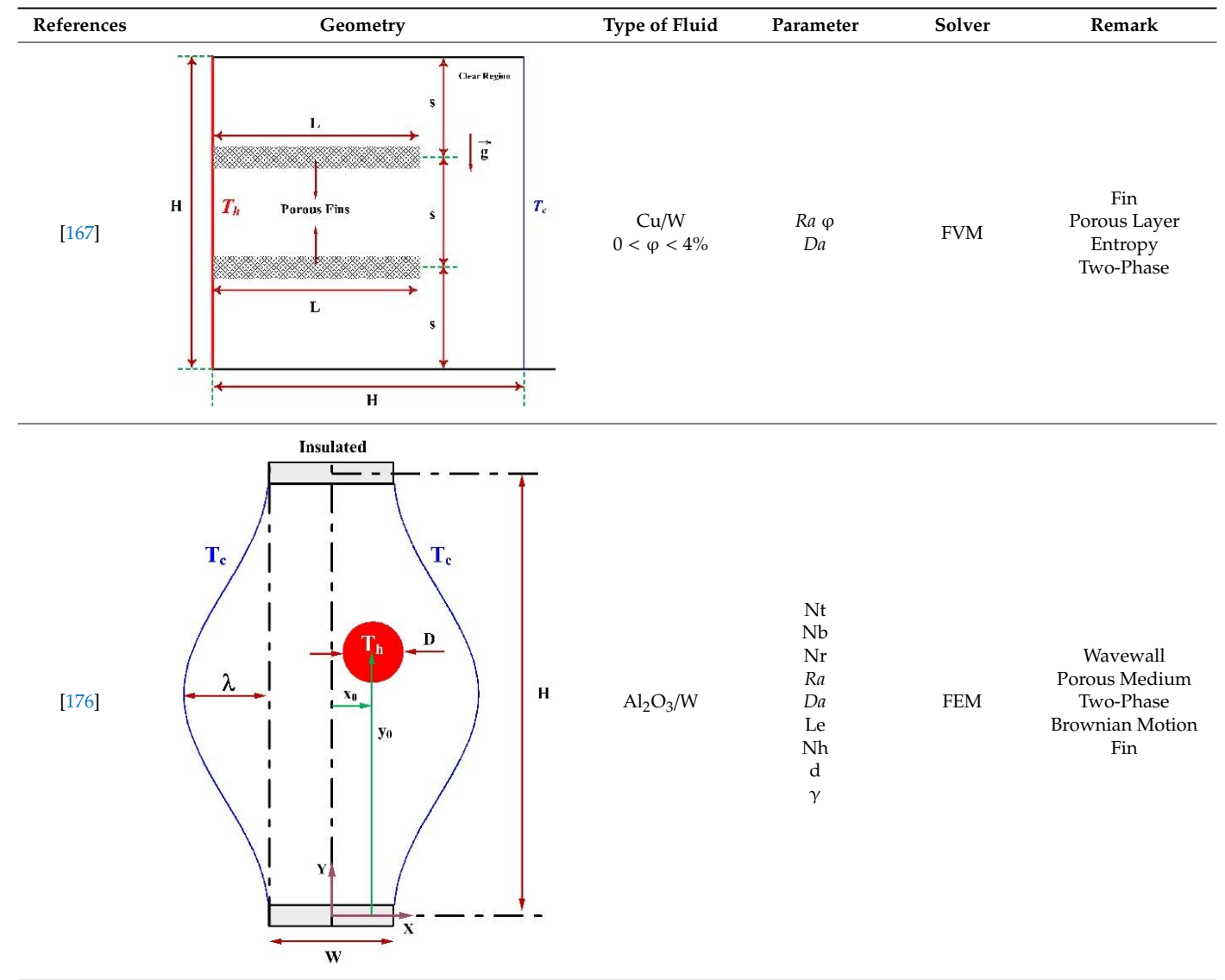


Table 12. Cont.

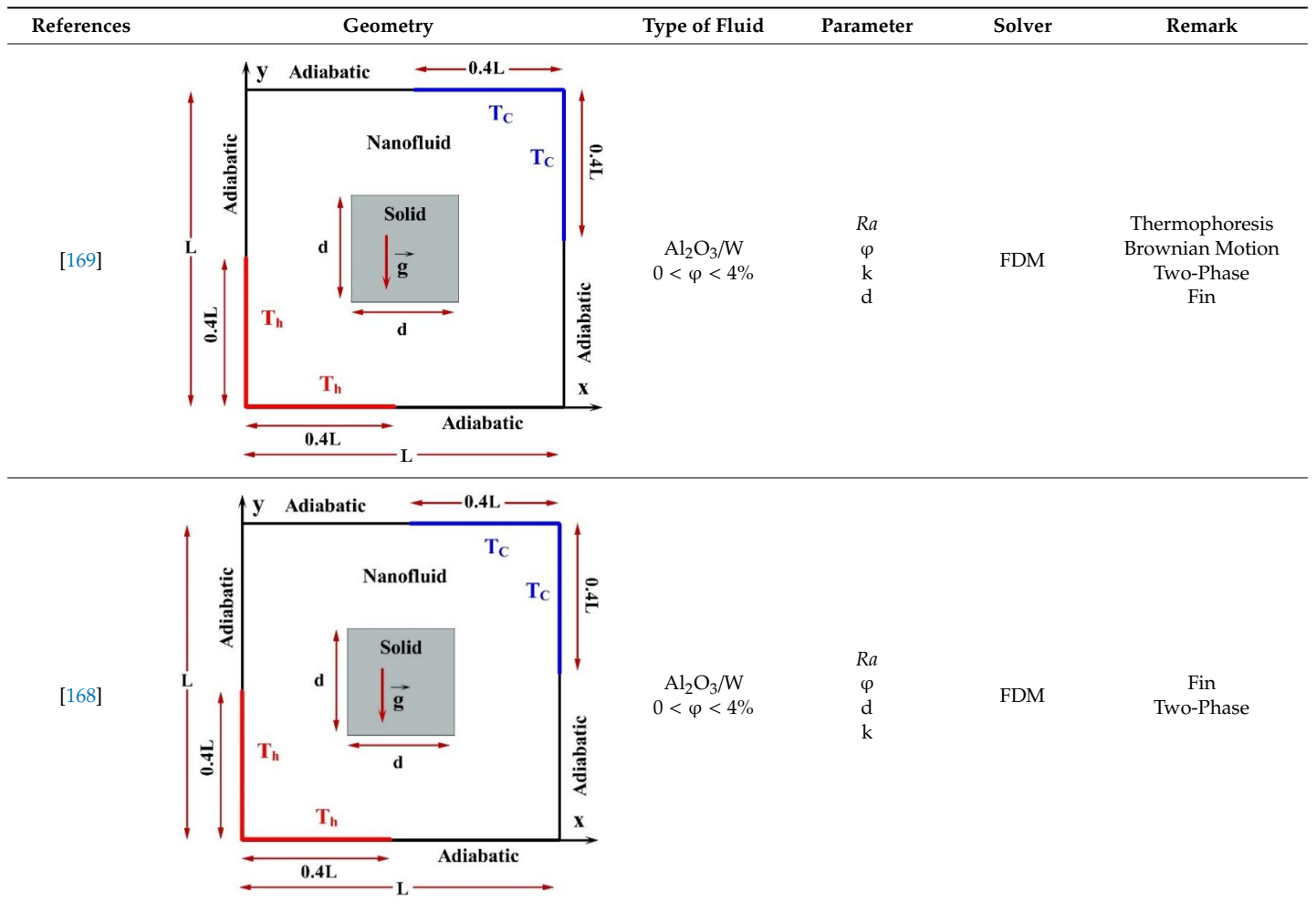

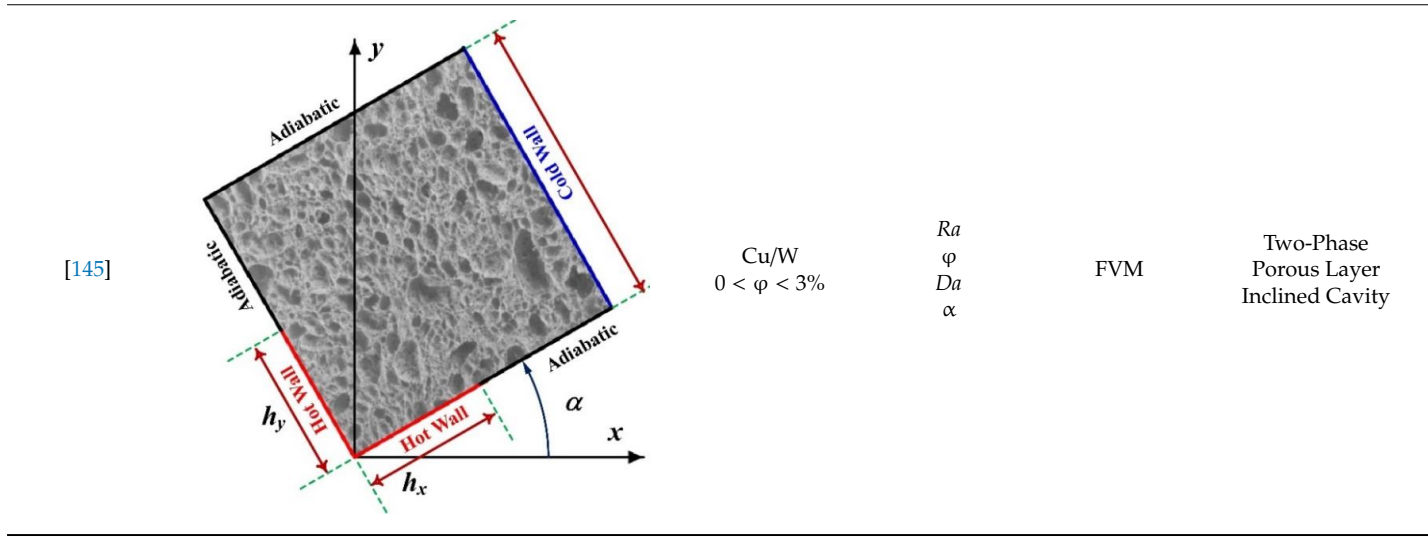

\section{Non-Rectangular Cavities}

Most scholars have studied rectangular cavities, but in recent years, some researchers have also looked at non-rectangular cavities such as triangular, circular. Rahimi et al. [250] examined $\mathrm{SiO}_{2}-\mathrm{TiO}_{2} / \mathrm{W}$-EG hybrid nanofluid in an $\mathrm{H}$-shaped enclosure using LBM. Bondereva et al. [251] did similar work on a trapezoidal open enclosure by means of the FDM. Bhowmick et al. [252] studied the transient convection with using the FVM in a triangle cavity. Das et al. [253] examined convection in cavities with different geometries such as triangles and square Dogonchi et al. [186] examined the natural convection copper nanofluids under magnetic field in a triangular cavity. There is a semi-circular niche in the lower part. They reported that by growing $R a$ and decreasing $H a$, the thermal characteristics are enhanced. Rashad et al. [212] examined natural convection of the alumina/copper hybrid nanofluid in water using the FDM. The cavity is triangular under the magnetic field. There was a constant thermal flux on the floor of the cavity. They found that the rate of heat transfer raises with increasing the $R a$ and the part where flux enters the cavity. Aghakhani et al. [132] examined the free convection in power-law model with using a non-Newtonian fluid exposed to a magnetic field in a C-shaped enclosure by means of LBM. They realized that reduction in $\mathrm{Nu}$ due to raising 
the power-law index. Using FVM, Esfe et al. [254] investigated free convection of CNT/water-EG nanofluids in trapezoidal configuration. Esfe et al. [255] studied the T-shaped cavity. There is also Table 13, summarizing of studies along with non-rectangular cavities. Table 14 summarizes some of the other works on free convection in enclosures by some researchers.

Table 13. Summaries of papers on non-rectangular cavities.

\begin{tabular}{cc}
\hline Ref & Geometry \\
\hline Astanina et al. [211]] & Examined a trapezoidal cavity \\
\hline Rahimi et al. [165] & L-shaped cavity \\
\hline Izadi et al. [173] & Inverted T cavity \\
\hline Dutta and Biswas [25] & Quarter circle cavity \\
\hline Ahmed et al. [227] & Cone cavity \\
\hline Lugarini et al. [43] & C-shaped cavity \\
\hline Zhang et al. [256] & Circular cavity \\
\hline Guestal et al. [257] & Circular cavity \\
\hline Armaghani et al. [213] & T-shaped cavity \\
\hline Enayati et al. [258] & Cylindrical cavity \\
\hline Snoussi et al. [259] & U-shaped cavity \\
\hline Ho et al. [44] & Cylindrical cavity \\
\hline Bhowmick et al. [252] & V-shaped cavity \\
\hline Mo et al. [187] & U-shaped cavity \\
\hline Malekpour et al. [260] & I-shaped cavity \\
\hline Sheikholeslami et al. [231] & Circular sectot between two circles \\
\hline Almudhaf et al. [229] & Trapezoidal cavity \\
\hline Amrani et al. [45] & Triangular cavity \\
\hline
\end{tabular}

Table 14. Summarizing papers along with their figures.

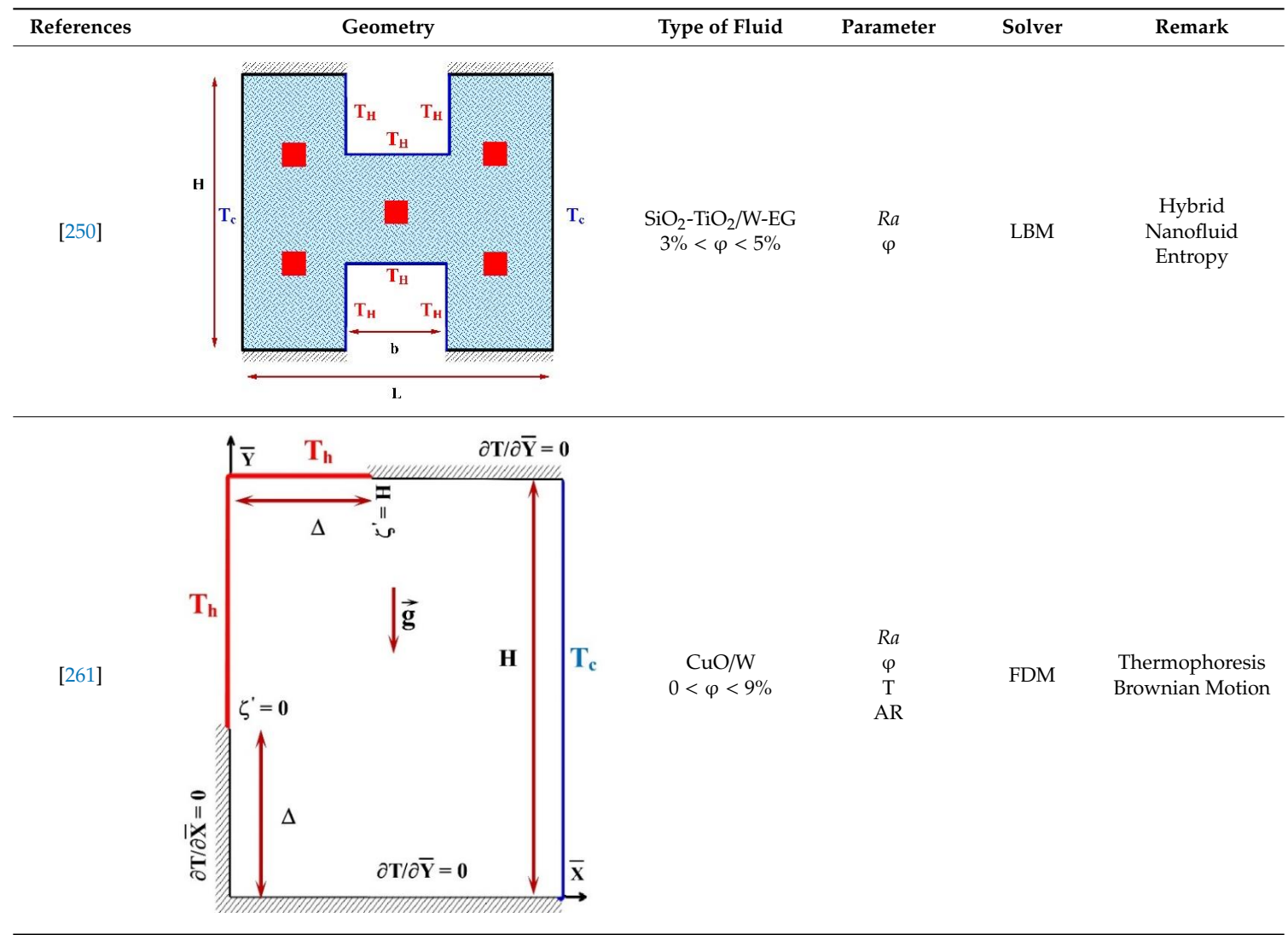


Table 14. Cont.

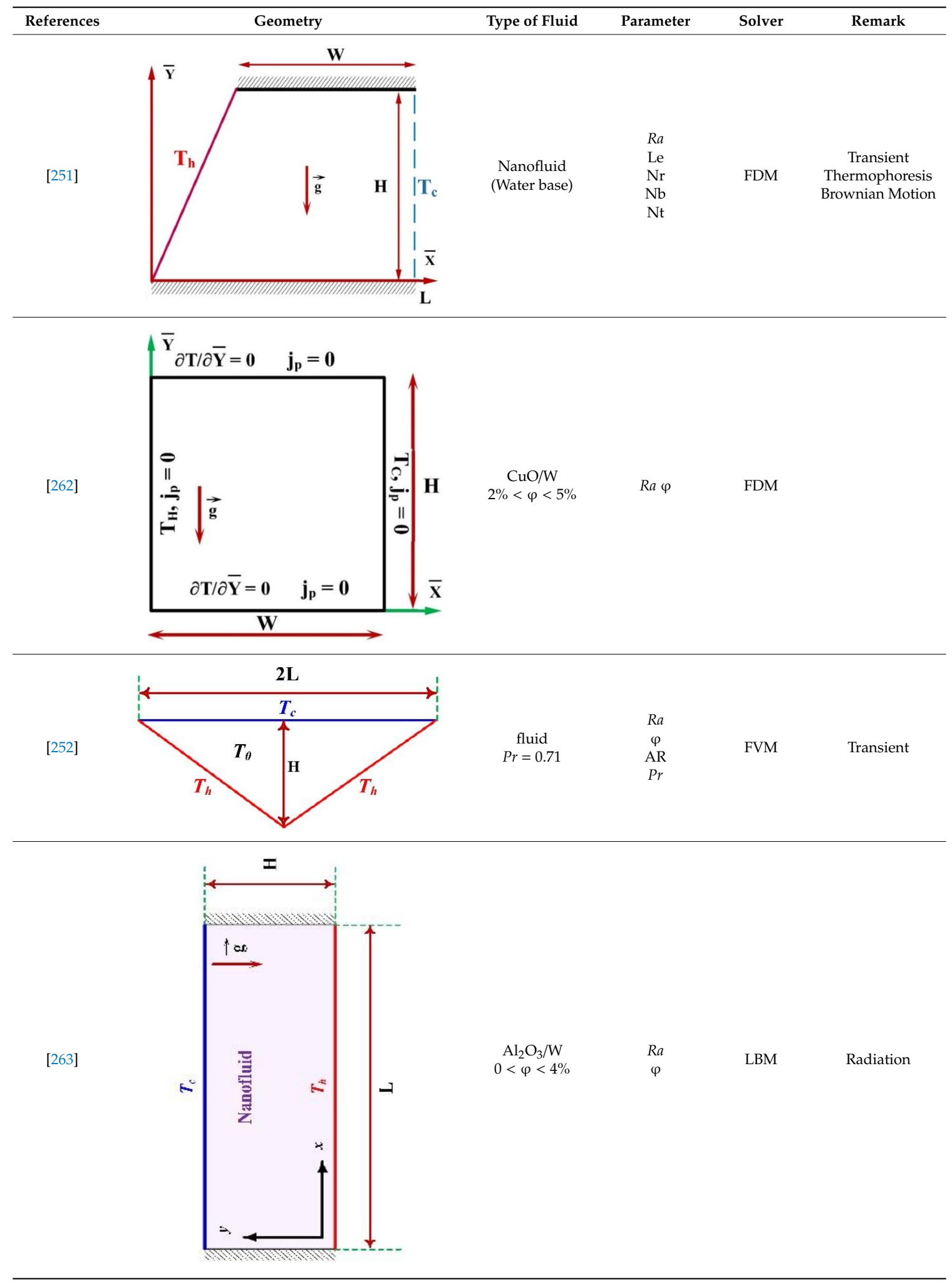


Table 14. Cont.

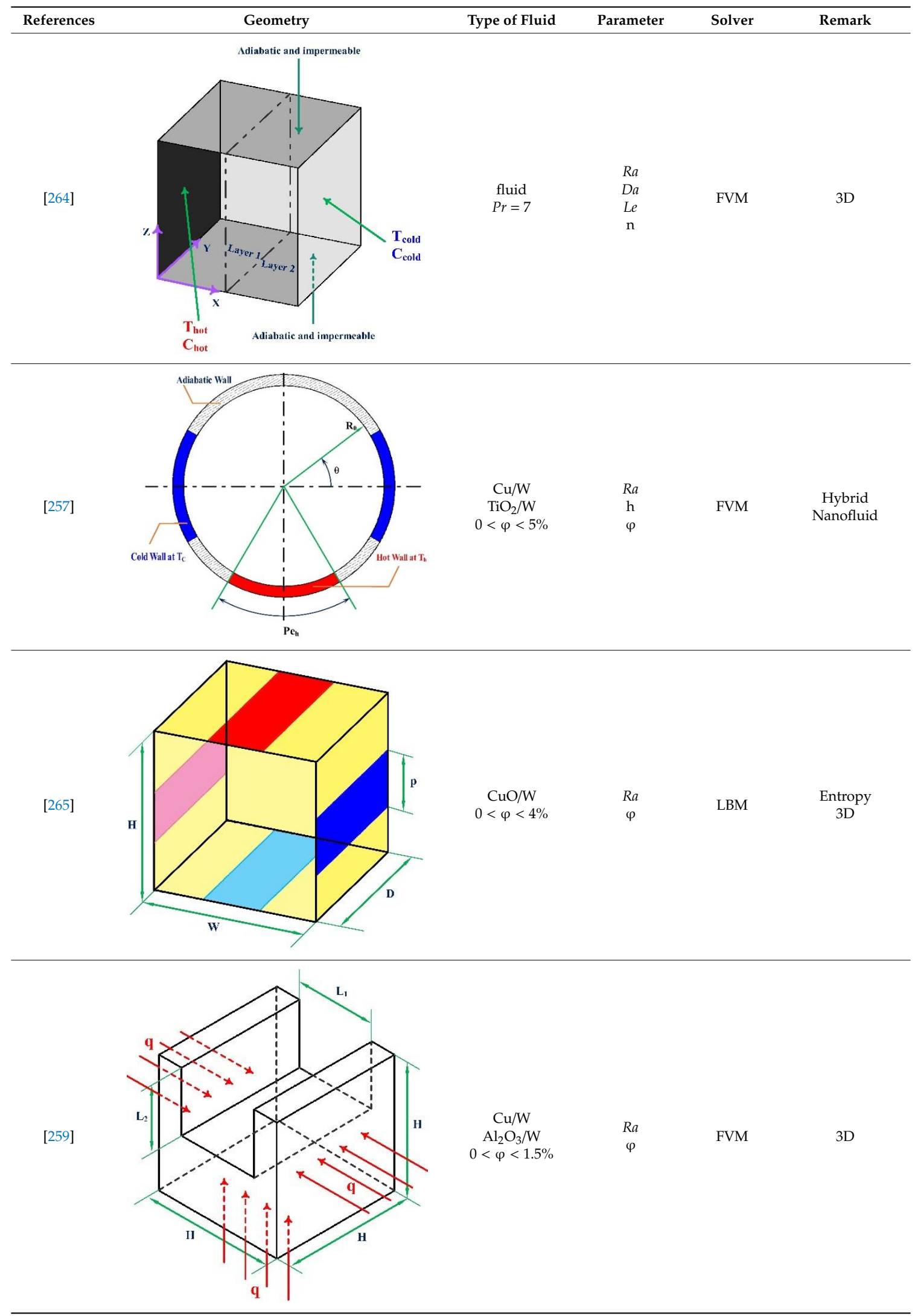




\section{Conclusions}

Researchers on free convection in cavities have been investigated in the current work. The focus has been on recent articles especially the articles presented in recent years. Experimental studies on the cavities were reviewed. In the next section, the agent fluids in the cavities were investigated including air, water, nanofluids, and non-Newtonian fluids. For each of the fluids, the thermophysical properties have been investigated and their important points were mentioned. Moreover, studies on cavities were investigated in several sections including effective parameters including the magnetic field, the cavity angle, the porous medium, and the fin. In each section, the articles in which the parameters are mentioned are stated. In the last section, papers on non-rectangular compartments have been investigated. This review paper showed that with increasing the Rayleigh number the thermal performance intensifies and the flow field strengths in the enclosure. The magnetic field reduces flow strength in enclosure and can be used as a flow controller. Nanoparticles, in addition, increase the thermal conductivity of fluids; however, they can also increase fluids viscosity. Since the viscosity has a noteworthy effect on convection, this can result in a reduction in thermal characteristics. Therefore, at high nanofluid concentrations, further studies on heat transfer are required. Particularly, there is still no accurate data consistent with the experimental data in two-phase analysis. The evaluation of nanoparticle deposition may be of much interest to researchers.

Author Contributions: S.R. and M.A. prepared the required sources; S.A., A.H.P. and G.C. wrote the paper; G.C. edited the paper; H.F.O. and M.S.S. managed the article and prepared the revised manuscript. All authors have read and agreed to the published version of the manuscript.

Funding: This research received no external funding.

Conflicts of Interest: The authors declare no conflict of interest.

\section{Nomenclature}

\begin{tabular}{llll} 
AR & Aspect ratio & \multicolumn{2}{l}{ Greek symbols } \\
$\mathrm{B}_{0}$ & Magnetic field strength & $\Omega$ & Magnetic field angle \\
$\mathrm{C}_{\mathrm{p}}$ & Specific heat & $\alpha$ & Thermal diffusivity \\
$\mathrm{CVFEM}$ & Control volume finite element method & $\varphi$ & Solid volume fraction \\
$\mathrm{CVM}$ & Control volume method & $\varepsilon$ & porosity \\
$\mathrm{Da}$ & Darcy number & $\theta$ & Temperature \\
$\mathrm{FDM}$ & Finite difference method & $\mu$ & Dynamic viscosity \\
$\mathrm{FEM}$ & Finite element method & $\vartheta$ & Kinematic viscosity \\
$\mathrm{FVM}$ & Finite volume method & $\rho$ & Density \\
$g$ & Gravitational acceleration & $\sigma$ & Electrical conductivity \\
$\mathrm{Gr}$ & Grashof number & $\gamma$ & Cavity angle \\
$h$ & Convection heat transfer coefficient & $\mathrm{Subscripts}$ \\
$\mathrm{Ha}$ & Hartmann number & $\mathrm{ave}$ & Average \\
$\mathrm{k}$ & Thermal conductivity & $\mathrm{c}$ & Cold \\
$\mathrm{L}$ & Enclosure length & $\mathrm{h}$ & Hot \\
$\mathrm{n}$ & Power-law index & $\mathrm{f}$ & Pure fluid \\
$\mathrm{Nu}$ & Nusselt number & $\mathrm{nf}$ & Nanofluid \\
$\mathrm{P}$ & Pressure & $\mathrm{p}$ & Particle \\
$\mathrm{Pr}$ & Prandtl number & $\mathrm{s}$ & Surface \\
$\mathrm{Ra}$ & Rayleigh number & $\mathrm{W}$ & Water \\
$\mathrm{Rd}$ & Radiation parameter & & \\
$t$ & Time & & \\
$\mathrm{T}$ & Temperature & & \\
$\mathrm{u}, \mathrm{v}$ & Velocity components in x and y directions & & \\
$x, y$ & Cartesian coordinates & &
\end{tabular}




\section{References}

1. Hines, A.L.; Maddox, R.N. Mass Transfer: Fundamentals and Applications; Prentice-Hall: Englewood-Cliffs, NJ, USA, 1985.

2. Incropera, F.P.; Lavine, A.S.; Bergman, T.L.; DeWitt, D.P. Principles of Heat and Mass Transfer; Wiley: Hoboken, NJ, USA, 2013.

3. Tian, M.-W.; Yan, S.-R.; Tian, X.-X.; Nojavan, S.; Jermsittiparsert, K. Risk and profit-based bidding and offering strategies for pumped hydro storage in the energy market. J. Clean. Prod. 2020, 256, 120715. [CrossRef]

4. Tian, M.-W.; Ebadi, A.G.; Jermsittiparsert, K.; Kadyrov, M.A.; Ponomarev, A.; Javanshir, N.; Nojavan, S. Risk-based stochastic scheduling of energy hub system in the presence of heating network and thermal energy management. Appl. Therm. Eng. 2019, 159, 113825. [CrossRef]

5. Tian, M.-W.; Yan, S.-R.; Tian, X.-X.; Kazemi, M.; Nojavan, S.; Jermsittiparsert, K. Risk-involved stochastic scheduling of plug-in electric vehicles aggregator in day-ahead and reserve markets using downside risk constraints method. Sustain. Cities Soc. 2020, 55, 102051. [CrossRef]

6. Karamoozian, A.; Tan, C.; Wang, L. Lattice Brake Disc Instability Analysis Using Transient Complex Eigenvalue Method in Terms of Excitation Applied to the Pad. SAE Tech. Paper Ser. 2018. [CrossRef]

7. Tian, M.-W.; Moria, H.; Mihardjo, L.W.; Kaood, A.; Dizaji, H.S.; Jermsittiparsert, K. Experimental thermal/economic/exergetic evaluation of hot/cold water production process by thermoelectricity. J. Clean. Prod. 2020, 271, 122923. [CrossRef]

8. Karamoozian, A.; Tan, C.A.; Wang, L.; Akbarzadeh, M.R.; Chen, G. Sensitivity analysis of the equal angle divider mechanism kinematics with the synthesis of the joint gap tolerances. Mech. Based Des. Struct. Mach. 2018, 46, 499-519. [CrossRef]

9. Yan, S.-R.; Moria, H.; Pourhedayat, S.; Hashemian, M.; Assadi, S.; Dizaji, H.S.; Jermsittiparsert, K. A critique of effectiveness concept for heat exchangers; theoretical-experimental study. Int. J. Heat Mass Transf. 2020, 159, 120160. [CrossRef]

10. Tian, M.-W.; Yan, S.-R.; Han, S.-Z.; Nojavan, S.; Jermsittiparsert, K.; Razmjooy, N. New optimal design for a hybrid solar chimney, solid oxide electrolysis and fuel cell based on improved deer hunting optimization algorithm. J. Clean. Prod. 2020, 249, 119414. [CrossRef]

11. Karamoozian, A.; Jiang, H.; Tan, C.A. Probability Based Survey of Braking System: A Pareto-Optimal Approach. IEEE Access 2020, 8, 128385-128406. [CrossRef]

12. Karatas, H.; Derbentli, T. Natural convection and radiation in rectangular cavities with one active vertical wall. Int. J. Therm. Sci. 2018, 123, 129-139. [CrossRef]

13. Mahmoudinezhad, S.; Rezaniakolaie, A.; Yousefi, T.; Shadloo, M.S.; Rosendahl, L. Adiabatic partition effect on natural convection heat transfer inside a square cavity: Experimental and numerical studies. Heat Mass Transf. 2017, 54, 291-304. [CrossRef]

14. Li, C.H.; Peterson, G. Experimental studies of natural convection heat transfer of Al2O3/DI water nanoparticle suspensions (nanofluids). Adv. Mech. Eng. 2010, 2, 742739. [CrossRef]

15. Ho, C.; Liu, W.; Chang, Y.; Lin, C. Natural convection heat transfer of alumina-water nanofluid in vertical square enclosures: An experimental study. Int. J. Therm. Sci. 2010, 49, 1345-1353. [CrossRef]

16. Karatas, H.; Derbentli, T. Natural convection in differentially heated rectangular cavities with time periodic boundary condition on one side. Int. J. Heat Mass Transf. 2019, 129, 224-237. [CrossRef]

17. Vasiliev, A.; Sukhanovskii, A.; Frick, P.; Budnikov, A.; Fomichev, V.; Bolshukhin, M.; Romanov, R. High Rayleigh number convection in a cubic cell with adiabatic sidewalls. Int. J. Heat Mass Transf. 2016, 102, 201-212. [CrossRef]

18. Bharti, O.S.; Saha, A.K.; Das, M.K.; Bansal, S. Simultaneous measurement of velocity and temperature fields during natural convection in a water-filled cubical cavity. Exp. Therm. Fluid Sci. 2018, 99, 272-286. [CrossRef]

19. Zhang, X.; Yu, J.; Su, G.; Yao, Z.; Hao, P.; He, F. Statistical analysis of turbulent thermal free convection over a small heat source in a large enclosed cavity. Appl. Therm. Eng. 2016, 93, 446-455. [CrossRef]

20. Zhang, X.; Su, G.; Yu, J.; Yao, Z.; He, F. PIV measurement and simulation of turbulent thermal free convection over a small heat source in a large enclosed cavity. Build. Environ. 2015, 90, 105-113. [CrossRef]

21. Chen, H.-T.; Lin, M.-C.; Chang, J.-R. Numerical and experimental studies of natural convection in a heated cavity with a horizontal fin on a hot sidewall. Int. J. Heat Mass Transf. 2018, 124, 1217-1229. [CrossRef] 
22. Córdoba, P.A.; Silin, N.; Osorio, D.; Dari, E. An experimental study of natural convection in a distribution transformer slice model. Int. J. Therm. Sci. 2018, 129, 94-105. [CrossRef]

23. Mahdavi, M.; Sharifpur, M.; Ghodsinezhad, H.; Meyer, J.P. Experimental and Numerical Investigation on a Water-Filled Cavity Natural Convection to Find the Proper Thermal Boundary Conditions for Simulations. Heat Transf. Eng. 2017, 39, 359-373. [CrossRef]

24. Saxena, A.; Kishor, V.; Singh, S.; Srivastava, A. Experimental and numerical study on the onset of natural convection in a cavity open at the top. Phys. Fluids 2018, 30, 057102. [CrossRef]

25. Dutta, S.K.; Biswas, A.K. Entropy generation due to natural convection with non-uniform heating of porous quadrantal enclosure-a numerical study. Front. Heat Mass Transf. 2018, 10, 1-12. [CrossRef]

26. Kwak, D.-B.; Noh, J.-H.; Yook, S.-J. Natural convection flow around heated disk in cubical enclosure. J. Mech. Sci. Technol. 2018, 32, 2377-2384. [CrossRef]

27. Verma, S.P.; Das, D. Analysis of natural convection heat transfer through staggered pin finned horizontal base plate within a rectangular enclosure. Heat Mass Transf. 2018, 54, 2635-2644. [CrossRef]

28. Choi, S.U.; Eastman, J.A. Enhancing Thermal Conductivity of Fluids with Nanoparticles; ANL-88-15Argonne National Lab: Lemont, IL, USA, 1995.

29. Sharma, A.K.; Velusamy, K.; Balaji, C.; Venkateshan, S. Conjugate turbulent natural convection with surface radiation in air filled rectangular enclosures. Int. J. Heat Mass Transf. 2007, 50, 625-639. [CrossRef]

30. Al-Rashed, A.A.; Ranjbarzadeh, R.; Aghakhani, S.; Soltanimehr, M.; Afrand, M.; Nguyen, T.K. Entropy generation of boehmite alumina nanofluid flow through a minichannel heat exchanger considering nanoparticle shape effect. Phys. A Stat. Mech. Its Appl. 2019, 521, 724-736. [CrossRef]

31. Yan, S.-R.; Aghakhani, S.; Karimipour, A. Influence of a membrane on nanofluid heat transfer and irreversibilities inside a cavity with two constant-temperature semicircular sources on the lower wall: Applicable to solar collectors. Phys. Scr. 2020. [CrossRef]

32. Zheng, Y.; Yaghoubi, S.; Dezfulizadeh, A.; Aghakhani, S.; Karimipour, A.; Tlili, I. Free convection/radiation and entropy generation analyses for nanofluid of inclined square enclosure with uniform magnetic field. J. Therm. Anal. Calorim. 2020, 141, 635-648. [CrossRef]

33. Tian, M.-W.; Yuen, H.-C.; Yan, S.-R.; Huang, W.-L. The multiple selections of fostering applications of hydrogen energy by integrating economic and industrial evaluation of different regions. Int. J. Hydrogen Energy 2019, 44, 29390-29398. [CrossRef]

34. Davis, G.D.V. Natural convection of air in a square cavity: A bench mark numerical solution. Int. J. Numer. Methods Fluids 1983, 3, 249-264. [CrossRef]

35. Job, V.M.; Gunakala, S.R. Unsteady MHD free convection nanofluid flows within a wavy trapezoidal enclosure with viscous and Joule dissipation effects. Numer. Heat Transfer Part A Appl. 2015, 69, 421-443. [CrossRef]

36. Rohsenow, W.M.; Hartnett, J.P.; Ganic, E.N.; Richardson, P.D. Handbook of Heat Transfer Fundamentals (Second Edition). J. Appl. Mech. 1986, 53, 232-233. [CrossRef]

37. Tsilingiris, $\mathrm{P}$. Thermophysical and transport properties of humid air at temperature range between 0 and $100{ }^{\circ}$ C. Energy Convers. Manag. 2008, 49, 1098-1110. [CrossRef]

38. Gupta, A.; Prasad, R.; Singh, S. A systematic approach for optimal positioning of heated side walls in a side vented open cavity under natural convection and surface radiation. Front. Heat Mass Transf. 2018, 1-12. [CrossRef]

39. Bhowmick, S.; Xu, F.; Zhang, X.; Saha, S.C. Natural convection and heat transfer in a valley shaped cavity filled with initially stratified water. Int. J. Therm. Sci. 2018, 128, 59-69. [CrossRef]

40. Groşan, T.; Sheremet, M.A.; Pop, I.; Pop, S.R. Double-Diffusive Natural Convection in a Differentially Heated Wavy Cavity Under Thermophoresis Effect. J. Thermophys. Heat Transf. 2018, 32, 1045-1058. [CrossRef]

41. Kogawa, T.; Chen, L.; Okajima, J.; Sakurai, A.; Komiya, A.; Maruyama, S. Effects of concentration of participating media on turbulent natural convection in cubic cavity. Appl. Therm. Eng. 2018, 131, 141-149. [CrossRef]

42. Nia, M.F.; Nassab, S.A.G.; Ansari, A.B. Transient combined natural convection and radiation in a double space cavity with conducting walls. Int. J. Therm. Sci. 2018, 128, 94-104. [CrossRef]

43. Lugarini, A.; Franco, A.T.; Junqueira, S.L.; Lage, J.L. Natural Convection and Surface Radiation in a Heated Wall, C-Shaped Fracture. J. Heat Transf. 2018, 140, 082501. [CrossRef] 
44. Ho, C.; Sou, G.; Lai, C.-M. Effects of a flow mode transition on natural convection heat transfer in a heat tracing enclosure. Proc. Inst. Mech. Eng. Part E: J. Process. Mech. Eng. 2018, 233, 489-499. [CrossRef]

45. Amrani, A.-I.; Dihmani, N.; Amraqui, S.; Mezrhab, A. Combined Natural Convection and Thermal Radiation Heat Transfer in a Triangular Enclosure with an Inner Rectangular Body. Defect Diffus. Forum 2018, 384, 49-68. [CrossRef]

46. Raisi, A.; Arvin, I. A numerical study of the effect of fluid-structure interaction on transient natural convection in an air-filled square cavity. Int. J. Therm. Sci. 2018, 128, 1-14. [CrossRef]

47. Akter, A.; Parvin, S. Analysis of Natural Convection Flow in a Trapezoidal Cavity Containing a Rectangular Heated Body in Presence of External Oriented Magnetic Field. J. Sci. Res. 2018, 10, 11-23. [CrossRef]

48. Cho, C.-C. Influence of magnetic field on natural convection and entropy generation in $\mathrm{Cu}-\mathrm{water}$ nanofluid-filled cavity with wavy surfaces. Int. J. Heat Mass Transf. 2016, 101, 637-647. [CrossRef]

49. Yan, S.-R.; Pordanjani, A.H.; Aghakhani, S.; Goldanlou, A.S.; Afrand, M. Management of natural convection of nanofluids inside a square enclosure by different nano powder shapes in presence of Fins with different shapes and magnetic field effect. Adv. Powder Technol. 2020, 31, 2759-2777. [CrossRef]

50. Mahmoudi, A.; Mejri, I.; Abbassi, M.A.; Omri, A. Lattice Boltzmann simulation of MHD natural convection in a nanofluid-filled cavity with linear temperature distribution. Powder Technol. 2014, 256, 257-271. [CrossRef]

51. Kefayati, G. Natural convection of ferrofluid in a linearly heated cavity utilizing LBM. J. Mol. Liq. 2014, 191, 1-9. [CrossRef]

52. Pordanjani, A.H.; Vahedi, S.M.; Aghakhani, S.; Afrand, M.; Oztop, H.F.; Abu-Hamdeh, N. Effect of magnetic field on mixed convection and entropy generation of hybrid nanofluid in an inclined enclosure: Sensitivity analysis and optimization. Eur. Phys. J. Plus 2019, 134, 412. [CrossRef]

53. Pordanjani, A.H.; Raisi, A.; Ghasemi, B. Numerical simulation of the magnetic field and Joule heating effects on force convection flow through parallel-plate microchannel in the presence of viscous dissipation effect. Numer. Heat Transfer Part A Appl. 2019, 76, 499-516. [CrossRef]

54. Tian, M.-W.; Khorasani, S.; Moria, H.; Pourhedayat, S.; Dizaji, H.S. Profit and efficiency boost of triangular vortex-generators by novel techniques. Int. J. Heat Mass Transf. 2020, 156, 119842. [CrossRef]

55. Afrand, M.; Pordanjani, A.H.; Aghakhani, S.; Oztop, H.F.; Abu-Hamdeh, N. Free convection and entropy generation of a nanofluid in a tilted triangular cavity exposed to a magnetic field with sinusoidal wall temperature distribution considering radiation effects. Int. Commun. Heat Mass Transf. 2020, 112, 104507. [CrossRef]

56. Nemati, H.; Farhadi, M.; Sedighi, K.; Fattahi, E.; Darzi, A. Lattice Boltzmann simulation of nanofluid in lid-driven cavity. Int. Commun. Heat Mass Transf. 2010, 37, 1528-1534. [CrossRef]

57. Aghakhani, S.; Pordanjani, A.H.; Afrand, M.; Sharifpur, M.; Meyer, J.P. Natural convective heat transfer and entropy generation of alumina/water nanofluid in a tilted enclosure with an elliptic constant temperature: Applying magnetic field and radiation effects. Int. J. Mech. Sci. 2020, 174, 105470. [CrossRef]

58. Khanafer, K.; Vafai, K.; Lightstone, M. Buoyancy-driven heat transfer enhancement in a two-dimensional enclosure utilizing nanofluids. Int. J. Heat Mass Transf. 2003, 46, 3639-3653. [CrossRef]

59. Oztop, H.F.; Abu-Nada, E.; Varol, Y.; Al-Salem, K. Computational analysis of non-isothermal temperature distribution on natural convection in nanofluid filled enclosures. Superlattices Microstruct. 2011, 49, $453-467$. [CrossRef]

60. Pordanjani, A.H.; Aghakhani, S.; Afrand, M.; Mahmoudi, B.; Mahian, O.; Wongwises, S. An updated review on application of nanofluids in heat exchangers for saving energy. Energy Convers. Manag. 2019, 198, 111886. [CrossRef]

61. Yan, S.-R.; Shirani, N.; Zarringhalam, M.; Toghraie, D.; Nguyen, Q.; Karimipour, A. Prediction of boiling flow characteristics in rough and smooth microchannels using molecular dynamics simulation: Investigation the effects of boundary wall temperatures. J. Mol. Liq. 2020, 306, 112937. [CrossRef]

62. Karamoozian, A.; Jiang, H.; Tan, C.A.; Wang, L.; Wang, Y.; Karamoozian, A. An Integrated Approach for Instability Analysis of Lattice Brake System Using Contact Pressure Sensitivity. IEEE Access 2020, 8 , 19948-19969. [CrossRef]

63. Aminossadati, S.; Ghasemi, B. Natural convection cooling of a localised heat source at the bottom of a nanofluid-filled enclosure. Eur. J. Mech. B/Fluids 2009, 28, 630-640. [CrossRef] 
64. Yan, S.-R.; Toghraie, D.; Hekmatifar, M.; Miansari, M.; Rostami, S. Molecular dynamics simulation of Water-Copper nanofluid flow in a three-dimensional nanochannel with different types of surface roughness geometry for energy economic management. J. Mol. Liq. 2020, 311, 113222. [CrossRef]

65. Tian, M.-W.; Rostami, S.; Aghakhani, S.; Goldanlou, A.S.; Qi, C. Investigation of 2D and 3D configurations of fins and their effects on heat sink efficiency of MHD hybrid nanofluid with slip and non-slip flow. Int. J. Mech. Sci. 2020, 105975. [CrossRef]

66. Öztop, H.F.; Abu-Nada, E. Numerical study of natural convection in partially heated rectangular enclosures filled with nanofluids. Int. J. Heat Fluid Flow 2008, 29, 1326-1336. [CrossRef]

67. Yan, S.-R.; Kalbasi, R.; Nguyen, Q.; Karimipour, A. Sensitivity of adhesive and cohesive intermolecular forces to the incorporation of MWCNTs into liquid paraffin: Experimental study and modeling of surface tension. J. Mol. Liq. 2020, 310, 113235. [CrossRef]

68. Aghakhani, S.; Ghasemi, B.; Pordanjani, A.H.; Wongwises, S.; Afrand, M. Effect of replacing nanofluid instead of water on heat transfer in a channel with extended surfaces under a magnetic field. Int. J. Numer. Methods Heat Fluid Flow 2019, 29, 1249-1271. [CrossRef]

69. Khodadadi, H.; Aghakhani, S.; Majd, H.; Kalbasi, R.; Wongwises, S.; Afrand, M. A comprehensive review on rheological behavior of mono and hybrid nanofluids: Effective parameters and predictive correlations. Int. J. Heat Mass Transf. 2018, 127, 997-1012. [CrossRef]

70. Masuda, H.; Ebata, A.; Teramae, K.; Hishinuma, N. Alteration of thermal conductivity and viscosity of liquid by dispersing ultra-fine particles. Dispersion of $\mathrm{Al2O} 3, \mathrm{SiO} 2$ and $\mathrm{TiO} 2$ ultra-fine particles. Netsu Bussei 1993, 7, 227-233. [CrossRef]

71. Yan, S.-R.; Zarringhalam, M.; Toghraie, D.; Foong, L.K.; Talebizadehsardari, P. Numerical investigation of non-Newtonian blood flow within an artery with cone shape of stenosis in various stenosis angles. Comput. Methods Programs Biomed. 2020, 192, 105434. [CrossRef]

72. Afrand, M.; Najafabadi, K.N.; Akbari, M. Effects of temperature and solid volume fraction on viscosity of $\mathrm{SiO} 2-\mathrm{MWCNTs} / \mathrm{SAE} 40$ hybrid nanofluid as a coolant and lubricant in heat engines. Appl. Therm. Eng. 2016, 102, 45-54. [CrossRef]

73. Yan, S.-R.; Toghraie, D.; Abdulkareem, L.A.; Alizadeh, A.; Barnoon, P.; Afrand, M. The rheological behavior of MWCNTs-ZnO/water-ethylene glycol hybrid non-Newtonian nanofluid by using of an experimental investigation. J. Mater. Res. Technol. 2020, 9, 8401-8406. [CrossRef]

74. Toghraie, D.; Alempour, S.M.; Afrand, M. Experimental determination of viscosity of water based magnetite nanofluid for application in heating and cooling systems. J. Magn. Magn. Mater. 2016, 417, 243-248. [CrossRef]

75. Esfe, M.H.; Saedodin, S.; Wongwises, S.; Toghraie, D. An experimental study on the effect of diameter on thermal conductivity and dynamic viscosity of Fe/water nanofluids. J. Therm. Anal. Calorim. 2014, 119, 1817-1824. [CrossRef]

76. Yan, S.-R.; Kalbasi, R.; Nguyen, Q.; Karimipour, A. Rheological behavior of hybrid MWCNTs-TiO2/EG nanofluid: A comprehensive modeling and experimental study. J. Mol. Liq. 2020, 308, 113058. [CrossRef]

77. Zheng, Y.; Shadloo, M.S.; Nasiri, H.; Maleki, A.; Karimipour, A.; Tlili, I. Prediction of viscosity of biodiesel blends using various artificial model and comparison with empirical correlations. Renew. Energy 2020, 153, 1296-1306. [CrossRef]

78. Afrand, M.; Nadooshan, A.A.; Hassani, M.; Yarmand, H.; Dahari, M. Predicting the viscosity of multi-walled carbon nanotubes/water nanofluid by developing an optimal artificial neural network based on experimental data. Int. Commun. Heat Mass Transf. 2016, 77, 49-53. [CrossRef]

79. Kwak, K.; Kim, C. Viscosity and thermal conductivity of copper oxide nanofluid dispersed in ethylene glycol. Korea-Australia Rheol. J. 2005, 17, 35-40.

80. Einstein, A. Eine neue bestimmung der moleküldimensionen. Ann. der Phys. 1906, 324, 289-306. [CrossRef]

81. Brinkman, H.C. The viscosity of concentrated suspensions and solutions. J. Chem. Phys. 1952, $20,571$. [CrossRef]

82. Batchelor, G.K. The effect of Brownian motion on the bulk stress in a suspension of spherical particles. J. Fluid Mech. 1977, 83, 97-117. [CrossRef]

83. Lundgren, T.S. Slow flow through stationary random beds and suspensions of spheres. J. Fluid Mech. 1972, 51, 273-299. [CrossRef] 
84. Graham, A.L. On the viscosity of suspensions of solid spheres. Flow Turbul. Combust. 1981, 37, $275-286$. [CrossRef]

85. Simha, R. The influence of Brownian movement on the viscosity of solutions. J. Phys. Chem. 1940, 44, 25-34. [CrossRef]

86. Mooney, M. A shearing disk plastometer for unvulcanized rubber. Ind. Eng. Chem. Anal. Ed. 1934, 6, 147-151. [CrossRef]

87. Eilers, H. Die viskosität von emulsionen hochviskoser stoffe als funktion der konzentration. Colloid Polym. Sci. 1941, 97, 313-321. [CrossRef]

88. Saito, N. Concentration dependence of the viscosity of high polymer solutions. I. J. Phys. Soc. Jpn. 1950, 5, 4-8. [CrossRef]

89. Frankel, N.; Acrivos, A. On the viscosity of a concentrated suspension of solid spheres. Chem. Eng. Sci. 1967, 22, 847-853. [CrossRef]

90. Mariano, A.; Gallego, M.J.P.; Lugo, L.; Mussari, L.; Piñeiro, M.M. Co3O4 ethylene glycol-based nanofluids: Thermal conductivity, viscosity and high pressure density. Int. J. Heat Mass Transf. 2015, 85, 54-60. [CrossRef]

91. Karamoozian, A.; Tan, C.A.; Wang, L. Squeal analysis of thin-walled lattice brake disc structure. Mater. Des. 2018, 149, 1-14. [CrossRef]

92. Esfe, M.H.; Esfandeh, S.; Afrand, M.; Rejvani, M.; Rostamian, S.H.; Esfande, S. Experimental evaluation, new correlation proposing and ANN modeling of thermal properties of EG based hybrid nanofluid containing ZnO-DWCNT nanoparticles for internal combustion engines applications. Appl. Therm. Eng. 2018, 133, 452-463. [CrossRef]

93. Maleki, A.; Elahi, M.; Assad, M.E.H.; Nazari, M.A.; Shadloo, M.S.; Nabipour, N. Thermal conductivity modeling of nanofluids with $\mathrm{ZnO}$ particles by using approaches based on artificial neural network and MARS. J. Therm. Anal. Calorim. 2020, 1-12. [CrossRef]

94. Zeng, J.; Xuan, Y. Enhanced solar thermal conversion and thermal conduction of MWCNT-SiO 2/Ag binary nanofluids. Appl. Energy 2018, 212, 809-819. [CrossRef]

95. Afrand, M.; Toghraie, D.; Sina, N. Experimental study on thermal conductivity of water-based Fe3O4 nanofluid: Development of a new correlation and modeled by artificial neural network. Int. Commun. Heat Mass Transf. 2016, 75, 262-269. [CrossRef]

96. Patel, J.; Parekh, K. Effect of size and morphology on stability and thermal conductivity of ZnO nanofluid. J. Nanofluids 2018, 7, 284-291. [CrossRef]

97. Komeilibirjandi, A.; Raffiee, A.H.; Maleki, A.; Nazari, M.A.; Shadloo, M.S. Thermal conductivity prediction of nanofluids containing $\mathrm{CuO}$ nanoparticles by using correlation and artificial neural network. J. Therm. Anal. Calorim. 2019, 139, 2679-2689. [CrossRef]

98. Pryazhnikov, M.; Minakov, A.V.; Rudyak, V.; Guzei, D. Thermal conductivity measurements of nanofluids. Int. J. Heat Mass Transf. 2017, 104, 1275-1282. [CrossRef]

99. Sundar, L.S.; Singh, M.K.; Sousa, A. Thermal conductivity of ethylene glycol and water mixture based Fe3O4 nanofluid. Int. Commun. Heat Mass Transf. 2013, 49, 17-24. [CrossRef]

100. Beck, M.P. Thermal Conductivity of Metal Oxide Nanofluids; Georgia Institute of Technology: Atlanta, GA, USA, 2008.

101. Kim, S.H.; Choi, S.R.; Kim, D. Thermal conductivity of metal-oxide nanofluids: Particle size dependence and effect of laser irradiation. J. Heat Transf. 2006, 129, 298-307. [CrossRef]

102. Karamoozian, A.; Tan, C.A.; Wang, L. Homogenized modeling and micromechanics analysis of thin-walled lattice plate structures for brake discs. J. Sandw. Struct. Mater. 2018, 22, 423-460. [CrossRef]

103. Huminic, A.; Huminic, G.; Fleaca, C.; Dumitrache, F.; Morjan, I. Thermal conductivity, viscosity and surface tension of nanofluids based on FeC nanoparticles. Powder Technol. 2015, 284, 78-84. [CrossRef]

104. Maxwell, J.C. A Treatise on Electricity and Magnetism; Clarendon Press: Oxford, UK, 1881.

105. Wasp, E.J.; Kenny, J.P.; Gandhi, R.L. Solid-liquid flow: Slurry pipeline transportation. [Pumps, valves, mechanical equipment, economics]. Ser. Bulk Mater. Handl. 1977, 106804135.

106. Bruggeman, V.D. Berechnung verschiedener physikalischer konstanten von heterogenen substanzen. I. Dielektrizitätskonstanten und leitfähigkeiten der mischkörper aus isotropen substanzen. Ann. Phys. 1935, 416, 636-664. [CrossRef]

107. Hamilton, R.L.; Crosser, O.K. Thermal conductivity of heterogeneous two-component systems. Ind. Eng. Chem. Fundam. 1962, 1, 187-191. [CrossRef] 
108. Koo, J.; Kleinstreuer, C. A new thermal conductivity model for nanofluids. J. Nanoparticle Res. 2004, 6, 577-588. [CrossRef]

109. Koo, J.; Kleinstreuer, C. Impact analysis of nanoparticle motion mechanisms on the thermal conductivity of nanofluids. Int. Commun. Heat Mass Transf. 2005, 32, 1111-1118. [CrossRef]

110. Avsec, J.; Oblak, M. The calculation of thermal conductivity, viscosity and thermodynamic properties for nanofluids on the basis of statistical nanomechanics. Int. J. Heat Mass Transf. 2007, 50, 4331-4341. [CrossRef]

111. Jang, S.P.; Choi, S.U.S. Effects of Various Parameters on Nanofluid Thermal Conductivity. J. Heat Transf. 2006, 129, 617-623. [CrossRef]

112. Pak, B.C.; Cho, Y.I. Hydrodynamic and heat transfer study of dispersed fluids with submicron metallic oxide particles. Exp. Heat Transf. 1998, 11, 151-170. [CrossRef]

113. Timofeeva, E.V.; Gavrilov, A.N.; McCloskey, J.M.; Tolmachev, Y.V.; Sprunt, S.; Lopatina, L.M.; Selinger, J.V. Thermal conductivity and particle agglomeration in alumina nanofluids: Experiment and theory. Phys. Rev. E 2007, 76, 061203. [CrossRef]

114. Kefayati, G. FDLBM simulation of magnetic field effect on natural convection of non-Newtonian power-law fluids in a linearly heated cavity. Powder Technol. 2014, 256, 87-99. [CrossRef]

115. Gallego, M.J.P.; Lugo, L.; Legido, J.L.; Piñeiro, M.M. Rheological non-Newtonian behaviour of ethylene glycol-based Fe2O3 nanofluids. Nanoscale Res. Lett. 2011, 6, 560. [CrossRef]

116. Zhang, R.; Aghakhani, S.; Pordanjani, A.H.; Vahedi, S.M.; Shahsavar, A.; Afrand, M. Investigation of the entropy generation during natural convection of Newtonian and non-Newtonian fluids inside the L-shaped cavity subjected to magnetic field: Application of lattice Boltzmann method. Eur. Phys. J. Plus 2020, 135, 184. [CrossRef]

117. Kefayati, G. Mesoscopic simulation of magnetic field effect on natural convection of power-law fluids in a partially heated cavity. Chem. Eng. Res. Des. 2015, 94, 337-354. [CrossRef]

118. Raisi, A. Natural convection of non-Newtonian fluids in a square cavity with a localized heat source. Strojniški Vestnik J. Mech. Eng. 2016, 62, 553-564. [CrossRef]

119. Kefayati, G. Simulation of magnetic field effect on natural convection of non-Newtonian power-law fluids in a sinusoidal heated cavity using FDLBM. Int. Commun. Heat Mass Transf. 2014, 53, 139-153. [CrossRef]

120. Turan, O.; Sachdeva, A.; Poole, R.J.; Chakraborty, N. Aspect ratio and boundary conditions effects on laminar natural convection of power-law fluids in a rectangular enclosure with differentially heated side walls. Int. J. Heat Mass Transf. 2013, 60, 722-738. [CrossRef]

121. Ternik, P.; Rudolf, R. Laminar Natural Convection of Non-Newtonian Nanofluids in a Square Enclosure with Differentially Heated Side Walls. Int. J. Simul. Model. 2013, 12, 5-16. [CrossRef]

122. Turan, O.; Sachdeva, A.; Chakraborty, N.; Poole, R. Laminar natural convection of power-law fluids in a square enclosure with differentially heated side walls subjected to constant temperatures. J. Non Newtonian Fluid Mech. 2011, 166, 1049-1063. [CrossRef]

123. Lamsaadi, M.; Naïmi, M.; Hasnaoui, M. Natural convection heat transfer in shallow horizontal rectangular enclosures uniformly heated from the side and filled with non-Newtonian power law fluids. Energy Convers. Manag. 2006, 47, 2535-2551. [CrossRef]

124. Kefayati, G. Simulation of heat transfer and entropy generation of MHD natural convection of non-Newtonian nanofluid in an enclosure. Int. J. Heat Mass Transf. 2016, 92, 1066-1089. [CrossRef]

125. Bin Kim, G.; Hyun, J.M.; Kwak, H.S. Transient buoyant convection of a power-law non-Newtonian fluid in an enclosure. Int. J. Heat Mass Transf. 2003, 46, 3605-3617. [CrossRef]

126. Zhou, E.; Bayazitoglu, Y. Developing laminar natural convection of power law fluids in vertical open ended channel. Int. J. Heat Mass Transf. 2019, 128, 354-362. [CrossRef]

127. Wang, L.; Huang, C.; Yang, X.; Chai, Z.-H.; Shi, B. Effects of temperature-dependent properties on natural convection of power-law nanofluids in rectangular cavities with sinusoidal temperature distribution. Int. J. Heat Mass Transf. 2019, 128, 688-699. [CrossRef]

128. Raizah, Z.; Aly, A.M.; Hussein, A.K.; Abdelraheem, Z.R.; Aly, M. Natural convection flow of a power-law non-Newtonian nanofluid in inclined open shallow cavities filled with porous media. Int. J. Mech. Sci. 2018, 140, 376-393. [CrossRef]

129. Sheremet, M.A.; Pop, I. Natural convection combined with thermal radiation in a square cavity filled with a viscoelastic fluid. Int. J. Numer. Methods Heat Fluid Flow 2018, 28, 624-640. [CrossRef] 
130. Kefayati, G.; Tang, H. MHD thermosolutal natural convection and entropy generation of Carreau fluid in a heated enclosure with two inner circular cold cylinders, using LBM. Int. J. Heat Mass Transf. 2018, 126, 508-530. [CrossRef]

131. Mishra, L.; Chhabra, R. Natural Convection in Power-Law Fluids in a Square Enclosure from Two Differentially Heated Horizontal Cylinders. Heat Transf. Eng. 2017, 39, 819-842. [CrossRef]

132. Aghakhani, S.; Pordanjani, A.H.; Karimipour, A.; Abdollahi, A.; Afrand, M. Numerical investigation of heat transfer in a power-law non-Newtonian fluid in a C-Shaped cavity with magnetic field effect using finite difference lattice Boltzmann method. Comput. Fluids 2018, 176, 51-67. [CrossRef]

133. Alloui, Z.; Vasseur, P.; Reggio, M. Natural convection of nanofluids in a shallow cavity heated from below. Int. J. Therm. Sci. 2011, 50, 385-393. [CrossRef]

134. Hu, Y.; He, Y.; Qi, C.; Jiang, B.; Schlaberg, H.I. Experimental and numerical study of natural convection in a square enclosure filled with nanofluid. Int. J. Heat Mass Transf. 2014, 78, 380-392. [CrossRef]

135. Ho, C.; Chen, M.; Li, Z. Numerical simulation of natural convection of nanofluid in a square enclosure: Effects due to uncertainties of viscosity and thermal conductivity. Int. J. Heat Mass Transf. 2008, 51, 4506-4516. [CrossRef]

136. Lin, K.C.; Violi, A. Natural convection heat transfer of nanofluids in a vertical cavity: Effects of non-uniform particle diameter and temperature on thermal conductivity. Int. J. Heat Fluid Flow 2010, 31, 236-245. [CrossRef]

137. Noriega, H.; Reggio, M.; Vasseur, P. Natural convection of nanofluids in a square cavity heated from below. Comput. Therm. Sci. Int. J. 2013, 5, 289-301. [CrossRef]

138. Hu, Y.; He, Y.; Wang, S.; Wang, Q.; Schlaberg, H.I. Experimental and Numerical Investigation on Natural Convection Heat Transfer of TiO2-Water Nanofluids in a Square Enclosure. J. Heat Transf. 2013, 136, 022502. [CrossRef]

139. Sheikholeslami, M.; Gorji-Bandpy, M.; Domairry, G. Free convection of nanofluid filled enclosure using lattice Boltzmann method (LBM). Appl. Math. Mech. 2013, 34, 833-846. [CrossRef]

140. Lai, F.-H.; Yang, Y.-T. Lattice Boltzmann simulation of natural convection heat transfer of Al2O3/water nanofluids in a square enclosure. Int. J. Therm. Sci. 2011, 50, 1930-1941. [CrossRef]

141. Guiet, J.; Reggio, M.; Vasseur, P. Natural Convection of Nanofluids in a Square Enclosure with a Protruding Heater. Adv. Mech. Eng. 2012, 4, 167296. [CrossRef]

142. Alloui, Z.; Guiet, J.; Vasseur, P.; Reggio, M. Natural convection of nanofluids in a shallow rectangular enclosure heated from the side. Can. J. Chem. Eng. 2011, 90, 69-78. [CrossRef]

143. Kefayati, G.; Hosseinizadeh, S.; Gorji, M.; Sajjadi, H. Lattice Boltzmann simulation of natural convection in an open enclosure subjugated to water/copper nanofluid. Int. J. Therm. Sci. 2012, 52, 91-101. [CrossRef]

144. Goodarzi, M.; D’Orazio, A.; Keshavarzi, A.; Mousavi, S.; Karimipour, A. Develop the nano scale method of lattice Boltzmann to predict the fluid flow and heat transfer of air in the inclined lid driven cavity with a large heat source inside, Two case studies: Pure natural convection \& mixed convection. Phys. A Stat. Mech. Appl. 2018, 509, 210-233. [CrossRef]

145. Emami, R.Y.; Siavashi, M.; Shahriari, G. The effect of inclination angle and hot wall configuration on Cu-water nanofluid natural convection inside a porous square cavity. Adv. Powder Technol. 2018, 29, 519-536. [CrossRef]

146. Kefayati, G. Double-diffusive natural convection and entropy generation of Bingham fluid in an inclined cavity. Int. J. Heat Mass Transf. 2018, 116, 762-812. [CrossRef]

147. Sheremet, M.A.; Pop, I. Effect of local heater size and position on natural convection in a tilted nanofluid porous cavity using LTNE and Buongiorno's models. J. Mol. Liq. 2018, 266, 19-28. [CrossRef]

148. Sajjadi, H.; Gorji, M.; Kefayati, G.; Ganji, D. Lattice Boltzmann simulation of natural convection in an inclined heated cavity partially using Cu/water nanofluid. Int. J. Fluid Mech. Res. 2012, 39, 348-372. [CrossRef]

149. Hosseini, M.; Mustafa, M.; Jafaryar, M.; Mohammadian, E. Nanofluid in tilted cavity with partially heated walls. J. Mol. Liq. 2014, 199, 545-551. [CrossRef]

150. Sheremet, M.; Pop, I.; Mahian, O. Natural convection in an inclined cavity with time-periodic temperature boundary conditions using nanofluids: Application in solar collectors. Int. J. Heat Mass Transf. 2018, 116, 751-761. [CrossRef]

151. Ogut, E.B. Natural convection of water-based nanofluids in an inclined enclosure with a heat source. Int. J. Therm. Sci. 2009, 48, 2063-2073. [CrossRef] 
152. Abu-Nada, E.; Öztop, H.F. Effects of inclination angle on natural convection in enclosures filled with Cu-water nanofluid. Int. J. Heat Fluid Flow 2009, 30, 669-678. [CrossRef]

153. Alnaqi, A.A.; Aghakhani, S.; Pordanjani, A.H.; Bakhtiari, R.; Asadi, A.; Tran, M.-D. Effects of magnetic field on the convective heat transfer rate and entropy generation of a nanofluid in an inclined square cavity equipped with a conductor fin: Considering the radiation effect. Int. J. Heat Mass Transf. 2019, 133, $256-267$. [CrossRef]

154. Pordanjani, A.H.; Aghakhani, S.; Karimipour, A.; Afrand, M.; Goodarzi, M. Investigation of free convection heat transfer and entropy generation of nanofluid flow inside a cavity affected by magnetic field and thermal radiation. J. Therm. Anal. Calorim. 2019, 137, 997-1019. [CrossRef]

155. Pordanjani, A.H.; Aghakhani, S.; Alnaqi, A.A.; Afrand, M.; Hajatzadeh, A. Effect of alumina nano-powder on the convection and the entropy generation of water inside an inclined square cavity subjected to a magnetic field: Uniform and non-uniform temperature boundary conditions. Int. J. Mech. Sci. 2019, 152, 99-117. [CrossRef]

156. Khanafer, K.; AlAmiri, A.; Bull, J. Laminar natural convection heat transfer in a differentially heated cavity with a thin porous fin attached to the hot wall. Int. J. Heat Mass Transf. 2015, 87, 59-70. [CrossRef]

157. Liu, Y.; Lei, C.; Patterson, J.C. Natural convection in a differentially heated cavity with two horizontal adiabatic fins on the sidewalls. Int. J. Heat Mass Transf. 2014, 72, 23-36. [CrossRef]

158. Saeid, N.H. Natural convection in a square cavity with discrete heating at the bottom with different fin shapes. Heat Transf. Eng. 2017, 39, 154-161. [CrossRef]

159. Benseghir, C.; Samir, R. Simulation of Heat Transfer in a Square Cavity with two Fins Attached to the Hot Wall. Energy Procedia 2012, 18, 1299-1306. [CrossRef]

160. Darzi, A.A.R.; Farhadi, M.; Jourabian, M.; Vazifeshenas, Y. Natural convection melting of NEPCM in a cavity with an obstacle using lattice Boltzmann method. Int. J. Numer. Methods Heat Fluid Flow 2013, 24, 221-236. [CrossRef]

161. Selimefendigil, F.; Öztop, H.F. Natural convection and entropy generation of nanofluid filled cavity having different shaped obstacles under the influence of magnetic field and internal heat generation. J. Taiwan Inst. Chem. Eng. 2015, 56, 42-56. [CrossRef]

162. Sheikholeslami, M.; Sadoughi, M. Mesoscopic method for MHD nanofluid flow inside a porous cavity considering various shapes of nanoparticles. Int. J. Heat Mass Transf. 2017, 113, 106-114. [CrossRef]

163. Sheikholeslami, M.; Ganji, D. Entropy generation of nanofluid in presence of magnetic field using Lattice Boltzmann Method. Phys. A Stat. Mech. Its Appl. 2015, 417, 273-286. [CrossRef]

164. Miroshnichenko, I.V.; Sheremet, M.A.; Oztop, H.F.; Abu-Hamdeh, N. Natural convection of Al 2 O 3/H 2 O nanofluid in an open inclined cavity with a heat-generating element. Int. J. Heat Mass Transf. 2018, 126, 184-191. [CrossRef]

165. Rahimi, A.R.; Kasaeipoor, A.; Malekshah, E.H.; Amiri, A. Natural convection analysis employing entropy generation and heatline visualization in a hollow L-shaped cavity filled with nanofluid using lattice Boltzmann method- experimental thermo-physical properties. Phys. E Low Dimens. Syst. Nanostruct. 2018, 97, 82-97. [CrossRef]

166. Alsabery, A.; Ishak, M.S.; Chamkha, A.J.; Hashim, I. Entropy Generation Analysis and Natural Convection in a Nanofluid-Filled Square Cavity with a Concentric Solid Insert and Different Temperature Distributions. Entropy 2018, 20, 336. [CrossRef]

167. Siavashi, M.; Yousofvand, R.; Rezanejad, S. Nanofluid and porous fins effect on natural convection and entropy generation of flow inside a cavity. Adv. Powder Technol. 2018, 29, 142-156. [CrossRef]

168. Alsabery, A.; Sheremet, M.; Chamkha, A.J.; Hashim, I. Conjugate natural convection of Al2O3-water nanofluid in a square cavity with a concentric solid insert using Buongiorno's two-phase model. Int. J. Mech. Sci. 2018, 136, 200-219. [CrossRef]

169. Alsabery, A.; Tayebi, T.; Chamkha, A.J.; Hashim, I. Effects of non-homogeneous nanofluid model on natural convection in a square cavity in the presence of conducting solid block and corner heater. Energies 2018, 11, 2507. [CrossRef]

170. Sheikholeslami, M.; Shehzad, S.; Li, Z. Water based nanofluid free convection heat transfer in a three dimensional porous cavity with hot sphere obstacle in existence of Lorenz forces. Int. J. Heat Mass Transf. 2018, 125, 375-386. [CrossRef] 
171. Sobhani, M.; Tighchi, H.A.; Esfahani, J.A. Taguchi optimization of combined radiation/natural convection of participating medium in a cavity with a horizontal fin using LBM. Phys. A Stat. Mech. Appl. 2018, 509, 1062-1079. [CrossRef]

172. Chi, H.A.T.; Sobhani, M.; Esfahani, J.A. Effect of volumetric radiation on natural convection in a cavity with a horizontal fin using the lattice Boltzmann method. Eur. Phys. J. Plus 2018, 133, 8. [CrossRef]

173. Izadi, M.; Mohebbi, R.; Karimi, D.; Sheremet, M.A. Numerical simulation of natural convection heat transfer inside $\mathrm{a}^{\perp}$ shaped cavity filled by a MWCNT-Fe3O4/water hybrid nanofluids using LBM. Chem. Eng. Process. Process Intensif. 2018, 125, 56-66. [CrossRef]

174. Yonezuka, S.; Fukue, T.; Kikuchi, M.; Hirose, K.; Wang, Q.-S.; Hiratsuka, W.; Okada, Y.; Sakaki, C. Relationship between natural convection cooling performance and tilt angle of thin enclosure. In Proceedings of the 2018 International Conference on Electronics Packaging and iMAPS All Asia Conference (ICEP-IAAC), Mie, Japan, 17-21 April 2018; Institute of Electrical and Electronics Engineers (IEEE), 2018; pp. 456-458.

175. Pordanjani, A.H.; Jahanbakhshi, A.; Nadooshan, A.A.; Afrand, M. Effect of two isothermal obstacles on the natural convection of nanofluid in the presence of magnetic field inside an enclosure with sinusoidal wall temperature distribution. Int. J. Heat Mass Transf. 2018, 121, 565-578. [CrossRef]

176. Hoghoughi, G.; Izadi, M.; Oztop, H.F.; Abu-Hamdeh, N. Effect of geometrical parameters on natural convection in a porous undulant-wall enclosure saturated by a nanofluid using Buongiorno's model. J. Mol. Liq. 2018, 255, 148-159. [CrossRef]

177. Mun, G.S.; Seo, Y.M.; Park, Y.G.; Ha, M.Y. Natural convection in a cold enclosure with four hot inner cylinders in a diamond array (Part-II: Effect of unequal horizontal and vertical distances of inner cylinders). Int. J. Heat Mass Transf. 2018, 120, 1365-1373. [CrossRef]

178. Kefayati, G.; Tang, H. Double-diffusive laminar natural convection and entropy generation of Carreau fluid in a heated enclosure with an inner circular cold cylinder (Part II: Entropy generation). Int. J. Heat Mass Transf. 2018, 120, 683-713. [CrossRef]

179. Kefayati, G.; Tang, H. Double-diffusive natural convection and entropy generation of Carreau fluid in a heated enclosure with an inner circular cold cylinder (Part I: Heat and mass transfer). Int. J. Heat Mass Transf. 2018, 120, 731-750. [CrossRef]

180. Campo, A.; Ben Cheikh, N.; Riahi, A. Water-Based Nanofluids for Natural Convection Cooling of a Pair of Symmetrical Heated Blocks Placed Inside a Rectangular Enclosure of Aspect Ratio Two. Int. J. Therm. Environ. Eng. 2018, 16, 1-10. [CrossRef]

181. Hussein, A.K.; Mustafa, A.W. Natural convection in a parabolic enclosure with an internal vertical heat source filled with Cu-water nanofluid. Heat Transfer Asian Res. 2017, 47, 320-336. [CrossRef]

182. Park, S.H.; Seo, Y.M.; Ha, M.Y.; Park, Y.G. Natural convection in a square enclosure with different positions and inclination angles of an elliptical cylinder Part I: A vertical array of one elliptical cylinder and one circular cylinder. Int. J. Heat Mass Transf. 2018, 126, 173-183. [CrossRef]

183. Cho, H.W.; Park, Y.G.; Ha, M.Y. The natural convection in a square enclosure with two hot inner cylinders, Part I: The effect of one elliptical cylinder with various aspect ratios in a vertical array. Int. J. Heat Mass Transf. 2018, 125, 815-827. [CrossRef]

184. Selimefendigil, F. Natural convection in a trapezoidal cavity with an inner conductive object of different shapes and filled with nanofluids of different nanoparticle shapes. Iran. J. Sci. Technol. Trans. Mech. Eng. 2017, 42, 169-184. [CrossRef]

185. Zahan, I.; Alim, M.A. Effects of Rayleigh number and wall conductivity on conjugate natural convection of nanofluid in a heat conducting rectangular vertical walled enclosure. In Disruptive Innovation in Mechanical Engineering for Industry Competitiveness, Proceedings of the 3rd International Conference on Mechanical Engineering (ICOME 2017), Jawa Timur, Indonesia, 5-6 October 2017; AIP Publishing: Melville, NY, USA, 2018; Volume 1980, p. 050017. [CrossRef]

186. Dogonchi, A.S.; Ismael, M.A.; Chamkha, A.J.; Ganji, D.D. Numerical analysis of natural convection of $\mathrm{Cu}$-water nanofluid filling triangular cavity with semicircular bottom wall. J. Therm. Anal. Calorim. 2018, 135, 3485-3497. [CrossRef]

187. Ma, Y.; Mohebbi, R.; Rashidi, M.; Yang, Z. Simulation of nanofluid natural convection in a U-shaped cavity equipped by a heating obstacle: Effect of cavity's aspect ratio. J. Taiwan Inst. Chem. Eng. 2018, 93, 263-276. [CrossRef] 
188. Berkovsky, B.; Medvedev, V.F.; Krakov, M.S. Magnetic Fluids: Engineering Applications; Oxford University Press: Oxford, UK, 1993.

189. Pirmohammadi, M.; Ghassemi, M. Effect of magnetic field on convection heat transfer inside a tilted square enclosure. Int. Commun. Heat Mass Transf. 2009, 36, 776-780. [CrossRef]

190. Ghasemi, B.; Aminossadati, S.; Raisi, A. Magnetic field effect on natural convection in a nanofluid-filled square enclosure. Int. J. Therm. Sci. 2011, 50, 1748-1756. [CrossRef]

191. Parekh, K.; Lee, H.S. Magnetic field induced enhancement in thermal conductivity of magnetite nanofluid. J. Appl. Phys. 2010, 107, 9. [CrossRef]

192. Al-Najem, N.; Khanafer, K.; El-Refaee, M. Numerical study of laminar natural convection in tilted enclosure with transverse magnetic field. Int. J. Numer. Methods Heat Fluid Flow 1998, 8, 651-672. [CrossRef]

193. Afrand, M.; Toghraie, D.; Karimipour, A.; Wongwises, S. A numerical study of natural convection in a vertical annulus filled with gallium in the presence of magnetic field. J. Magn. Magn. Mater. 2017, 430, $22-28$. [CrossRef]

194. Teamah, M.A.; El-Maghlany, W.M. Augmentation of natural convective heat transfer in square cavity by utilizing nanofluids in the presence of magnetic field and uniform heat generation/absorption. Int. J. Therm. Sci. 2012, 58, 130-142. [CrossRef]

195. Sheikholeslami, M.; Vajravelu, K. Nanofluid flow and heat transfer in a cavity with variable magnetic field. Appl. Math. Comput. 2017, 298, 272-282. [CrossRef]

196. Sheikholeslami, M.; Shehzad, S.A. CVFEM for influence of external magnetic source on Fe3O4-H2O nanofluid behavior in a permeable cavity considering shape effect. Int. J. Heat Mass Transf. 2017, 115, 180-191. [CrossRef]

197. Sheikholeslami, M. Numerical simulation of magnetic nanofluid natural convection in porous media. Phys. Lett. A 2017, 381, 494-503. [CrossRef]

198. Sheikholeslami, M.; Ganji, D. Numerical modeling of magnetohydrodynamic CuO—Water transportation inside a porous cavity considering shape factor effect. Colloids Surfaces A Physicochem. Eng. Asp. 2017, 529, 705-714. [CrossRef]

199. Sajjadi, H.; Delouei, A.A.; Atashafrooz, M.; Sheikholeslami, M. Double MRT Lattice Boltzmann simulation of 3-D MHD natural convection in a cubic cavity with sinusoidal temperature distribution utilizing nanofluid. Int. J. Heat Mass Transf. 2018, 126, 489-503. [CrossRef]

200. Selimefendigil, F.; Oztop, H.F. MHD Natural convection and entropy generation in a nanofluid-filled cavity with a conductive partition. Exerg. Energ. Environ. Dimens. 2018, 763-778. [CrossRef]

201. Selimefendigil, F.; Öztop, H.F. Corrugated conductive partition effects on MHD free convection of CNT-water nanofluid in a cavity. Int. J. Heat Mass Transf. 2019, 129, 265-277. [CrossRef]

202. Mejri, I.; Mahmoudi, A.; Abbassi, M.A.; Omri, A.; Mahmoudi, A.; Omri, A. Lattice Boltzmann simulation of MHD natural convection in a nanofluid-filled enclosure with non-uniform heating on both side walls. In Proceedings of the 2014 International Conference on Composite Materials \& Renewable Energy Applications (ICCMREA), Sousse, Tunisia, 22-24 January 2014; pp. 1-5. [CrossRef]

203. Sivaraj, C.; Sheremet, M. MHD natural convection and entropy generation of ferrofluids in a cavity with a non-uniformly heated horizontal plate. Int. J. Mech. Sci. 2018, 149, 326-337. [CrossRef]

204. Ashorynejad, H.R.; Shahriari, A. MHD natural convection of hybrid nanofluid in an open wavy cavity. Results Phys. 2018, 9, 440-455. [CrossRef]

205. Haq, R.U.; Soomro, F.A.; Mekkaoui, T.; Al-Mdallal, Q. MHD natural convection flow enclosure in a corrugated cavity filled with a porous medium. Int. J. Heat Mass Transf. 2018, 121, 1168-1178. [CrossRef]

206. Javaherdeh, K.; Najjarnezami, A. Lattice Boltzmann simulation of MHD natural convection in a cavity with porous media and sinusoidal temperature distribution. Appl. Math. Mech. 2018, 39, 1187-1200. [CrossRef]

207. Sheikholeslami, M.; Shehzad, S.A. RETRACTED: Magnetohydrodynamic nanofluid convective flow in a porous enclosure by means of LBM. Int. J. Heat Mass Transf. 2017, 113, 796-805. [CrossRef]

208. Selimefendigil, F.; Öztop, H.F. Role of magnetic field and surface corrugation on natural convection in a nanofluid filled 3D trapezoidal cavity. Int. Commun. Heat Mass Transf. 2018, 95, 182-196. [CrossRef]

209. Al-Rashed, A.A.; Kalidasan, K.; Kolsi, L.; Aydi, A.; Malekshah, E.H.; Hussein, A.K.; Kanna, P.R. Three-dimensional investigation of the effects of external magnetic field inclination on laminar natural convection heat transfer in CNT-water nanofluid filled cavity. J. Mol. Liq. 2018, 252, 454-468. [CrossRef] 
210. Dogonchi, A.S.; Chamkha, A.J.; Ganji, D.D. A numerical investigation of magneto-hydrodynamic natural convection of $\mathrm{Cu}$-water nanofluid in a wavy cavity using CVFEM. J. Therm. Anal. Calorim. 2018, 135, 2599-2611. [CrossRef]

211. Astanina, M.; Sheremet, M.A.; Oztop, H.F.; Abu-Hamdeh, N. MHD natural convection and entropy generation of ferrofluid in an open trapezoidal cavity partially filled with a porous medium. Int. J. Mech. Sci. 2018, 136, 493-502. [CrossRef]

212. Rashad, A.M.; Chamkha, A.J.; Ismael, M.A.; Salah, T. Magnetohydrodynamics natural convection in a triangular cavity filled with a CU-al2o3/Water hybrid nanofluid with localized heating from below and internal heat generation. J. Heat Transf. 2018, 140, 072502. [CrossRef]

213. Armaghani, T.; Kasaeipoor, A.; Izadi, M.; Pop, I. MHD natural convection and entropy analysis of a nanofluid inside T-shaped baffled enclosure. Int. J. Numer. Methods Heat Fluid Flow 2018, 28, 2916-2941. [CrossRef]

214. Dogonchi, A.S.; Selimefendigil, F.; Ganji, D. Magneto-hydrodynamic natural convection of CuO-water nanofluid in complex shaped enclosure considering various nanoparticle shapes. Int. J. Numer. Methods Heat Fluid Flow 2019, 29, 1663-1679. [CrossRef]

215. Abbassi, M.A.; Orfi, J. Effects of Magnetohydrodynamics on Natural Convection and Entropy Generation with Nanofluids. J. Thermophys. Heat Transf. 2018, 32, 1059-1071. [CrossRef]

216. Kaviany, M. Principles of Heat Transfer in Porous Media; Springer Science \& Business Media: Berlin, Germany, 2012.

217. Ghalambaz, M.; Sabour, M.; Pop, I. Free convection in a square cavity filled by a porous medium saturated by a nanofluid: Viscous dissipation and radiation effects. Eng. Sci. Technol. Int. J. 2016, 19, 1244-1253. [CrossRef]

218. Zeng, Z.; Grigg, R.B. A Criterion for Non-Darcy Flow in Porous Media. Transp. Porous Media 2006, 63, 57-69. [CrossRef]

219. Ergun, S.J.C.E.P. Fluid flow through packed columns. Chem. Eng. Prog. 1952, 48, 89-94.

220. Brinkman, H.J.F. On the permeability of media consisting of closely packed porous particles. Flow Turbul Combust. 1949, 1, 81. [CrossRef]

221. Du, Z.G.; Bilgen, E. Natural convection in vertical cavities with internal heat generating porous medium. Wärme Stoffuibertragung 1992, 27, 149-155. [CrossRef]

222. Kakaç, S.; Shah, R.K.; Aung, W. Handbook of Single-Phase Convective Heat Transfer; Wiley and Sons Inc.: New York, NY, USA, 1987.

223. Miroshnichenko, I.V.; Sheremet, M.A.; Öztop, H.F.; Abu-Hamdeh, N. Natural convection of alumina-water nanofluid in an open cavity having multiple porous layers. Int. J. Heat Mass Transf. 2018, 125, 648-657. [CrossRef]

224. Sheikholeslami, M.; Seyednezhad, M. Simulation of nanofluid flow and natural convection in a porous media under the influence of electric field using CVFEM. Int. J. Heat Mass Transf. 2018, 120, 772-781. [CrossRef]

225. Sheikholeslami, M.; Li, Z.; Shamlooei, M. Nanofluid MHD natural convection through a porous complex shaped cavity considering thermal radiation. Phys. Lett. A 2018, 382, 1615-1632. [CrossRef]

226. Gibanov, N.S.; Sheremet, M.A.; Öztop, H.F.; Al-Salem, K. MHD natural convection and entropy generation in an open cavity having different horizontal porous blocks saturated with a ferrofluid. J. Magn. Magn. Mater. 2018, 452, 193-204. [CrossRef]

227. Ahmed, N.J.S.; Kamangar, S.; Al-Rashed, A.A.; Govindaraju, K.; Khan, T.Y. Natural convection in annular cone: Influence of radius ratio. AIP Conf. Proc. 2018, 1953, 140052.

228. Dutta, S.K.; Biswas, A.K.; Pati, S. Natural convection heat transfer and entropy generation inside porous quadrantal enclosure with nonisothermal heating at the bottom wall. Numer. Heat Transfer Part A Appl. 2018, 73, 222-240. [CrossRef]

229. Al-Mudhaf, A.F.; Rashad, A.M.; Hussein, A.K.; Chamkha, A.J.; El-Kabeir, S. Soret and Dufour effects on unsteady double diffusive natural convection in porous trapezoidal enclosures. Int. J. Mech. Sci. 2018, 140, 172-178. [CrossRef]

230. Mehryan, S.; Izadi, M.; Sheremet, M.A. Analysis of conjugate natural convection within a porous square enclosure occupied with micropolar nanofluid using local thermal non-equilibrium model. J. Mol. Liq. 2018, 250, 353-368. [CrossRef]

231. Sheikholeslami, M.; Shehzad, S.A.; Kumar, R. Natural Convection of Fe 3 O 4-Ethylene Glycol Nanouid under the Impact of Electric Field in a Porous Enclosure. Commun. Theor. Phys. 2018, 69, 667. [CrossRef] 
232. Kalteh, M.; Abbassi, A.; Saffar-Avval, M.; Harting, J. Eulerian-Eulerian two-phase numerical simulation of nanofluid laminar forced convection in a microchannel. Int. J. Heat Fluid Flow 2011, 32, 107-116. [CrossRef]

233. Moraveji, M.K.; Ardehali, R.M. CFD modeling (comparing single and two-phase approaches) on thermal performance of Al2o3/water nanofluid in mini-channel heat sink. Int. Commun. Heat Mass Transf. 2013, 44, 157-164. [CrossRef]

234. Toosi, M.H.; Siavashi, M. Two-phase mixture numerical simulation of natural convection of nanofluid flow in a cavity partially filled with porous media to enhance heat transfer. J. Mol. Liq. 2017, 238, 553-569. [CrossRef]

235. Saghir, M.Z.; Ahadi, A.; Yousefi, T.; Farahbakhsh, B. Two-phase and single phase models of flow of nanofluid in a square cavity: Comparison with experimental results. Int. J. Therm. Sci. 2016, 100, 372-380. [CrossRef]

236. Shadloo, M.S.; Rahmat, A.; Karimipour, A.; Wongwises, S. Estimation of pressure drop of two-phase fluid in horizontal long pipes using artificial neural networks. J. Energy Resour. Technol. 2020, 1-21. [CrossRef]

237. Yan, S.-R.; Golzar, A.; Sharifpur, M.; Meyer, J.P.; Liu, D.-H.; Afrand, M. Effect of U-shaped absorber tube on thermal-hydraulic performance and efficiency of two-fluid parabolic solar collector containing two-phase hybrid non-Newtonian nanofluids. Int. J. Mech. Sci. 2020, 185, 105832. [CrossRef]

238. Shariat, M.; Akbarinia, A.; Nezhad, A.H.; Behzadmehr, A.; Laur, R. Numerical study of two phase laminar mixed convection nanofluid in elliptic ducts. Appl. Therm. Eng. 2011, 31, 2348-2359. [CrossRef]

239. Moghari, R.M.; Akbarinia, A.; Shariat, M.; Talebi, F.; Laur, R. Two phase mixed convection Al2O3-water nanofluid flow in an annulus. Int. J. Multiph. Flow 2011, 37, 585-595. [CrossRef]

240. Alinia, M.; Ganji, D.; Gorji-Bandpy, M. Numerical study of mixed convection in an inclined two sided lid driven cavity filled with nanofluid using two-phase mixture model. Int. Commun. Heat Mass Transf. 2011, 38, 1428-1435. [CrossRef]

241. Aminfar, H.; Mohammadpourfard, M.; Kahnamouei, Y.N. A 3D numerical simulation of mixed convection of a magnetic nanofluid in the presence of non-uniform magnetic field in a vertical tube using two phase mixture model. J. Magn. Magn. Mater. 2011, 323, 1963-1972. [CrossRef]

242. Mirmasoumi, S.; Behzadmehr, A. Numerical study of laminar mixed convection of a nanofluid in a horizontal tube using two-phase mixture model. Appl. Therm. Eng. 2008, 28, 717-727. [CrossRef]

243. Liu, F.; Zhang, D.; Cai, Y.; Qiu, Z.; Zhu, Q.; Zhao, J.; Wang, L.; Tian, H. Multiplicity of forced convective heat transfer of nanofluids in curved ducts. Int. J. Heat Mass Transf. 2019, 129, 534-546. [CrossRef]

244. Albojamal, A.; Vafai, K. Analysis of single phase, discrete and mixture models, in predicting nanofluid transport. Int. J. Heat Mass Transf. 2017, 114, 225-237. [CrossRef]

245. Hanafizadeh, P.; Ashjaee, M.; Goharkhah, M.; Montazeri, K.; Akram, M. The comparative study of single and two-phase models for magnetite nanofluid forced convection in a tube. Int. Commun. Heat Mass Transf. 2015, 65, 58-70. [CrossRef]

246. Goktepe, S.; Atalık, K.; Ertürk, H. Comparison of single and two-phase models for nanofluid convection at the entrance of a uniformly heated tube. Int. J. Therm. Sci. 2014, 80, 83-92. [CrossRef]

247. Akbari, M.; Galanis, N.; Behzadmehr, A. Comparative assessment of single and two-phase models for numerical studies of nanofluid turbulent forced convection. Int. J. Heat Fluid Flow 2012, 37, 136-146. [CrossRef]

248. Rostami, J.; Abbassi, A. Conjugate heat transfer in a wavy microchannel using nanofluid by two-phase Eulerian-Lagrangian method. Adv. Powder Technol. 2016, 27, 9-18. [CrossRef]

249. Xu, D.; Hu, Y.; Li, D. A lattice Boltzmann investigation of two-phase natural convection of Cu-water nanofluid in a square cavity. Case Stud. Therm. Eng. 2019, 13, 100358. [CrossRef]

250. Rahimi, A.R.; Sepehr, M.; Lariche, M.J.; Mesbah, M.; Kasaeipoor, A.; Malekshah, E.H. Analysis of natural convection in nanofluid-filled $\mathrm{H}$-shaped cavity by entropy generation and heatline visualization using lattice Boltzmann method. Phys. E Low Dimens. Syst. Nanostruct. 2018, 97, 347-362. [CrossRef]

251. Bondareva, N.S.; Sheremet, M.A.; Öztop, H.F.; Abu-Hamdeh, N. Transient natural convection in a partially open trapezoidal cavity filled with a water-based nanofluid under the effects of Brownian diffusion and thermophoresis. Int. J. Numer. Methods Heat Fluid Flow 2018, 28, 606-623. [CrossRef]

252. Bhowmick, S.; Saha, S.C.; Qiao, M.; Xu, F. Transition to a chaotic flow in a V-shaped triangular cavity heated from below. Int. J. Heat Mass Transf. 2019, 128, 76-86. [CrossRef]

253. Das, D.; Lukose, L.; Basak, T. Role of multiple solar heaters along the walls for the thermal management during natural convection in square and triangular cavities. Renew. Energy 2018, 121, 205-229. [CrossRef] 
254. Esfe, M.H.; Arani, A.A.A.; Yan, W.-M.; Ehteram, H.; Aghaie, A.; Afrand, M. Natural convection in a trapezoidal enclosure filled with carbon nanotube-EG-water nanofluid. Int. J. Heat Mass Transf. 2016, 92, 76-82. [CrossRef]

255. Esfe, M.H.; Arani, A.A.A.; Yan, W.-M.; Aghaei, A. Natural convection in T-shaped cavities filled with water-based suspensions of $\mathrm{COOH}$-functionalized multi walled carbon nanotubes. Int. J. Mech. Sci. 2017, 121, 21-32. [CrossRef]

256. Zhang, W.; Wei, Y.; Chen, X.; Dou, H.-S.; Zhu, Z. Partitioning effect on natural convection in a circular enclosure with an asymmetrically placed inclined plate. Int. Commun. Heat Mass Transf. 2018, 90, 11-22. [CrossRef]

257. Guestal, M.; Kadja, M.; Hoang, M.T. Study of heat transfer by natural convection of nanofluids in a partially heated cylindrical enclosure. Case Stud. Therm. Eng. 2018, 11, 135-144. [CrossRef]

258. Enayati, H.; Chandy, A.J.; Braun, M.J. Large eddy simulation (LES) calculations of natural convection in cylindrical enclosures with rack and seeds for crystal growth applications. Int. J. Therm. Sci. 2018, 123, $42-57$. [CrossRef]

259. Snoussi, L.; Ouerfelli, N.; Chesneau, X.; Chamkha, A.J.; Belgacem, F.B.M.; Guizani, A. Natural Convection Heat Transfer in a Nanofluid Filled U-Shaped Enclosures: Numerical Investigations. Heat Transf. Eng. 2017, 39, 1450-1460. [CrossRef]

260. Malekpour, A.; Karimi, N.; Mehdizadeh, A. Magnetohydrodynamics, Natural Convection, and Entropy Generation of CuO-Water Nanofluid in an I-Shape Enclosure-A Numerical Study. J. Therm. Sci. Eng. Appl. 2018, 10, 061016. [CrossRef]

261. Astanina, M.S.; Abu-Nada, E.; Sheremet, M.A. Combined Effects of Thermophoresis, Brownian Motion, and Nanofluid Variable Properties on CuO-Water Nanofluid Natural Convection in a Partially Heated Square Cavity. J. Heat Transf. 2018, 140, 082401. [CrossRef]

262. Revnic, C.; Abu-Nada, E.; Groşan, T.; Pop, I. Natural convection in a rectangular cavity filled with nanofluids. Int. J. Numer. Methods Heat Fluid Flow 2018, 28, 1410-1432. [CrossRef]

263. Safaei, M.R.; Karimipour, A.; Abdollahi, A.; Nguyen, T.K. The investigation of thermal radiation and free convection heat transfer mechanisms of nanofluid inside a shallow cavity by lattice Boltzmann method. Phys. A Stat. Mech. Appl. 2018, 509, 515-535. [CrossRef]

264. Hadidi, N.; Bennacer, R. Heat and mass transfer by natural convection in a bi-layered cubic enclosure with opposing temperature and concentration gradients. Int. J. Therm. Sci. 2018, 132, 534-551. [CrossRef]

265. Rahimi, A.R.; Kasaeipoor, A.; Amiri, A.; Doranehgard, M.H.; Malekshah, E.H.; Kolsi, L. Lattice Boltzmann method based on Dual-MRT model for three-dimensional natural convection and entropy generation in $\mathrm{CuO}-$ water nanofluid filled cuboid enclosure included with discrete active walls. Comput. Math. Appl. 2018, 75, 1795-1813. [CrossRef]

(C) 2020 by the authors. Licensee MDPI, Basel, Switzerland. This article is an open access article distributed under the terms and conditions of the Creative Commons Attribution (CC BY) license (http://creativecommons.org/licenses/by/4.0/). 